\title{
Drug Metabolism Determines Resistance of Colorectal Cancer to Resorcinol-Based HSP90 Inhibitors
}

\author{
Dissertation \\ for the award of the degree \\ "Doctor rerum naturalium" (Dr. rer. nat.) \\ in the "Biology of Cells" Program \\ at the Georg August University Göttingen, \\ Faculty of Biology
}

submitted by

Hannes Landmann

born in

Hannover, Germany

Göttingen, August 2014 


\section{Thesis Committee}

Prof. Dr. Matthias Dobbelstein

Institute for Molecular Oncology, Faculty of Medicine

Prof. Dr. Heidi Hahn

Tumor Genetics, Department of Human Genetics, Faculty of Medicine

Prof. Dr. Dieter Kube

Department for Hematology and Oncology, Faculty of Medicine

\section{Members of the Examination Board}

Referee: Prof. Dr. Matthias Dobbelstein, Institute for Molecular Oncology

$2^{\text {nd }}$ Referee: Prof. Dr. Heidi Hahn, Tumor Genetics, Department of Human Genetics

\section{Further members of the Examination Board}

Prof. Dr. Dieter Kube

Department for Hematology and Oncology, Faculty of Medicine

PD Dr. Halyna Shcherbata

Research Group Gene Expression and Signaling,

Max Planck Institute for Biophysical Chemistry

Prof. Dr. Ralph Kehlenbach

Department of Molecular Biology, Faculty of Biochemistry

PD Dr. Wilfried Kramer

Department for Molecular Genetics, Institute for Microbiology and Genetics

Date of oral examination: $19^{\text {th }}$ of September 2014 


\section{AFFIDAVIT}

Herewith I declare that I prepared the PhD thesis "Drug Metabolism Determines Resistance of Colorectal Cancer to Resorcinol-Based HSP90 Inhibitors" on my own with no other aids and sources than quoted.

Hannes Landmann,

Göttingen in August 2014 
The findings in this work were accepted for publication in the open access journal Cell Death and Disease:

Landmann, H., Proia, D.A., He, S., Ogawa, L.S., Kramer, F., Beißbarth, T., Grade, M., Gaedcke, J., Ghadimi, M., Moll, U. \& Dobbelstein, M. UDP glucuronosyltransferase 1A expression levels determine the response of colorectal cancer cells to the heat shock protein 90 inhibitor ganetespib. Cell Death and Disease (accepted for publication in July 2014). 


\section{Table of Contents}

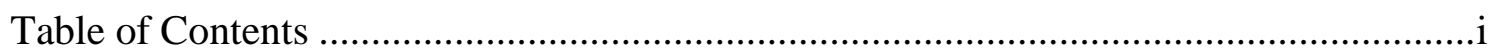

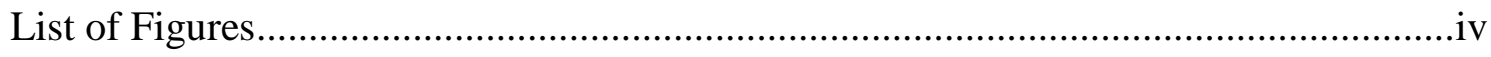

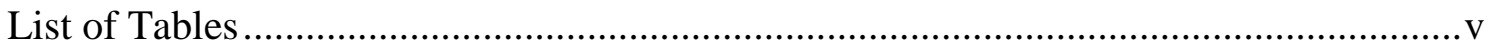

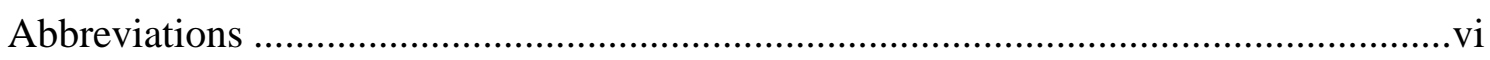

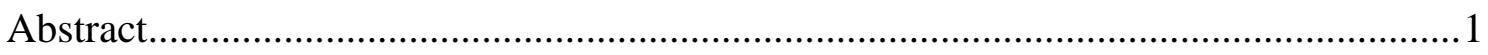

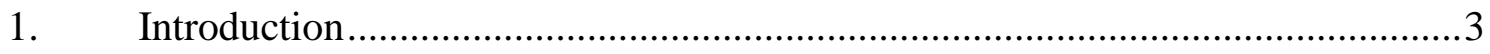

1.1 Global Perspective on Cancer Treatment ......................................................

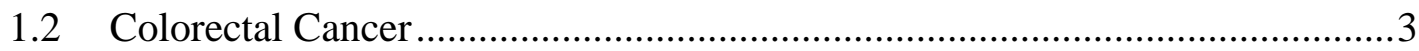

1.3 The Chaperone Protein HSP90 …...........................................................

1.4 HSP90 Clients Involved in Cancer...........................................................6

1.5 Inhibition of HSP90 as a Cancer Therapy Approach ....................................

1.5.1 The First Generation of HSP90 Inhibitors: Derivatives of Geldanamycin .8

1.5.2 The Second Generation of HSP90 Inhibitors: Small Synthetic Molecules.9

1.5.3 Rationale for the Clinical Use of HSP90 Inhibitors ................................11

1.5.4 Potential Risks Linked to the Clinical Use of HSP90 Inhibitors ..............11

1.5.5 Varying Pharmacology of Different HSP90 Inhibitors.............................12

1.6 Enzymes of the Drug Metabolism................................................................ 14

1.6.1 Enzymes from the Phase I of the Drug Metabolism ................................14

1.6.2 Enzymes from the Phase II of the Drug Metabolism ...............................15

1.6.3 The UDP-Glucuronosyltransferases and Their Role in Drug Metabolism16

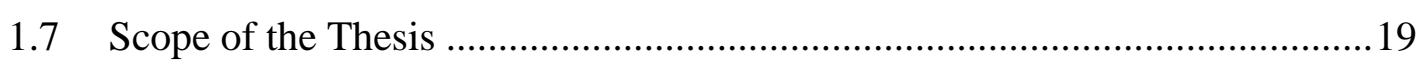

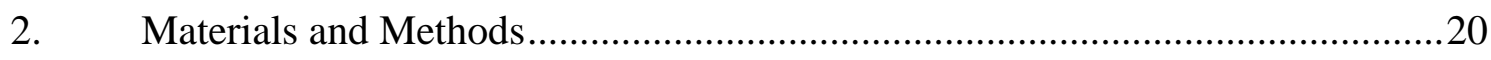

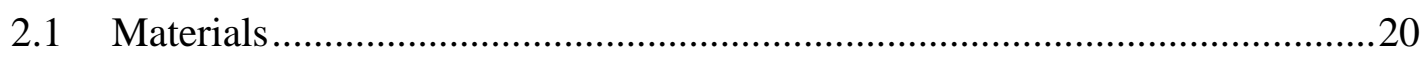

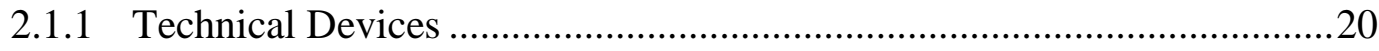

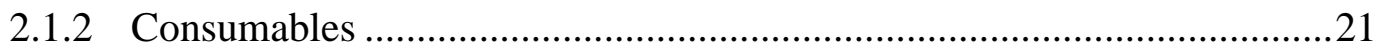

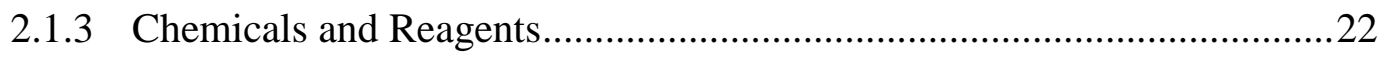

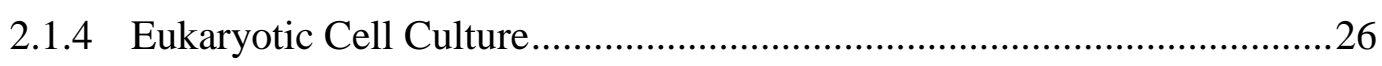

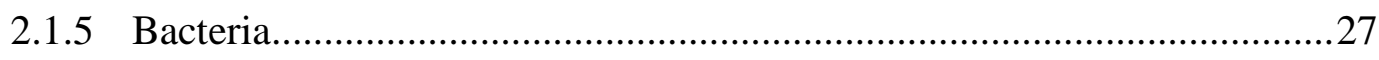

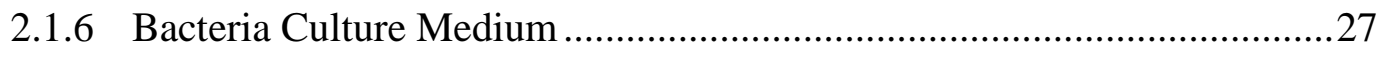

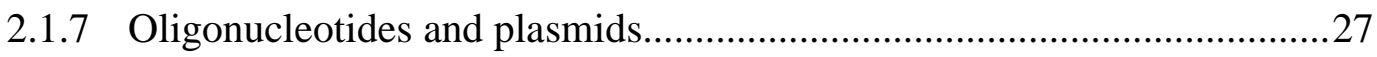

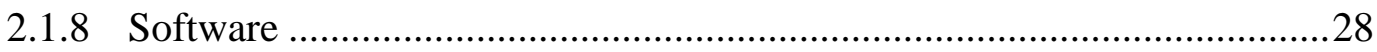




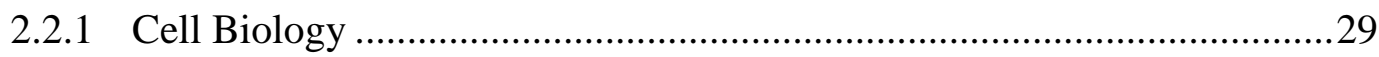

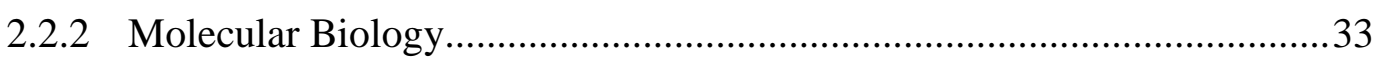

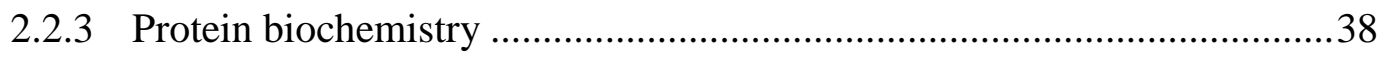

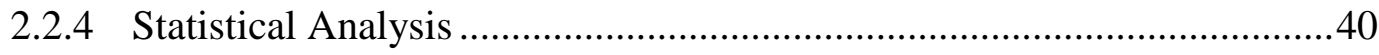

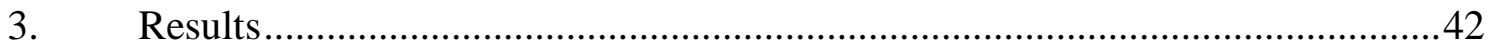

3.1 Expression of UGT1A Correlates with Resistance to Ganetespib Treatment 42

3.2 UGT1A Knockdown Sensitizes Resistant CRC Cell Lines to Ganetespib .....44

3.3 Overexpression of UGT1A10 Renders Sensitive Cells Resistant to

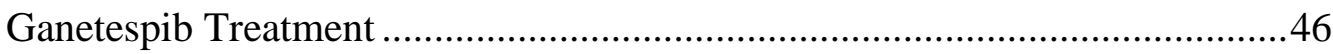

3.4 Verification of Ganetespib Glucuronidation by LC-MS/MS ........................49

3.5 UGT1A Expression Levels do not Correlate to Susceptibility to the First

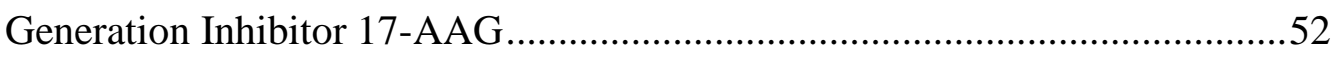

3.6 Susceptibility of Ganetespib-Resistant and -Sensitive Cell Lines to Second Generation HSP90 Inhibitors .......................................................................53

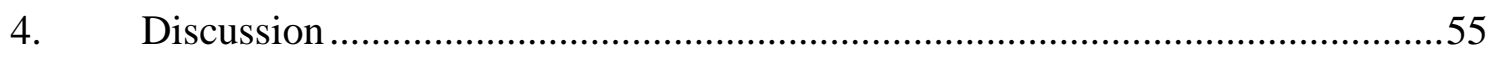

4.1 UGT1A Renders CRC Cells Resistant to Ganetespib.....................................55

4.2 UGT1A and the Resistance to Other Anti-Cancer Drugs .............................56

4.3 Implications for the Different Classes of HSP90 Inhibitors ..........................57

4.4 Role of UGT1A Glucuronidation in Other Cancer Types .............................58

4.5 Other Factors that Might Influence the Efficacy of Glucuronidation by

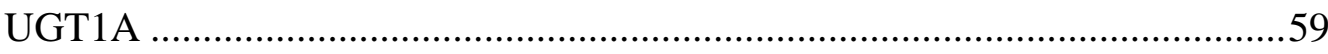

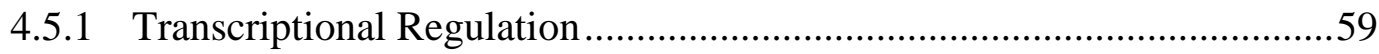

4.5.2 Factors Regulating the Activity of UGT1A .........................................61

4.5.3 Potential Influence of Co-Substrate Supply ...........................................62

4.5.4 Potential Influence of Metabolite Transport .........................................62

4.6 UGT1A Isoforms in Ganetespib Resistance .............................................63

4.7 Strategies to Circumvent Ganetespib Resistance by Glucuronidation.............64

4.8 Implications for the Clinical Use of Resorcinolic HSP90 Inhibitors ..............65

4.8.1 Mouse Models for in vivo Studies of Resorcinolic Hsp90 Inhibitors .......66

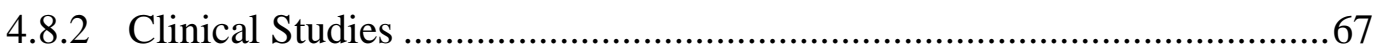

4.9 UGT1A as a Drug-Related Biomarker for Ganetespib Treatment.................68

4.9.1 Clinical Assessment of UGT1A mRNA Levels......................................69

4.9.2 Standardization of the mRNA Evaluation Process ...................................70 


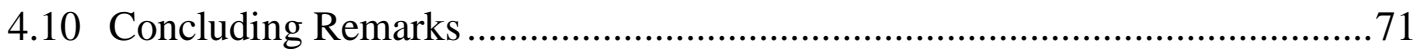

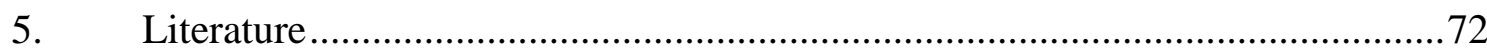

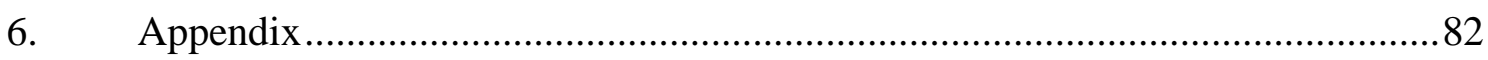

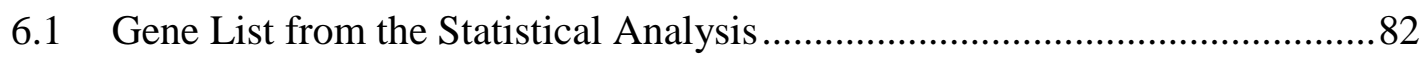

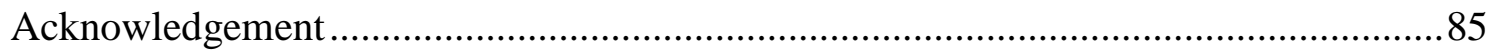




\section{List of Figures}

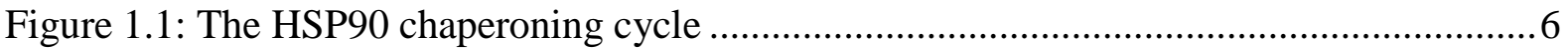

Figure 1.2: Chemical structures of geldanamycin derivatives...........................................

Figure 1.3: Chemical structures of second generation HSP90 inhibitors. ............................. 10

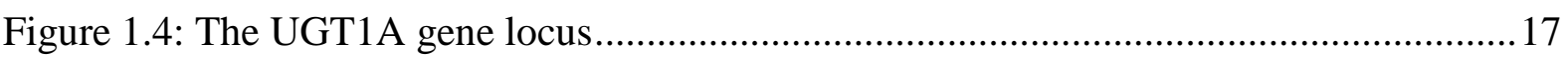

Figure 2.1: The calculation of $\mathrm{IC}_{50}$ values from the confluence measurements..................... 32

Figure 3.1: Ganetespib resistance correlates with high expression levels of UGT1A in CRC-

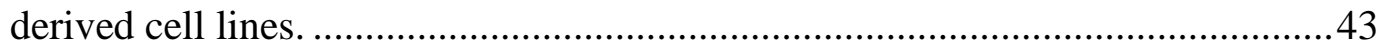

Figure 3.2: UGT1A knockdown renders HT29 cells more susceptible to ganetespib............45

Figure 3.3: UGT1A knockdown in HT29 cells destabilizes HSP90 clients upon ganetespib treatment.

Figure 3.4: Two clusters of UGT1A isoforms are expressed at high levels in ganetespibresistant cell lines.

Figure 3.5: Overexpression of UGT1A10 leads to ganetespib-resistance. 48

Figure 3.6: HSP90 client proteins are stabilized in ganetespib sensitive cell lines upon UGT1A10 overexpression. 49

Figure 3.7: Ganetespib is a substrate for UDP-glucuronosyl conjugation by tumor cells.......50

Figure 3.8: Ganetespib is a substrate for UDP-glucuronosyl conjugation by tumor cells.......51

Figure 3.9: 17-AAG resistance does not correlate with UGT1A expression levels. .52

Figure 3.10: Ganetespib and 17AAG induce different effects on levels of HSP90 clients in CRC cell lines.

Figure 3.11: Susceptibility of cell lines to different classes of second generation inhibitors..54

Figure 4.1: Chemical structures of ganetespib and AUY922 with HSP90 interacting sites....64

Figure 4.2: Overlay of distributions of UGT1A expression levels in primary tumor samples and in vitro $\mathrm{CRC}$ cell lines 


\section{List of Tables}

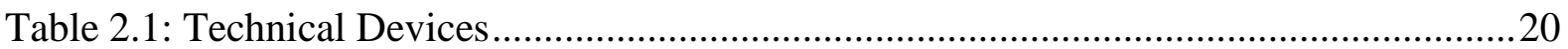

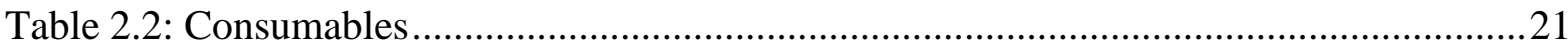

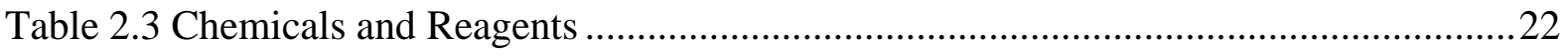

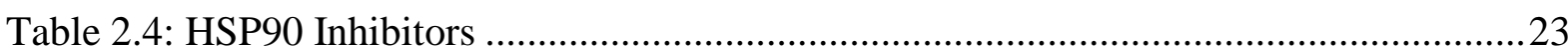

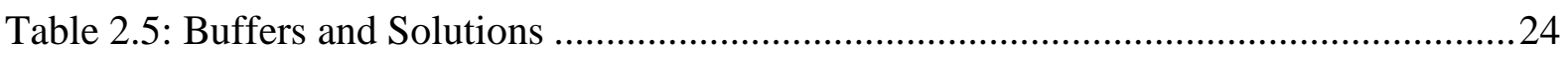

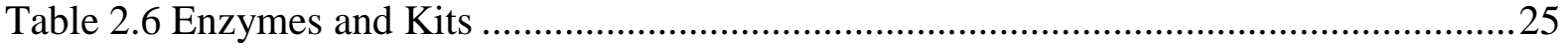

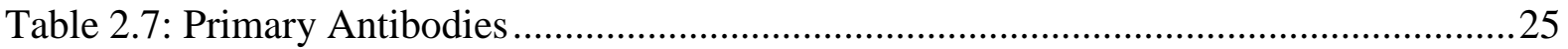

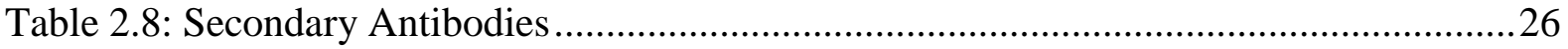

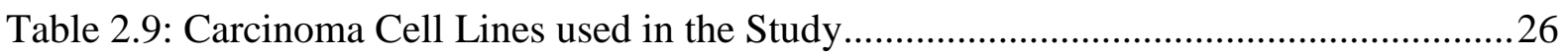

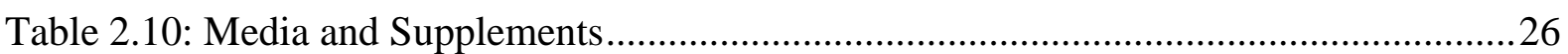

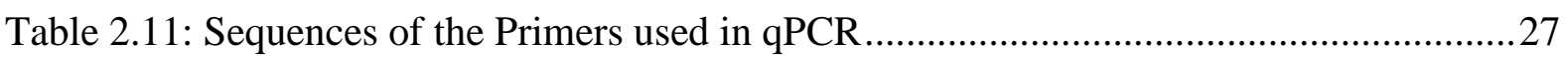

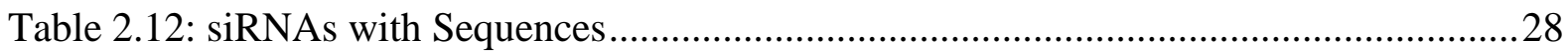

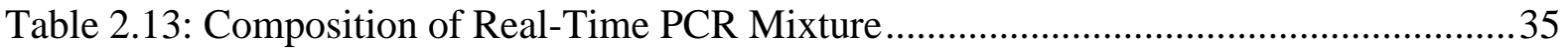

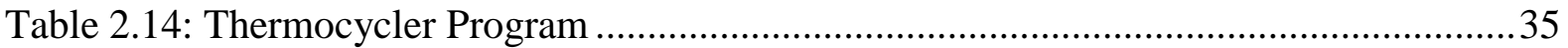

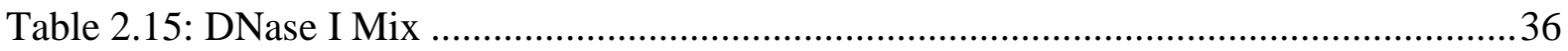

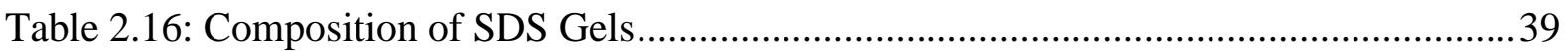




\section{Abbreviations}

${ }^{\circ} \mathrm{C}$

17-AAG 17-N-allylamino-17-demethoxygeldanamycin

A Ampere / adenosine

ADP adenosine diphosphate

AhR aryl hydrocarbon receptor

AHRR aryl-hydrocarbon receptor repressor

AOM azoxymethane

AKT RAC serine/threonine-protein kinase

ALK anaplastic lymphoma kinase

APC adenomatous polyposis coli protein

APS ammonium persulfate

approx. approximately

ATP adenosine triphosphate

AUY922 short name of NVP-AUY922

bp base pairs

$\beta$-Gal beta-galactosidase

BRAF Serine/threonine-protein kinase B-raf

BSA bovine serum albumin

CA California

CAR constitutive androstane receptor

cDNA complementary DNA

ChIP chromatin immuneprecipitation

CNOT2 CCR4 NOT transcription complex subunit 2

CRC colorectal cancer

CT cycle threshold

CYP cytochrome P450

Da Dalton

dATP deoxyadenosine triphosphate

dCTP deoxycytidine triphosphate

dDTT dithiothreitol

DMEM Dulbecco's Modified Eagle Medium

DMSO dimethyl sulfoxide

DNA deoxyribonucleic acid

dNTP deoxyribonucleotide

DPD dihydropyrimidine dehydrogenase

DSS dextran sodium sulphate

dTTP deoxythymidine triphosphate

E. coli Escherichia coli

EDTA ethylenediaminetetraacetic acid

ERK extracellular signal-regulated kinase (Mitogen-activated protein kinase)

$\mathrm{EtBr} \quad$ ethidiumbromid 


\begin{tabular}{|c|c|}
\hline $\mathrm{EtOH}$ & ethanol \\
\hline FCS & fetal calf serum \\
\hline FMO & flavin-containing monooxygenases \\
\hline g & gramm \\
\hline GAPDH & glyceraldehyde 3-phosphate dehydrogenase \\
\hline GI (tract) & gastrointestinal (tract) \\
\hline GRP94 & glucose-regulated protein $94 \mathrm{kDa}$ (endoplasmin) \\
\hline GSH & glutathione \\
\hline GSSG & glutathione disulfide \\
\hline GST & glutathione-S-transferases \\
\hline GTP & guanosine triphosphate \\
\hline hc & high concentration \\
\hline HES2 & hairy and enhancer of split 2 \\
\hline HIF $1 \alpha$ & hypoxia-inducible factor 1 -alpha \\
\hline HPLC & high performance liquid chromatography \\
\hline HRP & horse radish peroxidase \\
\hline HPRT1 & hypoxanthine-guanine phosphoribosyltransferase \\
\hline HSF1 & heat shock transcription factor 1 \\
\hline HSP90 & heat-shock protein 90 \\
\hline HLTF & helicase-like transcription factor \\
\hline $\mathrm{IC}_{50}$ & half maximal inhibitory concentration \\
\hline $\mathrm{k}$ & kilo $\left(10^{3}\right)$ \\
\hline $\mathrm{kb} / \mathrm{Kb}$ & kilo base pairs \\
\hline $\mathrm{kd}$ & knockdown \\
\hline $\mathrm{L}$ & liter \\
\hline LB & lysogeny broth \\
\hline LC & liquid chromatography \\
\hline $\mathrm{m}$ & $\operatorname{milli}\left(10^{-3}\right)$ \\
\hline$\mu$ & $\operatorname{mikro}\left(10^{-6}\right)$ \\
\hline M & mole per Liter (mol/L) \\
\hline MA & Massachusetts \\
\hline Met & hepatocyte growth factor receptor \\
\hline $\min$ & minutes \\
\hline mRNA & messenger ribonucleic acid \\
\hline MS & mass spectrometry \\
\hline MT & methyltransferase \\
\hline $\mathrm{n}$ & nano $\left(10^{-9}\right)$ \\
\hline NAT & $\mathrm{N}$-acyltransferase \\
\hline NJ & New Jersey \\
\hline NQO & NADPH-quinone oxidoreductase \\
\hline NY & New York \\
\hline $\mathrm{OH}$ & hydroxyl group \\
\hline $\mathrm{p}$ & pico $\left(10^{-12}\right)$ \\
\hline PAGE & polyacrylamide gel electrophoresis \\
\hline
\end{tabular}




\begin{tabular}{|c|c|}
\hline PAPS & 3'-phosphoadenisine- $5^{\prime}$-phosphosulfate \\
\hline PBS & phosphate buffered saline \\
\hline PCR & polymerase chain reaction \\
\hline $\mathrm{Pi}$ & Phosphate $\left(\mathrm{PO}_{4}^{3-}\right)$ \\
\hline p-ERK & phosphorylated ERK \\
\hline PXR & pregnane $\mathrm{X}$ receptor \\
\hline qPCR & quantitative real-time polymerase chain reaction \\
\hline RAF & RAF proto-oncogene serine/threonine-protein kinase \\
\hline ref. & reference \\
\hline RNA & ribonucleic acid \\
\hline RNA-seq & RNA sequencing \\
\hline rpm & revolutions per minute \\
\hline RT & room temperature / reverse transcription \\
\hline RT-PCR & real-time polymerase chain reaction \\
\hline S & $\operatorname{second}(\mathrm{s})$ \\
\hline s75 & siRNA Silencer® Select S231075 \\
\hline s76 & siRNA Silencer® Select S231076 \\
\hline SAM & S-adenosyl-methionine \\
\hline SCID & severe combined immunodeficiency \\
\hline scr & scrambled siRNA \\
\hline SDS & sodium dodecyl sulfate \\
\hline siRNA & small interfering RNA \\
\hline SMAD-4 & mothers against decapentaplegic homolog 4 \\
\hline SULT & sulfotransferase \\
\hline $\mathrm{T}$ & thymine \\
\hline TBS & Tris-buffered saline \\
\hline TBST & Tris-buffered saline with $0.1 \%$ Tween 20 \\
\hline TCEAL4 & transcription elongation factor A protein-like 4 \\
\hline TEMED & Tetramethylethylenediamine \\
\hline TGF-b & Transforming growth factor-beta \\
\hline TPMT & thiopurine S-methyltransferase \\
\hline TRAP1 & mitochondrial heat shock protein $75 \mathrm{kDa}$ \\
\hline Tris & tris(hydroxymethyl)aminomethane \\
\hline $\mathrm{U}$ & enzyme unit \\
\hline UGDH & uridinediphospho-glucose 6-dehydrogenase \\
\hline UGT & uridine diphosphate glucuronosyltransferases \\
\hline UPD & uridine diphosphate \\
\hline UK & United Kingdom \\
\hline
\end{tabular}




\begin{abstract}
Tumor cells are characterized by intrinsic proteotoxic stress and the accumulation of mutated proteins. Therefore, malignant cells depend on the activity of heat shock protein 90 (HSP90) much more than normal cells to maintain a functionally intact proteome. Thus, the inhibition of HSP90 by small molecules is currently being evaluated as a new approach to cancer therapy. One of the most promising drugs of this class is ganetespib, which is currently in intensive clinical trials.

We analyzed the susceptibility of colorectal cancer (CRC) cell lines to ganetespib and recorded large differences in the cell line-specific drug concentrations required for $50 \%$ growth inhibition $\left(\mathrm{IC}_{50}\right)$. Two groups of cancer cells became apparent; ganetespib-sensitive and -resistant cell lines with a difference in $\mathrm{IC}_{50}$ values up to 70 -fold $(36-2,500 \mathrm{nM})$. Therefore, the aim of this study was to elucidate the molecular determinants that govern the response of CRC cells to ganetespib treatment.

A statistical correlation of the $\mathrm{IC}_{50}$ values of $\mathrm{CRC}$ cell lines with their transcriptomes revealed that the expression of UDP-glucuronosyltransferase 1A (UGT1A) correlates strongly with resistance to ganetespib. UGT1A is involved in the metabolism of a variety of drugs, and it has been previously reported that high expression levels of this enzyme in cancer cells are responsible for the resistance to some established chemotherapeutic drugs. Knockdown of UGT1A in ganetespib-resistant cells and overexpression of UGT1A in ganetespib-sensitive cells confirmed the causal connection of increased ganetespib tolerance to the expression of UGT1A. The protective effect of UGT1A was also observed by immunoblot analysis of HSP90 clients, as they were not degraded in sensitive cell lines despite the presence of ganetespib when UGT1A was overexpressed.

A similar resistance in cells with increased UGT1A expression was also observed for another, structurally related HSP90 inhibitor, NVP-AUY922. However, HSP90 inhibitors from other classes do not seem to be subject to glucuronidation-induced resistance mechanisms. We hypothesize that glucuronidation by UGT1A takes place at the resorcinol moiety of ganetespib and NVP-AUY922. The metabolites of this glucuronidation process, the glucuronides of ganetespib and NVP-AUY922, were detected by mass spectrometry in a collaborating laboratory to support this hypothesis.

In summary, we show that the biological activities of ganetespib and NVP-AUY922, two resorcinolic HSP90 inhibitors, are impaired by UGT1A-catalyzed glucuronidation in
\end{abstract}


CRC cell lines. Notably, the UGT1A expression levels of primary CRC tumor samples have been found to be in the same range as in the CRC cell lines. Therefore, the occurrence of resistance to ganetespib and NVP-AUY922 in clinical applications is a conceivable scenario. We suggest that the expression of UGT1A can be used as a drug-related biomarker in cancer to ensure the activity of resorcinolic HSP90 inhibitors. These findings are of pivotal importance for the clinical application of these drugs in cancers which have the potential to express UGT1A. 


\section{Introduction}

\subsection{Global Perspective on Cancer Treatment}

Malignant neoplasms, commonly referred to as cancer, represents the second most common cause of death worldwide and the leading cause of death in developed countries. ${ }^{[1]}$ With the increasing life expectancy in developed and developing countries, as well as the continuing adaption of Western life style in emerging parts of the world, the global cancer incidence will rise significantly in the decades to come. ${ }^{[2]}$ Therefore, it becomes increasingly important to find new cancer therapies.

Despite the advances that have been made in cancer research so far, there is still need for improvement of the efficacy and specificity of cancer therapeutics. Most of the drugs used today are either chemotherapeutics that cause DNA damage or drugs that inhibit signaling intermediates involved in cell growth. The major drawbacks of these established cancer drugs is the unspecific DNA-damaging character of chemotherapeutics that can give rise to secondary malignancies and the very frequent development of drug resistance in cells treated with drugs that target signaling pathways. ${ }^{[3]}$ The development of drug resistance by some tumors is one of the main obstacles researchers need to approach in the future. ${ }^{[4]}$ Promising approaches are the combination of multiple drugs or treatment with drugs that target cellular machineries that are essential for tumor growth, like the Hsp90 machinery (see chapters 1.3, 1.4 , and 1.5.3) or the proteasome. ${ }^{[3,4]}$

\subsection{Colorectal Cancer}

Colorectal cancer (CRC) is the second most frequent type of malignant tumors in men and in women in Germany, and every seventh malignant neoplasia develops in the colon or rectum. ${ }^{[5]}$ Worldwide more than half of the prevalence burden is found in the developed countries, although they only harbor one sixth of the world population. ${ }^{[6]}$ The incidence rises with industrialization and urbanization, supposedly due to increased risk factors that come with the Western life style, like higher consumption of meat and alcohol, as well as higher body mass. ${ }^{[6]}$ More than $50 \%$ of the Western population develops a colorectal tumor by the age of 70 and about 1 in 10 of these adenomas progresses to the malignant state. ${ }^{[7]}$

For colorectal carcinoma, surgical resection remains the mainstay of treatment measures. ${ }^{[8]}$ Therefore an early diagnosis of the initially formed adenoma and a surgical 
removal by polypectomy is fundamental for successful treatment. As colorectal tumors often give rise to symptoms at early stages of development, they are fairly treatable and the survival rate is relatively high. ${ }^{[6]}$ A treatment with established chemotherapeutics can be beneficial for the individual patient, dependent on the stage of the carcinoma, molecular markers, and metastatic potential. ${ }^{[9,10]}$ Nevertheless, in general the identification of predictive markers for patient stratification is difficult. ${ }^{[11]}$

About $85 \%$ of all colorectal tumors exhibit a mutation in the gene encoding the adenomatous polyposis coli (APC) protein. ${ }^{[7]}$ A mutation of this tumor suppressor is thought to be of pivotal importance for the initiation of colorectal cancer growth due to APCs central function as a negative regulator of the Wnt signaling pathway. The Wnt pathway activates several genes involved in fundamental cellular processes like proliferation, differentiation, and survival. ${ }^{[12]}$ The mutation on the APC gene is thought to be the first in a cascade of mutations that drive the oncogenic alteration from normal epithelium via adenoma to carcinoma. ${ }^{[13]}$ The sequence of genetic alterations is well described and the loss of APC function is often followed or accompanied by an activating mutation of K-Ras, which then induces the hyperproliferation of the epithelial cells even further. Subsequent loss of SMAD-4, a component of the TGF- $\beta$ pathway, leads to the abrogation of the TGF- $\beta$-induced G1-cell cycle stalling. Late in colorectal tumor development, close to the manifestation of the carcinoma stage, the tumor suppressor p53 is mutated. ${ }^{[14]}$

Despite the current understanding of the genetic background of colorectal cancer development and the fact that localized CRC is fairly treatable by resection, the optimization of an adjuvant therapy for pre- and post-resection treatment might improve the outcome of surgery by preventing recurrence and thereby improve the life expectancy of patients. ${ }^{[15]}$

\subsection{The Chaperone Protein HSP90}

Cancer cells in general have to cope with increased proteotoxic stress due to hypoxia in the microenvironment, conformationally aberrant oncoproteins, an increased amount of reactive oxygen species, and disproportionally expressed proteins due to chromosomal instability. ${ }^{[16,17]}$ These conditions lead to an elevated proportion of misfolded proteins in cancer cells and hence an increased dependence on chaperone machineries. These chaperone networks support the correct folding of proteins in cells challenged by proteotoxic stress and help to maintain the integrity of the proteome in cancer cells. One of the most important chaperones for cancer cells is the heat-shock protein 90 (HSP90). ${ }^{[18]}$ 
HSP90 is a largely cytoplasmic protein. Unlike other chaperones, HSP90 binds its client proteins in a late stage of folding, thereby helping these proteins to acquire and maintain their native structure. ${ }^{[19]}$ Compromising the function of HSP90 leads to the proteasomal degradation of its client proteins. Therefore, the chaperoning function of HSP90 is essential in all eukaryotes. Its sequence is highly evolutionary conserved, e.g. in yeast $60 \%$ of the Hsp90 nucleotide sequence is identical to human Hsp90. ${ }^{[20]}$ HSP90 exists in two isoforms in human; HSP90 $\alpha$, an inducible isoform, and HSP90ß, which is constitutively expressed. The two isoforms differ only slightly in their functions and share the vast majority of their respective clients. ${ }^{[21]}$ Altogether their functional diversity is poorly understood. ${ }^{[22]}$ Apart from these two cytosolic HSP90 isoforms, there are also homologues localized to the mitochondria (TRAP1) or the endoplasmic reticulum (GRP94), but both homologs are of minor importance and have not been studied thoroughly. ${ }^{[23]}$

Under normal conditions HSP90 makes up to $2 \%$ of the cellular protein content and this portion is only about two-fold increased upon stress. ${ }^{[18]}$ A large and complex network of co-chaperones controls the HSP90 chaperone machinery thereby regulating its client specificity and activity, e.g. by client protein shuttling, induction of conformational change, or by binding, and stabilizing an intermediate state of the chaperoning cycle. ${ }^{[24]}$

The chaperone works as a homodimer in which two molecules of HSP90 dimerize at the C-terminal dimerization domains of the monomers. ${ }^{[25]}$ The client binding domain is in the middle part of the protein and the N-terminal region harbors the ATP-binding domain. ${ }^{[26]}$ Upon binding of ATP the lid segment of the $\mathrm{N}$-terminal domain closes and thereby promotes the dimerization of the N-terminal regions. This closed state of the two monomers adopts a twisted confirmation and the central parts of the two monomers form a surface at which most client interactions take place. ${ }^{[27,28]}$ The client protein binds to the closed conformation and the chaperoning process takes place together with a simultaneous ATP-hydrolysis. Upon release of the correctly folded client protein as well as ADP, the open state is generated again (see Figure 1.1). ${ }^{[27]}$

In the deep binding pocket of HSP90, ATP adopts a relatively unusual structure called the Bergerat fold. This unusual, kinked conformation is only observed in a few other ATPases and kinases, namely in gyrases, histidine kinases and the bacterial DNA mismatch repair proteins MutL. ${ }^{[29]}$ This specific arrangement of ATP permits the design of inhibitors that bind the ATP binding site of HSP90 with a very high specificity. ${ }^{[30,31]}$ 


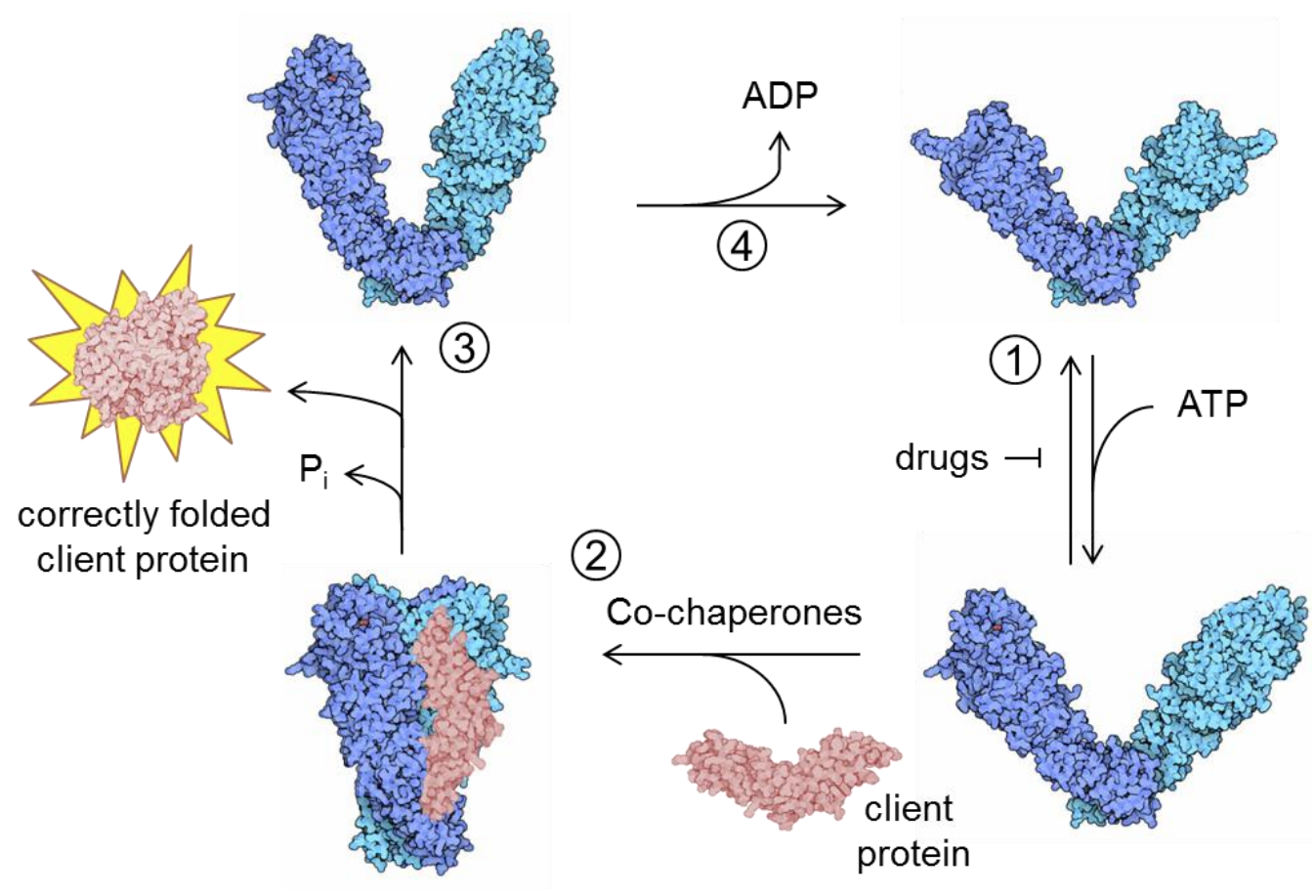

Figure 1.1: The HSP90 chaperoning cycle (schematic, adapted from ref [23] and [32]). HSP90 homodimer shown in blue, client protein shown in magenta. (1) Formation of closed state upon binding of ATP. (2) Binding of the misfolded client protein to the chaperone. The chaperoning function is fulfilled upon hydrolysis of adenosine triphosphate (ATP). Co-chaperones govern the specificity and activity of HSP90. (3) Release of the correctly folded client protein and phosphate (Pi). (4) Open confirmation is regenerated upon release of adenosine diphosphate (ADP).

\subsection{HSP90 Clients Involved in Cancer}

The continuous research on HSP90 and its role in cancer gives rise to a long and ever growing list of known client proteins (see http://www.picard.ch/downloads/ Hsp90interactors.pdf). Many of these client proteins are conformationally labile signal transducers that have a crucial role in growth control, cell survival, or in developmental processes. ${ }^{[19]}$ The maintenance of these processes is crucial for the development of cancer. In this regard HSP90 is working as a buffer for the numerous genetic lesions present in cancer cells. The mutations lead to thermal instability of the proteins and in the absence of HSP90 they are prone to misfold. The activity of HSP90 however, retains the function of mutated proteins and prevents the clients from proteasomal degradation. ${ }^{[23]}$ Due to the fact that mutated clients proteins depend on the HSP90 activity far more than the proteins in their native state, HSP90 inhibitors should show a higher impact on cancer cells which contain mutated proteins compared to normal cells. 
One group of HSP90 clients are key oncogenic proteins involved in the control of proliferation (e.g. Receptor tyrosine-protein kinase ErbB2/Her2, or Hepatocyte growth factor receptor Met), immortalization (e.g. telomerase), apoptosis (e.g. RAC serine/threonineprotein kinase AKT), and angiogenesis (e.g. Hypoxia-inducible factor 1-alpha HIF1 $\alpha$ ). ${ }^{[18]}$ Also, the tumor suppressor p53 is a client of HSP90, and it can serve as an example for the change in the HSP90 - client protein interaction after the client has become mutated. Aberrations of the TP53 gene (encoding p53) are the most common mutations in human cancers and the mutant forms are dependent on the HSP90 activity to a much larger extent compared to the wild-type form. ${ }^{[33]}$ Wild type p53 is subjected to a fast turnover by proteasomal degradation, whereas mutant p53 and HSP90 form a stable complex which prevents the ubiquitination of the tumor suppressor, thereby leading to the observed accumulation of mutant p53 protein within tumor cells. ${ }^{[34]}$ The turn-about in p53 function, from a tumor suppressor in native form to an oncogenic driver when mutated, is commonly referred to as "gain-of-function" and the accumulation of mutant p53 protein is an essential feature of this cancer promoting character of mutant $\mathrm{p} 53 .{ }^{[34]}$

The fact that HSP90 is over-active in cancer cells makes it an interesting target for the treatment of cancer. The increased demand for HSP90 activity due to accumulation of mutated proteins leads to an overexpression of the chaperone and supposedly to the formation of large stabilized multichaperone complexes that include HSP90, co-chaperones, and client proteins. ${ }^{[18]}$ It is proposed that these complexes exhibit a much higher activity compared to HSP90 in normal cells. ${ }^{[35]}$ In order to maintain the function of several oncogenic proteins, tumor cells are thought to be addicted to the hyper-active HSP90 chaperone. ${ }^{[36]}$ Due to this hyperactivity of cancerous HSP90, the chaperone binds to its inhibitors with approximately 100-fold higher affinity than in normal cells. ${ }^{[37]}$ This preference of HSP90 inhibitors for tumor cells, together with the already described oncogenic character of many HSP90 clients, the higher sensitivity of cells with mutated client proteins, and the fact that some of the HSP90 inhibitors accumulate in cancer, underscores the high potential of HSP90 inhibitors for the treatment of cancer. ${ }^{[23,38,39,40]}$

\subsection{Inhibition of HSP90 as a Cancer Therapy Approach}

HSP90 inhibition is a vital field of research nowadays due to the promising prospects of this strategy for the treatment of cancers. The advantage over the established cancer therapies is the directed disturbance of a cellular machinery which is more important for 
tumor cells compared to cells in normal, healthy tissue. ${ }^{[3]}$ Therefore HSP90 inhibitors should not exhibit the major drawbacks of established chemotherapeutics that target the DNA replication or single molecules from signaling pathways (described in chapter 1.1).

\subsubsection{The First Generation of HSP90 Inhibitors: Derivatives of Geldanamycin}

The first HSP90 inhibitor, geldanamycin, is a natural compound from the bacteria Streptomyces hygroscopicus and was initially analyzed due to its weak antibiotic effect. ${ }^{[41]}$ Following this, it was found to be an anti-cancer agent due to its ability to reverse the transformation of cells that was driven by v-Src. Later this observation was traced back to the inhibition of HSP90 activity by geldanamycin. ${ }^{[2,43]}$ The tyrosine-protein kinase transforming protein Src is an oncogenic protein and one of the numerous HSP90 clients among the receptors, kinases, and transcription factors involved in carcinogenesis.

Geldanamycin and its derivative 17-N-allylamino-17-demethoxygeldanamycin (17-AAG) (structures in Figure 1.2) inhibit HSP90 by binding to its ATP-binding pocket and have been the subject of intensive research, including clinical trials. ${ }^{[44]}$ However, due to some major drawbacks including high hepatotoxicity, poor solubility, complications with formulation, relatively weak target potency, and low bioavailability, the evaluation of geldanamycin-derivatives as drugs for cancer treatment was stopped. ${ }^{[45,46]}$

The high toxicity of geldanamycin compounds is caused by their quinone moiety. For this reason, and due to fact that the quinone form only represents a less active pro-drug of the inhibitors (see chapter 1.5.5 for details), a chemically reduced and stabilized hydroquinone form of 17-AAG called retaspimycin is now undergoing evaluation in clinical trials (structure in Figure 1.2). It has increased water solubility and bioavailability and is considerably less toxic than its parent compound 17-AAG. ${ }^{[47]}$
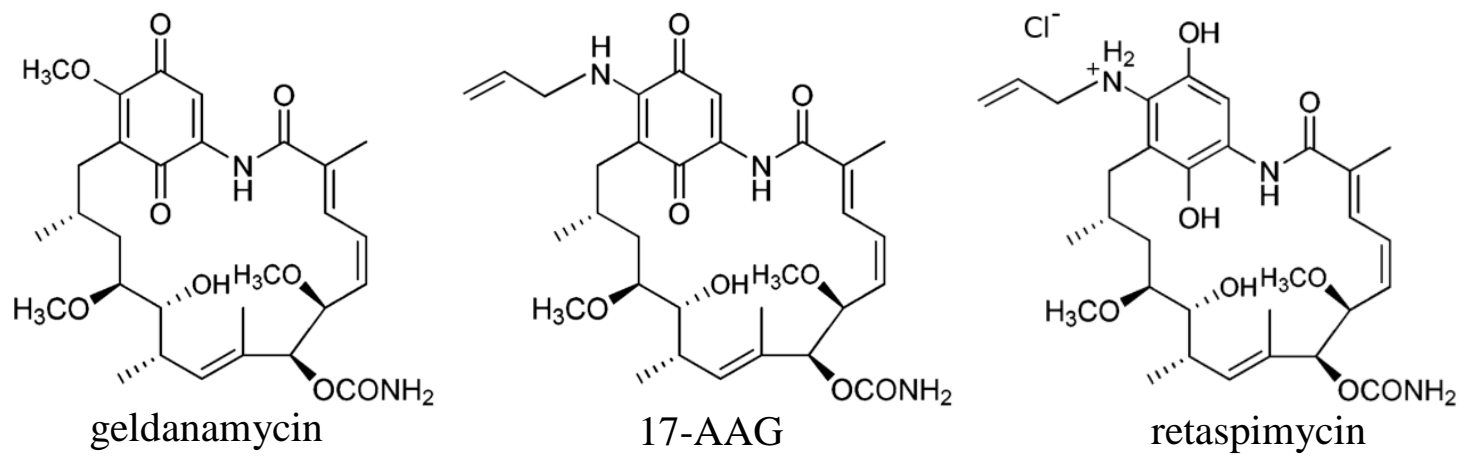

Figure 1.2: Chemical structures of geldanamycin derivatives.

Geldanamycin, 17-N-allylamino-17-demethoxy-geldanamycin (17-AAG) and retaspimycin. 
However, the overall profound drawbacks for geldanamycin derivatives led to the intensive research for other HSP90 inhibitors; the so called second generation of HSP90 inhibitors.

\subsubsection{The Second Generation of HSP90 Inhibitors: Small Synthetic Molecules}

The second generation of HSP90 inhibitors includes small synthetic molecules like ganetespib, NVP-AUY922, PU-H71 and SNX-2112, which all inhibit HSP90 by binding to its ATP-binding pocket.

Ganetespib is a resorcinolic triazolone inhibitor (see structure in Figure 1.3) which is licensed by Synta Pharmaceuticals ${ }^{\circledR}$ and shows promising properties for the application in cancer treatment. Currently, many clinical trials are in progress in various cancer types aiming to elucidate the feasibility of ganetespib as a clinical HSP90 inhibitor in combination with established cancer therapy treatments, i.e. cytostatics (docetaxel, capecitabine, paclitaxel, pemetrexed), a specific kinase inhibitor (crizotinib) or an estrogen receptor antagonist (fulvestrant). ${ }^{[48]}$ Additionally, ganetespib is evaluated as a single agent against tumors which rely on specific oncogenic drivers that are known HSP90 clients. Encouraging clinical activity has been observed in ALK-driven non-small cell lung cancer and Her2overexpressing breast cancers. ${ }^{[49,50]}$ Like all second generation inhibitors, ganetespib is more potent than inhibitors from the first generation. This advantage is partly due to its ability to bind the open as well as the closed conformation of the ATP binding pocket of HSP90, whereas the larger molecules from the first generation of inhibitors are limited to binding to the open conformation. ${ }^{[40]}$ Also, additional hydrogen bonds are formed with HSP90 via the triazolone moiety of ganetespib increasing its binding affinity, thereby surpassing the inhibitors from the first generation in terms of binding potential. ${ }^{[40]}$ Like all second generation inhibitors that are currently under investigation, ganetespib lacks the quinone moiety, which is known to cause the severe toxicity of geldanamycin and its derivatives. The consequence is an advantageous toxicity profile compared to first generation inhibitors. ${ }^{[40]}$

Another second generation inhibitor is called NVP-AUY922 (AUY922). This compound is licensed to Novartis and is also based on resorcinol, here coupled to an isoxazole (Figure 1.3). This inhibitor was developed on the basis of high-throughput screening of a compound library followed by structure-based optimization. ${ }^{[51,52]}$ AUY922 is currently in phase I and II clinical trials in multiple myeloma as a single agent or in 
combination with the proteasome inhibitor bortezomib. ${ }^{[46]}$ It is also combined with monoclonal antibodies in breast cancer trials. ${ }^{[46]}$

The purine scaffold HSP90 inhibitor PU-H71 (see structure in Figure 1.3) was developed utilizing structure based drug design. In this approach new insights from crystal structure studies of HSP90 in binding complex with geldanamycin or with ATP were taken into account. When binding to HSP90, the adenine moiety of PU-H71 forms hydrogen bonds and adopts an orientation similar to ATP. ${ }^{[53]}$ In preclinical trials, PU-H71 has shown very good anti-tumor effects in both in vitro and in vivo settings, and there are currently phase I clinical trials ongoing to test its safety and tolerability in patients with solid tumors. ${ }^{[46,54]}$

The HSP90 inhibitor SNX-2112 and its pro-drug form SNX-5422 were discovered by a chemoproteomics approach using an ATP-affinity column. ${ }^{[55]}$ It contains a dihydroindazolone derivate (see structure in Figure 1.3) and represents a unique class of HSP90 inhibitors, structurally unrelated to the other compounds discussed previously. Although treatment with the drug showed very promising properties in preclinical trials, the development of SNX-2112 was discontinued due to its ocular toxicity resulting in potentially irreversible retinal damage. ${ }^{[56,57]}$

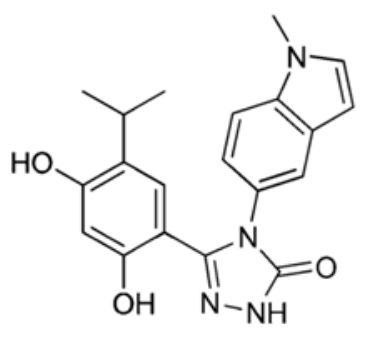

ganetespib

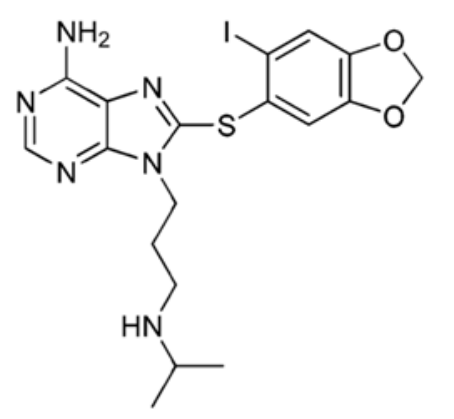

PU-H71

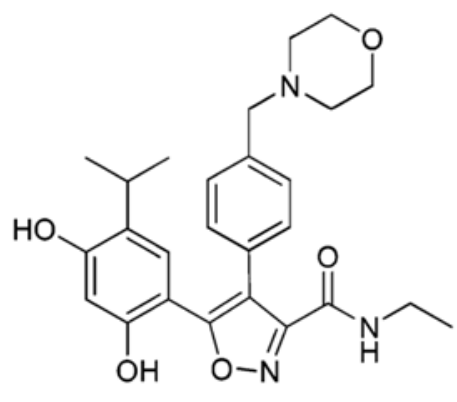

AUY922

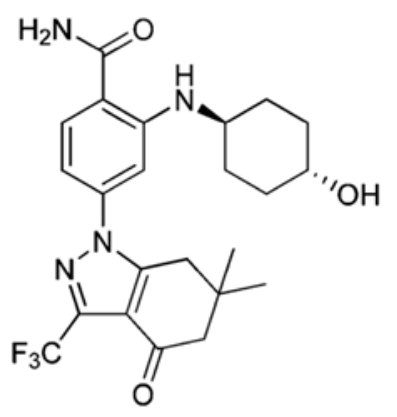

SNX-2112

Figure 1.3: Chemical structures of second generation HSP90 inhibitors.

Ganetespib, AUY922, PU-H71 and SNX-2112. 


\subsubsection{Rationale for the Clinical Use of HSP90 Inhibitors}

Almost all clinical trials with HSP90 inhibitors aim at the application of the inhibitors in combination with established chemotherapeutics to treat cancer. ${ }^{[46]}$ Due to the fact that HSP90 is protecting the cells under stress conditions such as induced during chemotherapy, the inhibition of this protective machinery sensitizes the cells to the effects of chemotherapeutics.

The list of HSP90 clients includes the Serine/threonine-protein kinase Chk1 and the Wee1 protein kinase, two key players from the DNA damage response that regulate the transition through the G1-S and G2-M checkpoints and ensure the interruption of DNA synthesis when DNA lesions are present. ${ }^{[58]}$ Therefore, HSP90 inhibitors could lead to the degradation of Chk1 and Wee1, which would in turn sensitize the cells to chemotherapeutics by abrogation of the G1/S arrest. ${ }^{[59,60]}$

Furthermore, the HSP90 client RAC serine/threonine-protein kinase (AKT) is involved in the regulation of metabolism, proliferation, cell survival, growth, and angiogenesis. ${ }^{[61]}$ The loss of this regulatory protein by HSP90 inhibition has been shown to sensitize the cells to induction of apoptosis by paclitaxel. ${ }^{[62]}$

In addition, the HSP90 clients AKT and Her2, together with the kinase Raf-1, are involved in the protection of cancer cells against $\gamma$-radiation induced cell death. ${ }^{[63,64,65]}$ The inhibition of HSP90 causes the degradation of these $\gamma$-radiation activated proteins, followed by enhanced G2 arrest upon radiotherapeutic treatment and ultimately increased induction of apoptosis. $^{[66]}$

As already described in chapter 1.4 the tumor suppressor p53 is a client of HSP90. This tumor suppressor is mutated very frequently in tumors and it has been observed that mutant p53 is forming stabilized complexes with HSP90, which prevent the proteasomal degradation of mutant $\mathrm{p} 53 .{ }^{[34]}$ The inhibition of Hsp90 could overcome this stabilization and lead to a decrease of the oncogenic effect that is caused by the accumulation of mutant p53.

\subsubsection{Potential Risks Linked to the Clinical Use of HSP90 Inhibitors}

In the light of all this cancer affecting impact, the inhibition of HSP90 seems very beneficial for treatment of cancer. However, there are some implications that might give rise to undesirable side effects of HSP90 inhibition.

Firstly, HSP90 has a broad spectrum of clients and an exact prediction of the consequences of HSP90 inhibition will remain a very complex process and is dependent on a 
lot of factors like genetic background of the patient, site and stage of the tumor, as well as stress levels and activated signaling pathways in the individual cells.

For some inhibitors it has been described that they lead to a short term induction of some client proteins, prior to their degradation. This can give rise to unwanted side effects following the release of these clients. ${ }^{[67,68]}$

HSP90 also plays a regulatory role in the heat shock response where, under stress-free conditions it binds and represses the heat shock transcription factor 1 (HSF1). Upon stress or inhibition of HSP90, HSF1 is released. This then trimerizes and binds heat shock elements to activate the heat shock response. Part of this heat shock response is the increased expression of Hsp27 and Hsp70 which may then serve to compensate for the loss of HSP90. ${ }^{69]}$ Also, HSF1 has been shown to increase the oncogenic potential of cancer cells, as it regulates the expression of numerous other genes that are involved in cell survival under stressful conditions. ${ }^{[70]}$ Therefore, the activation of HSF1 might give rise to side effects or the development of resistance to Hsp90 inhibitors. Cisplatin has been shown to block the binding of HSF1 to the heat shock elements, which partly explains the synergistic effect observed when it is used in combination with HSP90 inhibitors. ${ }^{[71]}$

Another aspect is that HSP90 also works as a buffer to maintain normal function of mutated proteins. Therefore in some cases upon inhibition of HSP90 the severe effects of these mutations might get revealed and the malignant phenotype might become apparent. ${ }^{[18]}$

\subsubsection{Varying Pharmacology of Different HSP90 Inhibitors}

For all second generation HSP90 inhibitors, the elucidation of their pharmacology is still in progress, but some significant differences are already apparent. Ganetespib, AUY922, and PU-H71 are currently in clinical trials and seem to have different effects on the spectrum of HSP90 client proteins. ${ }^{[53]}$ Furthermore, they differ in their tumor cell retention and half-life in vivo. ${ }^{[53]}$ Nevertheless, even for short-lived HSP90 inhibitors it has been shown that they can induce the degradation of the relevant clients. ${ }^{[44]}$ The HSP90 inhibitor-treated cells then might need several days to resynthesize these proteins. Therefore, even the short-lived HSP90 inhibitors might have a long lasting pharmacodynamic effect. ${ }^{[44]}$

The resorcinol-based inhibitors ganetespib and AUY922 show quite similar behavior as they interact with the ATP-binding pocket of HSP90 by forming almost identical hydrogen bonds. ${ }^{[72]}$ Despite these similarities, AUY922 exhibits a higher ocular toxicity compared to 
ganetespib due to its retention in photoreceptor cells. ${ }^{[73]}$ This phenomenon makes AUY922 less favorable for use in therapy compared to ganetespib.

While for ganetespib the tolerability of efficient doses has been demonstrated in previous studies, the elucidation of drug tolerance for PU-H71 is still ongoing. Phase I clinical trials and a metabolism study based on positron emission tomography are in progress to understand the drugs pharmacokinetics. ${ }^{[74]}$

Any effects which might compromise the impact of a given drug have to be known and need to be considered before its administration as a new standard therapy. For instance, some proteins or enzymes which are highly expressed in different tumor types might affect the activity or the uptake and efflux of the drug. On the other hand, the lack of enzymes responsible for systemic metabolism of the drug can lead to severed effects caused by accumulation of the drug in the body.

The enzyme that determines the outcome of geldanamycin drug treatment is known and has been studied quite intensely. The activities of geldanamycin and all drugs derived from it, except for retaspimycin, depend on the reduction of their less active quinone form of the pro-drug to the more potent hydroquinone form. For example 17-AAG gets reduced to its more active metabolite $17-\mathrm{AAGH}_{2} \cdot{ }^{[75]}$ This reduction is facilitated by the NADPH-quinone oxidoreductase 1 (NQO1), which has previously been identified as a potential biomarker for geldanamycin derived HSP90 inhibitors. A tumor that lacks this enzyme is prone to exhibit resistance to treatment with the drug. ${ }^{[76]}$

For other chemotherapeutics various response-related biomarker are already known, which are associated with the route of systemic drug metabolism in the human body. For instance, the uracil analog 5-fluorouracil, which is widely prescribed for colorectal cancer, is dependent on hepatic dihydropyrimidine dehydrogenase (DPD) for its metabolism. Patients with low DPD activity in the liver cannot efficiently inactivate 5-FU and the active drug accumulates in the patients in amounts that can cause lethal toxicity. ${ }^{[77]}$ Also, thiopurine drugs such as thioguanin are dependent on the activity of thiopurine methyltransferase (TPMT) for their metabolism and lack of this metabolizing enzyme can give rise to severe adverse effects. ${ }^{[78]}$

However, in current clinical practice the screening for genetic polymorphisms that influence the drug metabolism is rare and almost exclusively done for patients that exhibit unexplained adverse effects or lack of response. ${ }^{[79]}$ This 'trial-and-error' approach for chemotherapeutic drug dose adjustments can be risky for the patients with certain genotypes and lead to severe side effects, which can be fatal in extreme cases. ${ }^{[77]}$ 
The drug metabolizing enzymes employed by the human body for turnover of xenobiotic compounds, might determine the outcome of a drug treatment, by lack or excess of drug activating or deactivating entities. Therefore, enzymes of this class are of particular interest when examining the pharmacodynamics of a new drug.

\subsection{Enzymes of the Drug Metabolism}

The gastrointestinal tract (GI tract) is the organ system, in which foodstuff and xenobiotic compounds such as drugs are metabolized. Whereas nutrients are absorbed and further processed for digestion, potentially harmful xenobiotics are subjected to a series of metabolizing reactions to deactivate them and facilitate their excretion. ${ }^{[80]}$ The liver, the colon and virtually all tissues throughout the GI tract are known to express enzymes involved in drug metabolism. Therefore cells derived from organs from the GI tract, such as the CRC cell lines used in this study, exhibit much higher drug metabolizing potential compared to cells derived from other, less metabolically active tissues.

The metabolism of compounds, regardless of their origin being endogenous or exterior, is facilitated in two phases of conversion. Reactions of the phase I of the drug metabolism introduce reactive and polar groups to their substrates by oxidation, reduction, or hydrolysis. In phase II the substrates are subjected to conjugation, in which charged moieties are coupled to these reactive sites of the usually hydrophobic target molecules. ${ }^{[80]}$ Substrates that undergo these processes usually become deactivated and their water solubility is increased to support their excretion. Nevertheless, some cases of bio-activation of pro-drugs by conjugation have also been described. ${ }^{[81,82]}$

\subsubsection{Enzymes from the Phase I of the Drug Metabolism}

Among the enzymes facilitating phase I reactions the superfamily of cytochromes P450 (CYPs) represents the most important one as they facilitate the first step of metabolism for the vast majority of therapeutic drugs. CYPs carry out oxidation, hydroxylation, dehalogenation, dealkylation, and deamination reactions during the metabolism of dietary and

xenobiotic compounds as well as during the synthesis of endogenous compounds. ${ }^{[80]}$ The twelve CYP isoforms, which are known to be involved in drug metabolism, are able to metabolize multiple substrates. This can lead to severe drug-drug interactions, where two 
drugs are metabolized by the same CYP isoform and therefore compete for the binding by this enzyme. ${ }^{[80]}$

The phase I enzymes from the superfamily of the flavin-containing monooxygenases are of less importance compared to CYPs, as they only oxidize a small fraction of xenobiotic compounds and they most often produce benign metabolites. ${ }^{[80]}$

Another group of enzymes that participate in the phase I of drug metabolism are the hydrolytic enzymes, which are comprised of the epoxide hydrolases and the carboxylesterases. The epoxide hydrolases deactivate potentially toxic epoxides which, if left unattended, would bind to cellular nucleophiles such as DNA, RNA or proteins, causing severe effects. Carboxylesterases hydrolyze ester and amide containing chemicals. They are not only involved in drug deactivation processes, but on the contrary often yield a more reactive species. For instance the pro-drug irinotecan is bioactivated by carboxylesterases to $\mathrm{SN}-38$, a potent topoisomerase inhibitor used in the treatment of advanced colorectal cancer. $^{[80]}$

\subsubsection{Enzymes from the Phase II of the Drug Metabolism}

Phase II of the drug metabolism is facilitated by enzymes catalyzing substrate conjugation reactions. Among these transfer reactions, the addition of glucuronic acid, sulfate, glutathione, or small acetyl or methyl groups are the most important ones.

The phase II enzyme with the broadest spectrum of xenobiotic substrates, the uridinediphospho(UDP)-glucuronosyltransferase (UGTs), are discussed in more detail in chapter 1.6.3.

Another major phase II reaction is sulfate transfer, which is facilitated by the sulfotransferases that conjugate sulfates from the co-substrate 3 '-phosphoadenisine-5'phosphosulfate onto hydroxyl- and amine-groups of the targets. The sulfotransferases metabolize a wide variety of endogenous and exogenous compounds and play an important role in human homeostasis. Drug metabolism by sulfation often leads to chemically more reactive compounds that can form electrophilic cations upon heterolytic cleavage. ${ }^{[80]}$

The conjugation of substrates by glucuronidation and sulfation yields metabolites with significantly increased water solubility, thereby leading to the accumulation of the compounds in the aqueous compartment of the cell allowing the targeted excretion of the substrates. ${ }^{[80]}$ 
The transfer of glutathione moieties to electrophilic substrates is catalyzed by the glutathione-S-transferases and serves to protect cellular macromolecules from these reactive species. ${ }^{[83]}$ The co-substrate for this phase II enzymes is the tripeptide glutathione, which is present in the cells in its oxidized (GSSG) and reduced (GSH) form. The ratio of GSH:GSSG determines the maintenance of the reductive environment in cells. ${ }^{[80]}$ Polymorphisms in glutathione-S-transferases genes are associated with increased susceptibility to carcinogens. $^{[83]}$

Transferases that conjugate substrates with small moieties like acetyl groups and methyl groups play only a minor role compared to the other classes of phase II enzymes discussed here. From a clinical perspective the most important methyltransferases is the thiopurine S-methyltransferase (TPMT) as it catalyzes the S-methylation of aromatic and heterocyclic sulfhydryl compounds and some drugs used in cancer treatment are subject to S-methylation by TPMT such as azathioprine and thioguanine. ${ }^{[78]}$

\subsubsection{The UDP-Glucuronosyltransferases and Their Role in Drug Metabolism}

The bulk of the phase II reactions in drug metabolism are facilitated by UDPglucuronosyltransferases (UGTs), which deactivate their substrates by transferring a glucuronate moiety from UDP-glucuronic acid onto hydrophilic side chains. These target groups can be hydroxyl, carboxyl, carbonyl, sulfuryl, or amine moieties. ${ }^{[80]}$ Like the phase I enzymes described in chapter 1.6.1, the UGTs are localized to the luminal site of the endoplasmic reticulum. ${ }^{[80]}$ They are highly expressed in the liver where the majority of metabolizing reactions take place. ${ }^{[84]}$

The superfamily of UGTs can be divided in two smaller groups; the UGT1A and the UGT2B families. ${ }^{[85]}$ While the UGT2B enzymes primarily target endogenous compounds, such as steroids, the UGT1A enzymes have a broad spectrum of xenobiotic substrates. ${ }^{[80]}$ Among these are many well-studied and intensively utilized drugs. ${ }^{[86]}$

The UGT1A family consists of nine isoforms that differ in substrate specificity (Figure 1.4). The UGT1A gene locus is encoded on chromosome 2 and spans nearly $200 \mathrm{~kb}$. Over $150 \mathrm{~kb}$ consists of a tandem array of exon regions that encode the $\mathrm{N}$-terminus of the individual UGT1A isoforms. These first exons encode the protein region that is responsible for substrate recognition and the individual expression of the isoforms is regulated by adjacent promoters in an inducible and tissue-specific manner. The C-terminal fractions of the isoforms are composed of four common exons that encode the active site of the enzymes 
and which are shared by all isoforms. ${ }^{[87]}$ The splicing process that yields individual isoforms is facilitated by a splice site on the $3^{\prime}$-end of the first exon, which is spliced to the $5^{\prime}$-end of the second exon. During the transcription process exons of other isoforms encoded in between are considered to have an intronic character and therefore play no role in the subsequent splicing process where the first exon of the transcribed isoform is linked to the common exons two to five. ${ }^{[88]}$

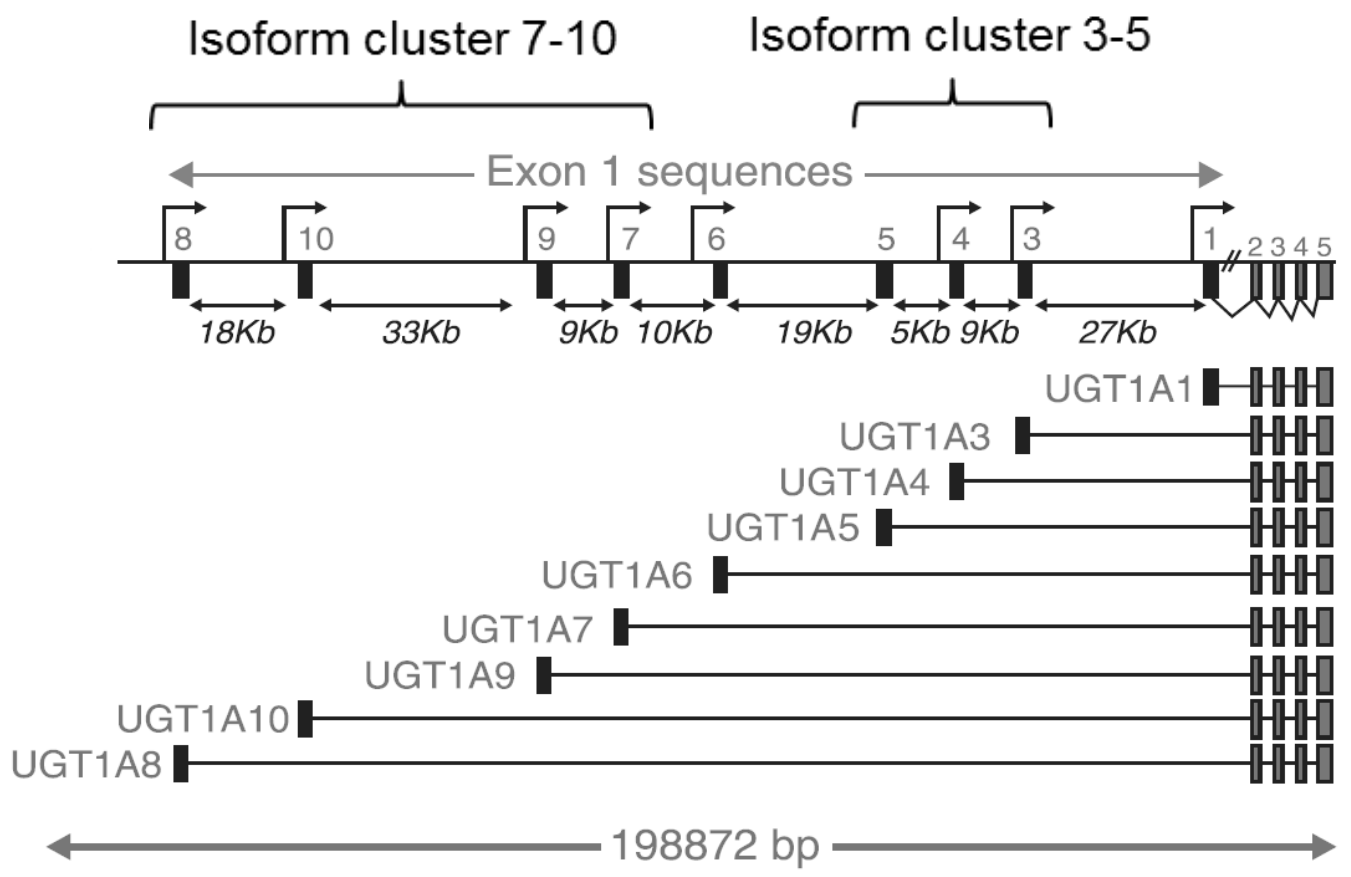

Figure 1.4: The UGT1A gene locus (adapted from ref [80])

For transcription of a specific UGT1A isoform, the individual first exon (black box) is spliced to the common exons 2 to 5 (gray boxes).

The isoforms of UGT1A can be divided into clusters due to their sequence similarities. The isoforms 3 through 5 and the isoforms 7 through 10 comprise a cluster respectively. The isoforms 1 and 6 are individual isozymes with no high similarity to other UGT1As. ${ }^{[89]}$ The high similarity in the two isozymes clusters of the UGT1A family implies that the isoforms of one cluster are able to perform glucuronidation on an overlapping set of substrates. ${ }^{[88]}$

As observed for most drug metabolizing enzymes, the UGT1A locus harbors several genetic polymorphisms which are associated with severe loss of enzyme activity. For instance, a homozygosity for a dinucleotide (TA) insertion in the UGT1A1 gene promoter region resulting in variant allele $(\mathrm{TA})_{7}$ (designated as $\left.U G T 1 A 1 * 28\right)$ and leads to an decreased UGT1A1 gene expression. The most important endogenous substrate of the isoform UGT1A1 
is bilirubin, a breakdown product of the heme metabolism. A defect in the glucuronidation of this product leads to elevated serum levels or hyperbilirubinemia, leading to a clinical symptom called jaundice i.e. yellowish skin. ${ }^{[80]}$ The loss of UGT1A1 activity by the UGT1A1*28 polymorphism results in severe hyperbilirubinemia, a condition termed Gilberts symdrome. The phenomenon of increased serum levels of bilirubin is also observed, when drugs are administered that require the metabolism by UGT1A1. These drugs can compete with bilirubin for the metabolism by UGT1A1 and the combination of substrates can exceed the glucuronidation capacity of the enzyme resulting in elevated levels of unmetabolized drug and bilirubin. ${ }^{[80]}$

In some rare cases the conjugation by UGT enzymes has an activating effect on the substrates, as is observed with morphine for example. This widely used opioid analgesic becomes biologically activated upon glucuronidation to the 6-O-glucuronide by UGT2B7. ${ }^{[90]}$ Conversely, morphine becomes deactivated when glucuronidated at the $3-\mathrm{OH}$ position by UGT1A1, UGT1A3, UGT2B1 or UGT2B7. This illustrates the rather complex effect such metabolizing reactions might have on a xenobiotic compound with pivotal effects on the organism as a whole. ${ }^{[81]}$ 


\subsection{Scope of the Thesis}

The promising prospects of HSP90 inhibition for treatment of cancer led to the development of a range of interesting small molecule inhibitors, many of which are currently in clinical trials. The expedient application of these drugs demands a thorough understanding of their pharmacokinetics and pharmacodynamics. The basis for the complete comprehension of the drug effects is the elucidation of all cellular processes that influence the drug distribution, the interaction with the target, the drug turnover and potential side effects of the drug. This understanding could provide the basis for efficient treatment of cancer patients, and could minimize the potential risk for patients in advance to the treatment.

The objective of this study was to ascertain the factors that determine the outcome of ganetespib treatment in CRC cell lines. For the clinical application it would be of immense importance to know the features of colorectal cancer that classify for a treatment with ganetespib or that dictate the amount of inhibitor that needs to be administered.

Interestingly, a previous study in which the gene expression of a broad spectrum of human cancer cell lines has been correlated to their susceptibility to various cancer drugs has been shown to be a useful tool for the detection of drug-related biomarkers (see ref. [91]). For instance, Barretina and coworkers predicted the dependence of 17-AAG susceptibility on NQO1-activity. The fact that this known drug-activation mechanism (described in chapter 1.5.5) was found by the comparative analysis can be seen as a prove-of-principal for the approach of the study. The correlation between drug susceptibility and gene expression data can be used for the detection of biomarkers that predict the response to treatment.

A similar correlation of the ganetespib susceptibility of the panel of CRC cell lines with gene expression data of the cells should provide a list of genes with potential influence on the ganetespib sensitivity of the cells. Therefore, the initial aim of this study was the elucidation of ganetespib susceptibility of a panel of CRC cell lines. The gene expression data were available from microarrays that were performed previously on the CRC cell lines by Spitzner and coworkers (see ref. [92]).

In the work presented here gene candidates from this correlation of gene expression and ganetespib susceptibility should be tested for their actual influence on ganetespib efficacy in the CRC cells including the mechanisms by that such genes affect drug sensitivity. The identification of a drug-related biomarker from this list of relevant genes would prove very helpful for the clinical application of the drug in treatment of colorectal cancer. 


\section{Materials and Methods}

\subsection{Materials}

\subsubsection{Technical Devices}

Table 2.1: Technical Devices

Device

Agilent 1100 HPLC

API 4000 tandem mass spectrometer

Blotting chamber

C1000 CFX96 real-time PCR thermocycler

Cell counting chamber Neubauer improved

Centrifuge 5415R

Centrifuge 5810R

Centrifuge Megafuge 1.0R

Chemiluminescence imager Chemocam HR 163200

Cytometer Celigo

Electrophoresis system, for SDS-PAGE

FACS machine Guava PCA-96 Base System

Freezer $-20^{\circ} \mathrm{C}$

Freezer $-80^{\circ} \mathrm{C}$

Heating Block

Ice-machine $B 100$

Kinetex $2.6 \mu \mathrm{m} \mathrm{C18}$ column

Laminar flow cabinet Hera Safe

Liquid nitrogen tank $L S 4800$

Magnetic stirrer MR Hei-Standard

Magnetic stirrer MR3001

Microscope Axovert 40C

Microscope, Axioscope 2 Plus

Microwave

Mini Centrifuge $M C F-2360$

pH-meter $W T W-720$

\section{Company}

Agilent Technologies, Santa Clara, CA

Applied Biosystems, Foster City, CA

Biozym, Hessisch Oldendorf, Germany

Bio-Rad Laboratories

Brand, Wertheim, Germany

Eppendorf, Hamburg, Germany

Eppendorf

Heraeus, Thermo Scientific, Waltham, MA, United States

Intas Science Imaging Instruments, Göttingen, Germany

Brooks Automation, Inc.Chelmsford, MA, United States

Amersham Biosciences, GE Healthcare, Little Chalfont, United Kingdom

Millipore, Merck, Darmstadt, Germany

Liebherr, Bulle, Switzerland

Heraeus, Thermo Scientific

Grant Instruments, Hillsborough, NJ, United States

Ziegra, Isernhagen, Germany

Phenomenex, Torrance, CA

Heraeus, Thermo Scientific

Taylor-Wharton, Theodore, AL, United

States

Heidolph, Schwabach, Germany

Heidolph

Zeiss, Oberkochen, Germany

Zeiss

Cinex, Lippstadt, Germany

LMS, Tokyo, Japan

WTW, Weilheim, Germany 
Pipets Eppendorf Research Series 2100

$(0.1-2.5 \mu \mathrm{l} ; 0.5-10 \mu \mathrm{l} ; 10-100 \mu \mathrm{l} ; 100-1,000 \mu \mathrm{l})$

Refrigerator $4^{\circ} \mathrm{C}$

Roller RM5 V-30

Rotator PTR 300

Scales Acculab ALC-6100.1

Scales LE623S

Scanner CanoScan 8600F

Shaker PROMAX 2020

Sonication device Bioruptor

Spectrophotometer NanoDrop ND-1000

Thermomixer comfort

Vacuum pump

Vortex Genie 2

Water bath TW 20
Eppendorf

Liebherr

CAT, Staufen, Germany

Grant Instruments

Sartorius, Göttingen, Germany

Sartorius

Canon, Tokyo, Japan

Heidolph

Diagenode, Liège, Belgium

PeqLab, Erlangen, Germany

Eppendorf

IBS Integra Biosciences, Fernwald, Germany

Scientific Industries, Bohemia, NY, USA

Julabo Labortechnik, Seelbach, Germany

\subsubsection{Consumables}

Table 2.2: Consumables

\section{Product}

12-well plates for microscopy

96-well plates for qPCR

Cell culture flasks $\left(25 \mathrm{~cm}^{2}, 75 \mathrm{~cm}^{2}, 125 \mathrm{~cm}^{2}\right)$

Cell culture plates (6-well, 12-well)

Cell scraper $(16 \mathrm{~cm}, 25 \mathrm{~cm})$

Cryo tubes Cryoline

Filter tips $(10 \mu \mathrm{l})$

Filter tips $(20 \mu 1,200 \mu 1,1,000 \mu 1)$

Optical covering foil for qPCR plates

Parafilm

Pipet tips $(10 \mu 1,20-200 \mu 1,1,000 \mu \mathrm{l})$

Protran nitrocellulose transfer membrane

Reaction tube $(0.2 \mathrm{~mL})$

Reaction tube $(0.5 \mathrm{~mL}, 1.5 \mathrm{~mL}, 2.0 \mathrm{~mL})$

Reaction tube $(15 \mathrm{~mL}, 50 \mathrm{~mL})$

Safe-lock reaction tube $(1.5 \mathrm{~mL})$

Sterile filter

Syringe

\section{Company}

Corning, Corning, NY, United States

4titude, Wotton, United Kingdom

Greiner, Frickenhausen, Germany

Greiner

Sarstedt

Nunc, Thermo Scientific

Starlab, Hamburg, Germany

Sarstedt

4titude

Brand

Greiner

Whatman, Dassel, Germany

Sarstedt

Eppendorf

Greiner

Eppendorf

Millipore, Merck

Henke-Sass, Wolf, Tuttlingen, Germany 


\subsubsection{Chemicals and Reagents}

Table 2.3 Chemicals and Reagents

Substance

Acetic acid

Acrylamide-bisacrylamide

Albumin Fraction V (Bovine Serum

Albumine, BSA)

Ammonium persulfate (APS)

Ammonium sulfate ((NH4)2SO4)

Ampicillin

Aprotinin

Bromophenol blue

Calcium chloride dihydrate $\left(\mathrm{CaCl}_{2} \mathrm{x}\right.$

$2 \mathrm{H}_{2} \mathrm{O}$ )

Chloroform

Dimethyl sulfoxide (DMSO)

Dithiotreitol (DTT)

DNA ladder

Deoxynucleotide triphosphates (dNTPs)

Ethanol 99.8\%

Ethanol $99.9 \%$ p.a.

Ethylene diamine tetraacetatic acid

(EDTA)

Ethylene glycol tetraacetic acid (EGTA)

Glycerol

Glycine

Glycogen

Glycogen blue

HEPES

Hydrogen chloride ( $\mathrm{HCl})$

Isopropanol

Lipofectamine 2000

Magnesium chloride $\left(\mathrm{MgCl}_{2}\right)$ for PCR

Magnesium chloride hexahydrate

$(\mathrm{MgCl} 2 \times 6 \mathrm{H} 2 \mathrm{O})$

Methanol >99\%

Milk powder

Nonidet P-40 substitute (NP-40)

Nuclease free water

Pefabloc SC

Pepstatin A

Ponceau $S$

Potassium chloride $(\mathrm{KCl})$

Potassium glutamate (KGlu)
Company

Roth, Karlsruhe, Germany

Roth

Roth

Roth

Roth

Sigma-Aldrich

AppliChem

Sigma-Aldrich

Roth

Roth

AppliChem

Sigma-Aldrich

Fermentas, Thermo Scientific

Bio-Budget, Krefeld, Germany

Roth

Merck

Roth

Roth

Roth

Roth

Fermentas, Thermo Scientific

Ambion, Life Technologies

Roth

Roth

Th. Geyer, Renningen, Germany

Invitrogen, Life Technologies

Fermentas, Thermo Scientific

Roth

Roth

Roth

Sigma Aldrich

Ambion, Life Technologies

Roth

AppliChem

Roth

Roth

Roth 
Potassium hydrogenphosphate (KH2PO4)

Prestained Protein Ladder

Random hexamer primers

RNase inhibitor

Rotiphorese Gel 30

Sodium acetate $(\mathrm{NaAc})$

Sodium bicarbonate (NaHCO3)

Sodium chloride $(\mathrm{NaCl})$

Sodium deoxycholate

Sodium dodecyl sulfate (SDS)

Sodium hydrogenphosphate

heptahydrate $\left(\mathrm{Na}_{2} \mathrm{HPO}_{4} \times 7 \mathrm{H}_{2} \mathrm{O}\right)$

Sodium hydroxide $(\mathrm{NaOH})$

SYBR green

Tetracycline

Tetramethylethylenediamine (TEMED)

Trehalose

Trisamine (Tris)

Triton X-100

TRIZOL

Tween 20

$\beta$-Mercaptoethanol
Roth

Fermentas, Thermo Scientific

Thermo Scientific

Fermentas

Roth

Roth

Roth

Roth

AppliChem

Roth

Roth

Sigma-Aldrich

Invitrogen, Life Technologies

Sigma-Aldrich

Roth

Sigma-Aldrich

Roth

AppliChem

Invitrogen, Life Technologies

AppliChem

Roth

\subsubsection{Inhibitors}

Table 2.4: HSP90 Inhibitors

\begin{tabular}{llll} 
Compound & provider & CAS-Number & Molecular weight \\
\hline 17-AAG & NCI & $75747-14-7$ & 585.7 \\
Ganetespib & Synta Pharmaceuticals ${ }^{\circledR}$ & $888216-25-9$ & 364.4 \\
NVP-AUY922 & Selleckchem & $1051919-22-2$ & 465.54 \\
PU-H71 & TOCRIS & $873436-91-0$ & 516.87 \\
SNX-2112 & Selleckchem & $908112-43-6$ & 464.48
\end{tabular}

Short name of NVP-AUY922 is AUY922. Chemical structures shown in Figure 1.2 and Figure 1.3. Stock solutions of $170 \mathrm{mM}$ (17-AAG) or $5 \mathrm{mM}$ (all other inhibitors) were prepared in DMSO, aliquoted and stored at $-80^{\circ} \mathrm{C}$. 


\subsubsection{Buffers and Solutions}

Table 2.5: Buffers and Solutions

Buffer / Solution

BSA solution

Cell lysis buffer

Laemmli buffer, $6 \mathrm{x}$

PBS, pH 7.4

TBS/T, pH 7.5

qPCR reaction buffer, 10x

qPCR reaction mix, 25x

Ripa lysis buffer, $\mathrm{pH} 7.5$

SDS running buffer

\section{Components}

$5 \%$ BSA

dissolved in TBST

$100 \%$ Ripa lysis buffer

2M Urea

$1 \mu \mathrm{g} / \mathrm{mL}$ Aprotinin

$1 \mu \mathrm{g} / \mathrm{mL}$ Leupeptin Hemisulfat

$1 \mu \mathrm{g} / \mathrm{mL}$ Pepstatin A

$1 \mathrm{mM}$ Pefabloc SC

$0.5 \mu \mathrm{g} / \mathrm{mL}$ Microcystin

$0.35 \mathrm{M}$ Tris, $\mathrm{pH} 6.8$

$30 \%$ Glycerin

$10 \%$ SDS

9.3\% DTT

$0.02 \%$ Bromphenol blue

dissolved in $\mathrm{H} 2 \mathrm{O}$

$24 \mathrm{mM} \mathrm{NaCl}$

$0.27 \mathrm{mM} \mathrm{KCl}$

$0.81 \mathrm{mM} \mathrm{Na}_{2} \mathrm{HPO}_{4} \times 7 \mathrm{H}_{2} \mathrm{O}$

$0.15 \mathrm{mM} \mathrm{KH}_{2} \mathrm{PO}_{4}$

dissolved in $\mathrm{H}_{2} \mathrm{O}$

$50 \mathrm{mM}$ Tris

$150 \mathrm{mM} \mathrm{NaCl}$

$0.1 \%$ Tween 20 (TBST only)

dissolved in $\mathrm{H} 2 \mathrm{O}$

750mM Tris-HCl, $\mathrm{pH} 8.5$

$200 \mathrm{mM}$ (NH4)2SO4

$0.1 \%$ Tween 20

dissolved in $\mathrm{H} 2 \mathrm{O}$

1x qPCR reaction buffer $10 \mathrm{x}$

$3 \mathrm{mM} \mathrm{MgCl} 2$

1:80,000 SYBR Green

$0.2 \mathrm{mM}$ dNTPs

20U/mL Taq polymerase

$0.25 \%$ Triton X-100

$300 \mathrm{mM}$ Trehalose in $10 \mathrm{mM}$ Tris, $\mathrm{pH} 8.5$

dissolved in water

$1 \%$ Triton X-100

$1 \% \mathrm{Na}$ deoxycholat

$0.1 \%$ SDS

$150 \mathrm{mM} \mathrm{NaCl}$

$10 \mathrm{mM}$ EDTA

$25 \mathrm{mM}$ Tris

$86.1 \mathrm{mM}$ glycin

$3.5 \mathrm{mM}$ SDS

dissolved in water 
Western blot blocking solution

Western blot buffer
$5 \%$ milk powder dissolved in TBT/T

$25 \mathrm{mM}$ Tris $192 \mathrm{mM}$ glycin $20 \%$ methanol dissolved in water

\subsubsection{Enzymes and Kits}

Table 2.6 Enzymes and Kits

Name

BCA Protein Assay Kit

DNase I, hc $(50 \mathrm{u} / \mu \mathrm{L})$

DNase I buffer

Immobilon Western HRP Substrate Peroxide

Solution

NucleoBond $^{\circledR}$ AXG

RT Buffer (5x)

Revert Aid Reverse transcriptase (RT) $(200 \mathrm{u} / \mu \mathrm{L})$

SuperSignal West Femto Maximum Sensitivity

Substrate

Taq polymerase

\section{Company}

Thermo Scientific

Thermo Scientific

Thermo Scientific

Millipore, Merck

Macherey Nagel, Düren, Germany

Thermo Scientific

Thermo Scientific

Thermo Scientific

Primetech, Minsk, Belarus

\subsubsection{Antibodies}

Table 2.7: Primary Antibodies

\begin{tabular}{|c|c|c|c|c|}
\hline target & clone, ID & $\begin{array}{c}\text { source } \\
\text { organism }\end{array}$ & $\begin{array}{c}\text { dilution for } \\
\text { immunoblotting }\end{array}$ & company \\
\hline Wee 1 & \#4936 & $\begin{array}{c}\text { rabbit, } \\
\text { polyclonal }\end{array}$ & $1: 1,000$ & $\begin{array}{c}\text { Cell Signaling, Frankfurt, } \\
\text { Germany }\end{array}$ \\
\hline AKT & \#9272 & $\begin{array}{c}\text { rabbit, } \\
\text { polyclonal }\end{array}$ & $1: 2,000$ & Cell signaling \\
\hline GAPDH & $\begin{array}{c}6 \mathrm{C} 5 \\
\mathrm{ab} 8245\end{array}$ & $\begin{array}{c}\text { mouse, } \\
\text { monoclonal }\end{array}$ & $1: 10,000$ & abcam, Cambridge, UK \\
\hline UGT1A & $\begin{array}{c}\text { B-4, } \\
\text { sc-271268 }\end{array}$ & $\begin{array}{c}\text { mouse, } \\
\text { monoclonal }\end{array}$ & $1: 500$ & $\begin{array}{c}\text { Santa Cruz, Heidelberg, } \\
\text { Germany }\end{array}$ \\
\hline phos ERK & $\begin{array}{c}\text { E-4, } \\
\text { sc-7383 }\end{array}$ & $\begin{array}{c}\text { mouse, } \\
\text { monoclonal }\end{array}$ & $1: 1,000$ & Santa Cruz \\
\hline ERK & $\begin{array}{l}\mathrm{K}-23 \\
\text { sc-94 }\end{array}$ & $\begin{array}{l}\text { rabbit, } \\
\text { polyclonal }\end{array}$ & $1: 1,000$ & Santa Cruz \\
\hline
\end{tabular}

(all diluted in TBST with 5\% skimmed milk powder) 
Table 2.8: Secondary Antibodies

\begin{tabular}{|c|c|c|c|}
\hline \multicolumn{2}{|r|}{ Name } & Cat.No. & Company \\
\hline \multicolumn{2}{|c|}{$\begin{array}{l}\text { HRP-coupled AffiniPure } \\
\text { F(ab')2 fragment, anti- } \\
\text { mouse IgG }(\mathrm{H}+\mathrm{L})\end{array}$} & $711-036-152$ & $\begin{array}{c}\text { Jackson Immunoresearch } \\
\text { Europe, Newmarket, UK }\end{array}$ \\
\hline \multirow{2}{*}{\multicolumn{3}{|c|}{$\begin{array}{l}\text { Goat anti-rabbit IgG-HRP } \\
\text { (all diluted in TBST with 5\% skimmed milk powder }\end{array}$}} & Santa Cruz \\
\hline & & & \\
\hline \multicolumn{4}{|c|}{ 2.1.4 Eukaryotic Cell Culture } \\
\hline 2.1.4.1 & Cell Lines & & \\
\hline \multicolumn{4}{|c|}{ Table 2.9: Carcinoma Cell Lines used in the Study } \\
\hline Name & Ori & & \\
\hline $\mathrm{CaCo} 2$ & Colorectal car & lon) & \\
\hline НCT116 & Colorectal car & lon) & \\
\hline HT29 & Colorectal car & lon) & \\
\hline LS1034 & Colorectal car & cum) & \\
\hline LS411N & Colorectal car & cum) & \\
\hline LS513 & Colorectal car & cum) & \\
\hline SW1463 & Colorectal car & ctum) & \\
\hline SW403 & Colorectal car & lon) & \\
\hline SW480 & Colorectal car & lon) & \\
\hline SW620 & Colorectal car & lon, derived frc & asis in lymph node) \\
\hline SW837 & Colorectal car & ctum) & \\
\hline
\end{tabular}

\subsubsection{Media and Supplements for Eukaryotic Cell Culture}

Table 2.10: Media and Supplements

\begin{tabular}{ll} 
Name & Company \\
\hline $\begin{array}{l}\text { RPMI 1640 medium } \\
\text { Dulbecco's Modified Eagle Medium (DMEM), } \\
\text { powder }\end{array}$ & Gibco, life technology \\
Fetal calf serum (FCS) & \\
L-glutamine & Thermo Scientific \\
PBS (tablets) & Gibco, life technology \\
Penicilin / Streptomycin & Gibco, life technology \\
Trypsin / EDTA & Gibco, life technology \\
Ciprofloxacin & Gibco, life technology \\
& Bayer, Leverkusen, Deutschland
\end{tabular}


For full medium (RPMI 1640-full): $\quad$ - 10\% fetal calf serum (FCS)

- 2 mM L-glutamin

- 50 units/mL penicillin

- 50 $\mu \mathrm{g} / \mathrm{mL}$ streptomycin

$-10 \mu \mathrm{g} / \mathrm{mL}$ ciprofloxacin

\subsubsection{Bacteria}

For the amplification of the plasmids the E. coli DH10B (Invitrogen) strain was used.

\subsubsection{Bacteria Culture Medium}

All bacteria were grown in lysogeny broth (LB) medium:

for 1 liter LB medium: $\quad-10 \mathrm{~g}$ peptone

$-5 \mathrm{~g}$ yeast extract

$-10 \mathrm{~g} \mathrm{NaCl}$

- $\mathrm{pH}$ was adjusted to 7 (with $\mathrm{NaOH}$ )

- water was added

- sterilized at $121^{\circ} \mathrm{C}$ for $15 \mathrm{~min}$

For plates $1.5 \%$ agar was added. For bacteria selection ampicillin $(200 \mu \mathrm{g} / \mathrm{mL})$ was added.

\subsubsection{Oligonucleotides and plasmids}

\subsubsection{Primers for Human Gene Expression Studies}

Table 2.11: Sequences of the Primers used in qPCR

\begin{tabular}{ccc} 
Target & forward primer & reverse primer \\
\hline UGT1A & ATCTGCTTGGTCACCCGATG & TCCATGCGCTTTGCATTGTC \\
UGT1A1 & GCCATTCCAAAGGGAGGATGTG & TGGGAACAGCCAGACAAAAGC \\
UGT1A3-5 & CATAATGAGGCCCTGATCAGGC & AATCGACAGGTACTTAGCCAG \\
UGT1A6 & GCTGGTGGTCCCTCAGGAC & CAGCTCTTCTTGGTCATACGGC \\
UGT1A7-10 & CACAGTGCCCTGCTCCTC & GTTTGGAGAATTTCAGAGGCTATTTC \\
HPRT1 & ATGCTGAGGATTTGGAAAGG & TCATCACATCTCGAGCAAGAC \\
HPRT1 = Hypoxanthine-guanine phosphoribosyltransferase
\end{tabular}




\subsubsection{2 $\quad$ SiRNA}

Table 2.12: siRNAs with Sequences

\begin{tabular}{lcl|l} 
& siRNA & \multicolumn{2}{c}{ Sequence } \\
\cline { 3 - 4 } Name & ID \# & \multicolumn{1}{c}{ sense } & antisense \\
\hline s75 & S231075 & GGUAAAAUUUUGAACCAUUtt & AATGGTTCAAAATTTTACCtt \\
s76 & S231076 & GGAUCAAUGGUCUCAGAAAtt & UUUCUGAGACCAUUGAUCCca \\
scr & $\# 4390844$ & Silencer $^{\circledR}$ Select Negative Control No. 1 & siRNA (Sequence not published)
\end{tabular}

All siRNAs were ordered from ambion ${ }^{\circledR}$ by life techniologies ${ }^{\mathrm{TM}}$ Corp.

\subsubsection{Plasmids}

For the expression of UGT1A10 and $\beta$-Gal in human cancer cells, the pCMVSPORT6 expression vector was used. This vector contains an ampicillin resistance site that confers resistance to ampicillin in E. coli. The genes are expressed under control of the human cytomegalovirus (CMV) promoter and a SV40 polyadenylation site ensures poly A capping.

For the expression of GFP in the cells, a pcDNA3 vector was used. It features the same elements for resistance in bacteria and also for expression as the pCMV-SPORT6 vector.

\subsubsection{Software}

For the confluence measurements of the plates the celigo ${ }^{\circledR}$ software was used.

All calculations concerning the $\mathrm{IC}_{50}$ determination, the expression level quantification by qPCR, and the generation of the graphs were done using Microsoft Excel $^{\circledR} 2010$.

The statistical analysis was performed by Frank Kramer using the free statistical software R (version 2.15.2; available from: www.r-project.org) with the limma package. ${ }^{[93]}$ 


\subsection{Methods}

\subsubsection{Cell Biology}

\subsubsection{Cultivation of Adherent Human Cells}

Adherent human cells were cultured in coated cell culture plates at $37^{\circ} \mathrm{C}, 5 \% \mathrm{CO}_{2}$ and in a humidified atmosphere in full RPMI 1640 medium.

The cell lines were split 2-3 times per week. Hence, after the medium was sucked off, cells were washed with pre-warmed PBS and detached by incubation with pre-warmed trypsin/EDTA at $37^{\circ} \mathrm{C}$ for a couple of minutes. After complete detachment of all cells the enzymatic reaction of trypsin was stopped by adding fresh culture medium. Finally, a portion of the trypsinized cells was transferred to a new cell culture dish and supplemented with fresh, pre-warmed RPMI 1640 culture medium.

\subsubsection{Freezing / Thawing of Adherent Cells}

For the long-term storage of cells in liquid nitrogen, low numbers of cell passages were used. For freezing, cells were trypsinized, and centrifuged ( $5 \mathrm{~min}, 800 \mathrm{rpm}$ at RT). Afterwards, the cells of one whole $10 \mathrm{~cm}$-plate were resuspended in $400 \mu \mathrm{L}$ freezing medium (10\% DMSO in FCS) and the cell suspension was transferred into cryo vials. To ensure slow and gradual lowering of the temperature the vials were incubated in a freezing container filled with isopropanol over night at $-80^{\circ} \mathrm{C}$. On the following day the vials were transferred into liquid nitrogen for long time storage.

For thawing, the cells were quickly defrosted using pre-warmed medium and transferred to a $10 \mathrm{~cm}$-plate with $10 \mathrm{~mL}$ RPMI 1640 medium. The medium was changed when the cells were adherent, to remove the toxic DMSO from growing cells.

\subsubsection{3 siRNA-Mediated Knockdown of Gene Expression}

UGT1A mRNA was knocked down in SW1463 and HT29 cells using commercially available siRNA (sequences see Table 2.12). For transfection of one well on a 6-well plate, 50 pmol siRNA were added to $250 \mu \mathrm{L}$ DMEM without any supplements (= DMEM (-)). Separately, $5 \mu$ L Lipofectamine 2000 was added to $250 \mu$ L DMEM (-). Both mixtures were vortexed for $10 \mathrm{~s}$ and incubated for $5 \mathrm{~min}$ at RT. The mixtures were combined, vortexed for $10 \mathrm{~s}$ and incubated for $20 \mathrm{~min}$ at RT. In the meantime cells were trypsinized and counted. The 
prepared mixture of siRNA and lipofectamine 2000 was spread across the well and 200,000 to 400,000 cells were added drop-wise to the well. Subsequently, each well was filled up with $2 \mathrm{~mL}$ of full RPMI medium and incubated over night at $37^{\circ} \mathrm{C}$. On the next day the medium was changed. 24 to $48 \mathrm{~h}$ after the knockdown, cells were either transferred to 12-well plates for confluence measurement (see chapter 2.2.1.6) or to 96-well plates for viability measurement (see chapter 2.2.1.8), or they were harvested for RNA expression analysis by qPCR (see chapter 2.2.2.6) or protein level analysis by immunoblotting (see chapter 2.2.3.1).

\subsubsection{Transfection of Cells with Plasmids for Transient Overexpression}

UGT1A or $\beta$-Gal was overexpressed in SW480 and HCT116 cells from a pCMVSPORT6 expression vector. For transfection of a 6-well, $2.5 \mu \mathrm{M}$ of the plasmid were added to 250 DMEM without any supplements (= DMEM (-)). Separately, $5 \mu \mathrm{L}$ Lipofectamine 2000 were added to $250 \mu \mathrm{L}$ DMEM (-). Both mixtures were vertexed for $10 \mathrm{~s}$ and incubated for $5 \mathrm{~min}$ at RT. The mixtures were combined, vortexed for $10 \mathrm{~s}$ and incubated for $20 \mathrm{~min}$ at RT. In the meantime cells were trypsinized and counted. The prepared mixture of vector and lipofectamine 2000 was spread across the well and 200,000 to 400,000 cells were added drop-wise to the well. The volume was filled up to $1 \mathrm{~mL}$ with DMEM (-). After $4 \mathrm{~h}$ of incubation at $37^{\circ} \mathrm{C}$ the medium was changed for full RPMI medium.For determination of transfection efficiency a GFP expression vector was added to the expression vector in a $1 / 10$ ratio.

24 to $48 \mathrm{~h}$ after the transfection the cells were either transferred to 12-well plates for confluence measurement (see chapter 2.2.1.6) or to 96-well plates for viability measurement (see chapter 2.2.1.8), or protein level analysis by immunoblotting (see chapter 2.2.3.1) after treatment with ganetespib.

\subsubsection{Treatment of the Cells with Inhibitors}

Cells were treated with various HSP90 inhibitors, applied in full RPMI 1640. For 17-AAG a $170 \mathrm{mM}$ stock solution was prepared in DMSO and aliquoted. The aliquots were diluted 1:33 to prepare the $5 \mathrm{mM}$ solutions used for treatment. For all other HSP90 inhibitors (ganetespib, AUY922, SNX-2112, PU-H71) stock solutions with $5 \mathrm{mM}$ concentrations were prepared in DMSO. From these stocks the concentrations needed were achieved by dilution 
in RPMI 1640 medium. For all applications RPMI with a DMSO concentration comparable to the highest treatment concentration was used as a control.

\subsubsection{Confluence Measurement with the Celigo ${ }^{\circledR}$ Cytometer}

Cells were seeded on 12-well plates (100,000 cells/well, except for CaCo2, LS513 and SW1463 200,000 cells/well) $24 \mathrm{~h}$ before treatment. The celigo ${ }^{\circledR}$ machine was used to take microscopic pictures of the cells at $0,24,48$, and $72 \mathrm{~h}$ after beginning of the treatment. Subsequently the pictures were analysed for the confluence of the wells with the celigo ${ }^{\circledR}$ software.

\subsubsection{Calculation of the $\mathrm{IC}_{50}$ Values}

The determination of concentrations that were needed to diminish the growth rate of the cells to the half maximum $\left(\mathrm{IC}_{50}\right)$, was based on the confluence measurements. When the confluence of the cell is plotted over the three day-time course, the growth rate representative for the according inhibitor concentration can be deduced from the slope of the linear regression line of the graph (Figure $2.1 \mathrm{a}$ ).

When plotting the growth rate against the inhibitor concentration (Figure $2.1 \mathrm{~b}$ ), the $\mathrm{IC}_{50}$ can be approximated by linear regression and calculation of the inhibitor concentration (x) for which the growth rate (y) equals half the value of the $y$-axis intersection $(x=y / 2)$. 


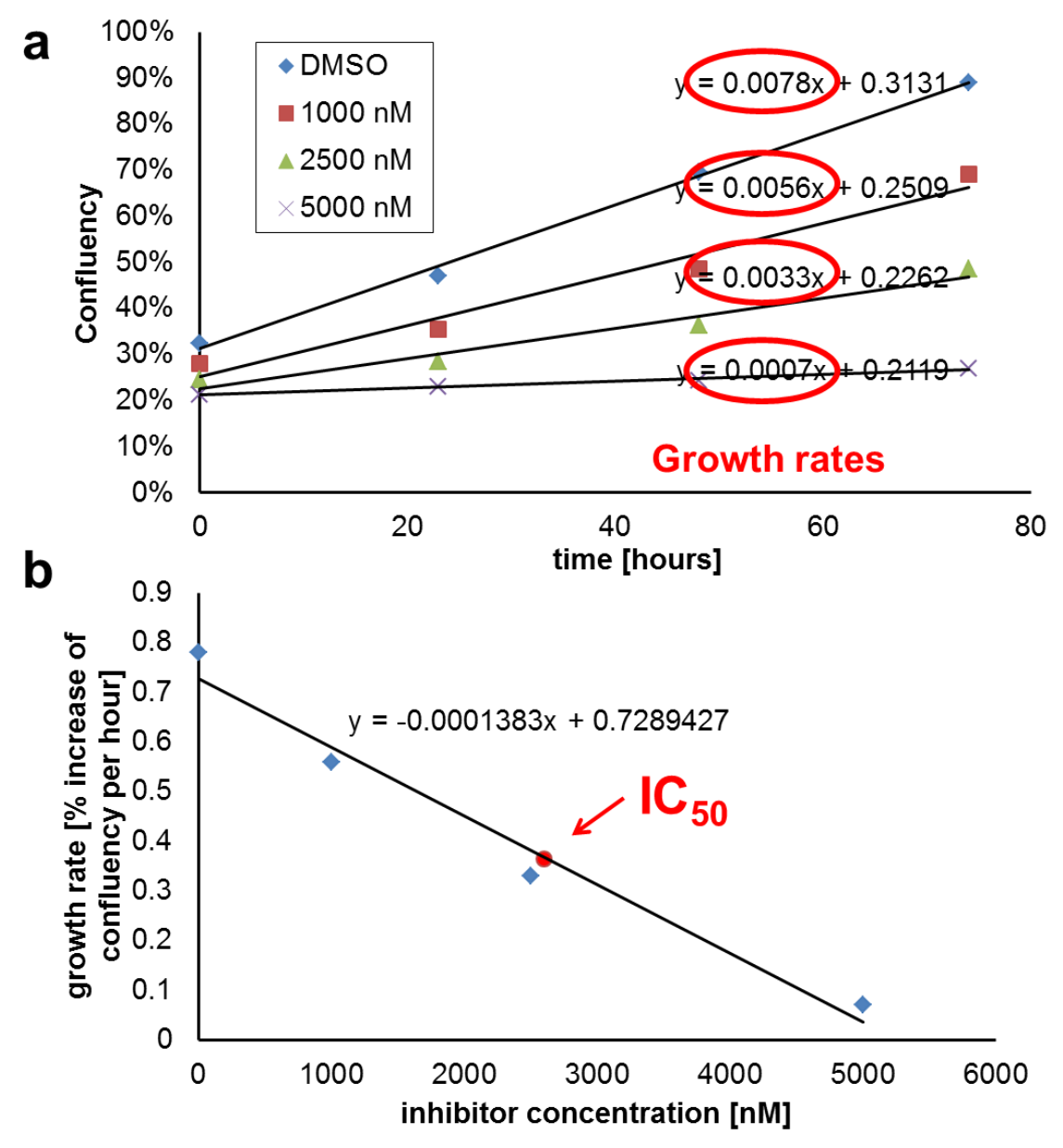

Figure 2.1: The calculation of $I_{50}$ values from the confluence measurements.

(a) Example of the deduction of the growth rate in dependence of the inhibitor concentration (ganetespib concentration in HT29 cells). The growth rates are deduced from the slope of the regression lines when confluence is plotted over time of the treatment. (b) Growth rates are plotted against inhibitor concentration, the $I C_{50}$ concentration is calculated from the regression line.

\subsubsection{Viability Assay}

For measuring the viability of the cells, they were transferred to a 96-well-plate $24 \mathrm{~h}$ after transfection. 5,000 cells (HCT116, SW480) or 10,000 cells (HT29) were seeded in triplicate one day before treatment with ganetespib. Cells were treated for $48 \mathrm{~h}$ and subjected to the CellTiterGlo ${ }^{\circledR}$ Luminescent Cell Viability assay (Promega, Madison WI, USA) according to the manual of the manufacturer. This luciferase assay determines the ATP concentration in the cells and thus reflects cell viability. 


\subsubsection{LC-MS/MS Analysis of Drug Metabolites}

The LC-MS/MS study was performed by David A. Proia, Suqin He, and Luisa Shin Ogawa (all employees of Synta Pharmaceuticals ${ }^{\circledR}$, Lexington, Kentucky, USA). They assessed levels of metabolized and unmetabolized ganetespib and AUY922 from cell lysates as well as from supernatant medium. Therefore the CRC cells were treated with $1 \mu \mathrm{M}$ of the according drug for 5, 15, 30, 60 or $480 \mathrm{~min}$. At each time point, media was collected and cell lysates were generated for subsequent bioanalysis of secreted and intracellular concentrations of ganetespib and its glucuronides, or AUY922 and its glucuronides. Equal protein concentrations from cell lysates or equal volumes of media were used for the bioanalysis.

Samples were extracted by protein precipitation with methanol containing the internal standards ([13C, 3H3]-ganetespib and [13C, 3H3]-ganetespib glucuronides), and 33nalysed by LC-MS/MS using an Agilent 1100 HPLC interfaced to an API 4000 tandem mass spectrometer. The separation of AUY922 and its glucuronide were performed on a Kinetex $2.6 \mu \mathrm{m} \mathrm{C18} \mathrm{(30} \mathrm{x} 2.1 \mathrm{~mm}$ ) column. Detection was accomplished in the positive electrospray ionization mode by selected reaction monitoring of the mass transitions. Quantitation was done by extrapolation from standard curves. Due to the lack of the authentic reference material, concentrations of AUY922 glucuronide were reported as analyte/internal standard peak area ratios.

\subsubsection{Molecular Biology}

\subsubsection{Transformation of Thermo-Competent E. coli}

Plasmids used for overexpression experiments were transformed in heat-shock competent E. coli DH10B. Hence, $50 \mu \mathrm{L}$ of the bacteria were mixed with $100 \mathrm{ng}$ DNA and incubated on ice for $30 \mathrm{~min}$. Cells were subsequently incubated for $10 \mathrm{~min}$ at $37^{\circ} \mathrm{C}$ and cooled down on ice for $10 \mathrm{~min}$. After addition of $950 \mu \mathrm{L} \mathrm{LB}$ medium the bacteria were kept at $37^{\circ} \mathrm{C}$ for $30 \mathrm{~min}$ and subsequently plated on LB agar containing Ampicillin $(200 \mu \mathrm{g} / \mathrm{mL})$ and incubated overnight at $37^{\circ} \mathrm{C}$. On the next day, a single colony was picked and expanded by an overnight culture in $50 \mathrm{~mL}$ LB medium containing $100 \mu \mathrm{g} / \mathrm{mL}$ ampicillin. Finally the plasmid was extracted using the PureYield ${ }^{\text {TM }}$ Plasmid Midiprep System (Promega), according to the manual of the manufacturer (see chapter 2.2.2.2). 


\subsubsection{Midi-Preparation of Plasmid DNA}

Midi-preparation of DNA from a $50 \mathrm{~mL}$ overnight culture was performed using the PureYield ${ }^{\mathrm{TM}}$ Plasmid Midiprep System kit from Promega as recommended by the manufacturer. Binding and washing of the membrane was performed under vacuum. Finally the DNA was eluted using $200 \mu \mathrm{L}$ nuclease-free water. The concentration was measured using the nanodrop spectrophotometer. Plasmids were stored at $-20^{\circ} \mathrm{C}$.

\subsubsection{Primer Design}

For design of the qPCR primers, the templates were retrieved from the NCBI web site (http://www.ncbi.nlm.nih.gov/gene/). The primers for UGT1A isoform cluster amplification were designed manually based on sequence alignments and checked for their specificity using the primer BLAST function on the ncbi web site (http://www.ncbi.nlm.nih.gov/tools/primerblast/). Basis for this platform is the primer3 software.

The criteria that were applied for the primer design and parallel quality check-up:

Product size: $\quad 100-250 \mathrm{bp}$

Primer size: $\quad 18-24$ nucleobases

GC content: $\quad 40-60 \%$

Melting temperature: $\quad 58-62^{\circ} \mathrm{C}$

Max poly X: $\quad 5.00$

Max self-complementarity: 3.00

GC clamp: 1

The nucleotides (see Table 2.11) were ordered from metabion (www.metabion.com).

\subsubsection{Quality Control of Primer}

Prior to the use of the primers in standard qPCR reactions (protocol see below in chapter 2.2.2.5), they were checked for efficiency and specificity. Therefore a dilution series of cDNA (1:20, 1:40, 1:80) was used as template for real-time PCR analysis for each primer pair.

From the $\mathrm{Ct}$ values the efficiency of the primer was calculated. As the 1:2 dilution of the cDNA should result in a $\mathrm{Ct}$ difference of 1.00. Primers that did not fulfil this quality criterion were rejected. 
A high specificity of the primers was ensured by a sharp peak of the melting curve. Shoulders or multiple peaks of the curves were not observed with the primers, indicating the amplification of a specific product.

\subsubsection{Quantitative Real-Time PCR}

The qPCR was performed in 96-well format. Each well contained the reaction mixture with the according primer. The temperature cycling program was used in the Chromo4 PCR machine.

Table 2.13: Composition of Real-Time PCR Mixture

\section{Compound}

Volume

(per $25 \mu \mathrm{L}$ reaction)

qPCR reaction mix, 25x (self-made, see Table 2.5)

$14 \mu \mathrm{L}$

Primer solution (containing both primers at concentration of $10 \mu \mathrm{M}$ )

$1 \mu \mathrm{L}$

Nuclease free water

$5 \mu \mathrm{L}$

cDNA (1:20 dilution)

$5 \mu \mathrm{L}$

\section{Table 2.14: Thermocycler Program}

\begin{tabular}{cccc} 
Step & Temperature & Time & \\
\cline { 1 - 3 } 1 & $95^{\circ} \mathrm{C}$ & $3 \mathrm{~min}$ & \\
2 & $95^{\circ} \mathrm{C}$ & $15 \mathrm{~s}$ & \\
3 & $58^{\circ} \mathrm{C}$ & $45 \mathrm{~s}$ & \\
4 & Return to step 2 & $\mathrm{x} 40$ & measurement \\
5 & $95^{\circ} \mathrm{C}$ & $1 \mathrm{~min}$ & \\
6 & Melting curve & $+0.5^{\circ} \mathrm{C} / \mathrm{s}$ & measurement at every step
\end{tabular}

\subsubsection{Isolation of Total RNA}

Total RNA was isolated using TRIZOL and used for subsequent reverse transcription and quantification by PCR.

The cells on the 6-well plates were washed with PBS. After removal of PBS, $600 \mu \mathrm{L}$ of TRIZOL were added directly to the wells for cell lysis. After 2 min of incubation, the 
TRIZOL was transferred to $1.5 \mathrm{~mL}$ Eppendorf tubes and the RNA was either stored at $-80^{\circ} \mathrm{C}$ for later RNA purification or directly subjected to the steps necessary for RNA isolation:

$120 \mu \mathrm{L}$ chloroform were added to the $600 \mu \mathrm{L}$ TRIZOL. The samples were shaken, incubated for $3 \mathrm{~min}$ at RT and centrifuged to separate the different phases (15 min, 12,000 g, $4^{\circ} \mathrm{C}$ ). The RNA containing aqueous upper phase was transferred carefully into a fresh Eppendorf tube and purified by precipitation with $500 \mu \mathrm{l}$ isopropanol. The samples were shaken and centrifuged (30-60 $\mathrm{min}, 12,000 \mathrm{rpm}, 4^{\circ} \mathrm{C}$ ). Subsequently, the pellet was washed twice with $75 \%$ Ethanol (5 min, 7,500 rpm, $4^{\circ} \mathrm{C}$ ). The supernatant was completely removed carefully and the pellet was air-dried. The RNA was dissolved in $20 \mu \mathrm{l}$ nuclease free $\mathrm{H}_{2} \mathrm{O}$ and heated for $5 \mathrm{~min}$ at $55^{\circ} \mathrm{C}$. The concentration and purity of the RNA was measure using the nanodrop spectrophotometer. All RNA samples were treated with Dnase to remove residual genomic DNA contaminations (see chapter 2.2.2.7).

\subsubsection{Dnase I Digest of RNA Samples}

To ensure a complete removal of any possible contamination of genomic DNA, a Dnase I digest was performed. Therefore the RNA sample was diluted to $100 \mu \mathrm{L}$ with nuclease-free water, mixed with $20 \mu \mathrm{L}$ Dnase I mix (see Table 2.15 ) and incubated at $37^{\circ} \mathrm{C}$ for $30 \mathrm{~min}$, shaking.

Table 2.15: Dnase I Mix (prepared as mastermix for multiple samples)

\begin{tabular}{cc} 
Compound & Volume \\
\hline 10x Dnase I Buffer & $12 \mu \mathrm{L}$ \\
Dnase I, hc & $0.25 \mu \mathrm{L}$ \\
RNase inhibitor & $1 \mu \mathrm{L}$ \\
Nuclease-free water & $6.75 \mu \mathrm{L}$
\end{tabular}

After incubation the samples were purified by a phenol-chloroform extraction. Therefore, $120 \mu \mathrm{L}$ of a phenol-chloroform (5:1, pH 4.3) mix were added to each RNA sample and vortexed for $10 \mathrm{~s}$. After short centrifugation of the tubes $\left(1 \mathrm{~min}, 13,000 \mathrm{rpm}\right.$ at $\left.4^{\circ} \mathrm{C}\right)$ the upper aqueous phase was transferred to a new Eppendorf tube and mixed with $375 \mu \mathrm{L} 96 \%$ ethanol and $17 \mu \mathrm{L}$ of a sodium acetate solution ( $3 \mathrm{~mol} / \mathrm{L}$ ) for RNA precipitation. The samples 
were incubated at $-80^{\circ} \mathrm{C}$ for one hour and centrifuged for $30 \mathrm{~min}\left(13,000 \mathrm{rmp}\right.$ at $\left.4^{\circ} \mathrm{C}\right)$. After removal of the supernatant, the resulting RNA pellet was washed with $150 \mu \mathrm{L} 70 \%$ ethanol. The pellet was air-dried and resuspended in $20 \mu \mathrm{L}$ nuclease-free water. The RNA was stored at $-80^{\circ} \mathrm{C}$.

\subsubsection{8 cDNA Synthesis}

The concentration of the RNA samples was measured at a wavelength of $260 \mathrm{nM}$ using the nanodrop spectrophotometer. $1 \mu \mathrm{g}$ of RNA was used for the cDNA synthesis. In an Eppendorf tube $2 \mu \mathrm{L}$ of a mix of random hexamer primers and $1 \mu \mathrm{L}$ dNTP mix $(10 \mathrm{mM}$ of dATP, dCTP, dGTP, and dTTP each) were added. The reaction volume was filled up to $16 \mu \mathrm{L}$ with nuclease-free water. The mix was heated up to $70^{\circ} \mathrm{C}$ for $5 \mathrm{~min}$, subsequently centrifuged shortly and kept on ice. A master was prepared containing (per reaction) $2 \mu \mathrm{L}$ of Reaction Buffer (10x), $0.25 \mu \mathrm{L}$ RNase Inhibitor (10 U), $0.125 \mu \mathrm{L}$ M-MuLV reverse transcriptase $(25 \mathrm{U})$ and $1.625 \mu \mathrm{L}$ nuclease-free water. $4 \mu \mathrm{L}$ of the mastermix were added to each sample and the tubes were incubated at $42^{\circ} \mathrm{C}$ for $1 \mathrm{~h}$. Afterwards the enzyme was deactivated by incubation at $95^{\circ} \mathrm{C}$ for $5 \mathrm{~min}$. The reaction was diluted to $400 \mu \mathrm{L}(1: 20$ dilution) prior to use in qPCR reactions. The cDNA was stored at $-20{ }^{\circ} \mathrm{C}$.

Because a DNA digest on the RNA was performed prior to the cDNA synthesis, there was no need to run a control without any reverse transcriptase in order to exclude contaminations by genomic DNA.

\subsubsection{Quantification of Relative Gene Expression}

The mRNA expression levels of diverse cellular genes were quantified by performing qPCR. Three independently extracted RNA / cDNA samples were used for every experimental condition (biological replicas). Technological replicas were included in the biological replicas. Reactions were pipetted according to Table 2.13 in a low profile 96-well plate. The plate was sealed with optical foil, vortexed and centrifuge shortly ( $1 \mathrm{~min}, 800 \mathrm{rpm}$, RT). All plates were prepared freshly and analysed directly after pipetting. The thermocycler program was applied as used for primer validation (Table 2.14).

Subsequently, the $\Delta \Delta \mathrm{CT}$ method was applied for the calculation of the relative gene expression. Therefore, the threshold was manually set and the relative $\mathrm{Ct}$ values for the reference and the target genes were obtained. To account for variations in the pipetting 
process, all analysis were performed in triplicates. The reference gene (HPRT1) was always analysed in parallel to ensure comparability between plates.

The $\Delta \mathrm{Ct}$ values were calculated by subtraction of the target gene Cts against the reference gene $\mathrm{Cts}$ for normalization. Next, the $\Delta \Delta \mathrm{Ct}$ values were calculated by subtracting the control sample values from the values of treated or knockdown samples and the $\Delta \Delta \mathrm{Ct}$ value of the control sample was set to 0 (= fold change). Ct values resemble logarithmic values to the basis of 2 . Hence, the mean $\log$ ratio was calculated by using the formula: $-2^{(-\Delta \Delta \mathrm{Ct})}$. Control or untreated samples were therefore set as 1 , whereas up- or downregulation are represented by a mean log-ratios of $>1$ or ranging between $0-1$ respectively.

\subsubsection{Protein biochemistry}

\subsubsection{Protein Harvest}

For protein preparation, adherent cells were scraped off directly in the culture medium, transferred to $2 \mathrm{~mL}$ Eppendorf tubes and centrifuged for $5 \mathrm{~min}$ (1,500 rpm, RT). The cell pellet was washed with ice cold PBS and centrifuged as before. The cells were lysed in cell lysis buffer. The amount of lysis buffer added (between 100 and $300 \mu \mathrm{L}$ ) was adjusted, depending on the amount of cells in the pellet. All cell lysates were kept on ice and were subjected to $15 \mathrm{~min}$ of sonication in the bioruptor at maximum intensity (30 $\mathrm{sec}$ on/off interval) in ice cold water, to disrupt any bulky genomic DNA. After sonication the protein concentration of all samples was analysed using the BCA method (see chapter 2.2.3.2). The protein samples were stored at $-80^{\circ} \mathrm{C}$.

\subsubsection{Determination of the Protein Concentration}

Protein concentration was measured using the BCA Protein Assay Kit. The determination of protein amount based on the biuret reaction was performed according to the manufacturer's instructions. In short, a master mix of $4 \%$ cupric sulfate and BCA solution (1:50) was added to the protein lysates (1:20) and incubated for $30 \mathrm{~min}$ at $37^{\circ} \mathrm{C}$. Afterwards the concentration was measured with Nanodrop. For calculation of absolute concentrations, a standard curve was measured in parallel with defined concentrations of albumin. 


\subsubsection{SDS-PAGE}

To separate proteins under denaturing conditions, SDS-PAGE was performed as developed by Shapiro and coworkers as well as Laemmli (see ref [94] and [95]). Separation of the proteins relies on their electrophoretic mobility, and separates them by their size. Prior the electrophoresis the proteins are boiled in presence of sodium dodecyl sulfate (SDS). The SDS coats the proteins, which leads to a negative over-all charge. Hence, the proteins move to the anode if an electric field is applied. The rate at which the proteins move through the pores of the gel depends on the protein size.

Basically the SDS-PAGE is performed using two layers of gel: the stacking gel and the separation gel. The stacking gel (5\% acrylamide at $\mathrm{pH} 6.8)$ contains large pores and the proteins are forming a stack between the leading chloride ions and the trailing ion Glycine. This leads to sharp protein bands. In the separation gel $(10 \%$ acrylamide at $\mathrm{pH} 8.8)$ the proteins are separated according to their molecular weight.

\section{Table 2.16: Composition of SDS Gels (mixture for four gels)}

\begin{tabular}{lc|c} 
Component & Separation gel & Stacking gel \\
\hline $\mathrm{H}_{2} \mathrm{O}$ & $13.2 \mathrm{~mL}$ & $6.8 \mathrm{~mL}$ \\
Acrylamide $(30 \%)$ & $16.0 \mathrm{~mL}$ & $1.7 \mathrm{~mL}$ \\
1.5 M Tris & $10.0 \mathrm{~mL}(\mathrm{pH} 8.8)$ & $1.25 \mathrm{~mL}(\mathrm{pH} 6.8)$ \\
SDS $(10 \%)$ & $0.4 \mathrm{~mL}$ & $0.1 \mathrm{~mL}$ \\
APS $(10 \%)$ & $0.4 \mathrm{~mL}$ & $0.1 \mathrm{~mL}$ \\
TEMED & $0.016 \mathrm{~mL}$ & $0.01 \mathrm{~mL}$
\end{tabular}

First the separation gel was casted between two glass plates, which were separated by two spacers. The gel was topped with isopropanol during the polymerization to ensure the generation of a sharp gel front and prevent air contact and dehydration. After the polymerisation, the stacking gel mixture was prepared and was filled on top. To form separated pockets for the application of the protein samples, a comb with 10 or 15 teeth was put in the liquid mixture prior to polymerization.

The protein concentrations of the samples were adjusted to the lowest protein concentration and 6x Laemmli buffer was added. For protein denaturation, the samples were boiled for $3 \mathrm{~min}$ at $95^{\circ} \mathrm{C}$ and subsequently applied to the pockets of the stacking gel, next to a pre-stained protein marker. The electrophoresis was performed at $20 \mathrm{~mA}$ per gel.

After appropriate separation of the proteins, the proteins in the gel were transferred to nitrocellulose membrane by applying the immunobloting technique. 


\subsubsection{Immunoblotting}

After separation by SDS-PAGE the proteins have to be transferred onto a nitrocellulose membrane, to make them more accessible for the staining with antibodies.

This transfer was performed in a cassette composed of two outer layers of sponges and three layers of Whatman-paper. Inside of the cassette, the gel was stacked onto the nitrocellulose membrane and the cassette was put into a blotting chamber. The gel was oriented towards the cathode and the membrane was pointing towards the anode. By applying a current of $100 \mathrm{~V}$ for $2 \mathrm{~h}$, the proteins were transferred to the membrane. The whole process was performed in the cold room and the chamber was surrounded with ice, to prevent overheating.

After the transfer, the membranes (or so called blots) were blocked in 5\% milk/TBST for $30 \mathrm{~min}$ at RT. The blocking prevents unspecific attachment of antibodies to the blot. The blots were subsequently incubated with dilutions of primary antibodies (see Table 2.7) either over night or at least for $4 \mathrm{~h}$ at $4^{\circ} \mathrm{C}$ in falcon tubes on a roller. After extensive washing (twice with 5\% milk in TBST, twice with TBST for $10 \mathrm{~min}$ each), the blots were incubated with secondary antibody (in 5\% milk in TBST) for $1 \mathrm{~h}$ at RT, rotating. After the same sequence of washing steps as before, the membrane was stained with Millipore staining solution and analyzed using the chemiluminescence detection machine Chemocam HR 163200 imager.

\subsubsection{Statistical Analysis}

The statistical analysis of the gene expression patterns and their correlation with drug sensitivities was performed by Frank Kramer from the department of statistical bioinformatics (Group of Prof. Tim Beissbarth in the department of medical statistics, University Medical Center Göttingen). For this analysis the mRNA expression levels were analyzed using $\log 2$ transformation and quantile normalization. ${ }^{[96]}$ Except for control spots, all 43,376 features were used without any a priori filtering. In order to determine significant differences of expression levels between the pooled groups of ganetespib-sensitive and ganetespib-resistant cell lines, a moderated Student's t test was computed on a gene-by-gene basis. Frank Kramer applied an empiric Bayes estimator to compute the linear models for thousands of genes in parallel and assess their significance. ${ }^{[97]}$ The gene list in the appendix is showing all genes of statistical relevance with a p-value of $<0.005$ and additional hits relevant for this work (chapter 6.1). 
In order to not exceed a false-discovery rate (FDR) of 5\%, the p-values were adjusted for multiple testing using the Benjamini-Hochberg method. ${ }^{[98]}$ All analyses were performed using the free statistical software $\mathrm{R}$ (version 2.15.2) with the limma package. ${ }^{\text {[93] }}$ 


\section{Results}

\subsection{Expression of UGT1A Correlates with Resistance to Ganetespib Treatment}

Ganetespib is a second generation HSP90 inhibitor, proved to efficiently inhibit tumor progression in various cancer types. Therefore we wanted to dissect how different CRC cell lines respond to treatment with the inhibitor.

To elucidate the different responses to ganetespib, the $\mathrm{IC}_{50}$ for eleven $\mathrm{CRC}$ cell lines were determined by a proliferation assay based on confluence measurements with the celigo ${ }^{\circledR}$ cytometer (see chapters 2.2.1.6 and 2.2.1.7). We determined two groups of cell lines with vast differences in their tolerance to ganetespib (Figure 3.1 a, blue bars). SW1463 and HT29 cells are able to withstand concentrations in the micro molecular range of ganetespib (1.6 and $2.5 \mu \mathrm{M}$ respectively), whereas the other nine cell lines already respond to ganetespib in the nano-molar range.

Therefore, a statistical analysis was conducted by Frank Kramer (department of statistical bioinformatics, University Medical Center Göttingen) on whole genome gene expression profiles which had been elucidated previously for all these cell lines (see ref. [92]). To determine significant differences in expression levels of single genes between the pooled groups of ganetespib-sensitive and ganetespib-resistant cell lines, Frank Kramer computed a moderated Student's t-test on a gene-by-gene basis. This comparison of gene expression patterns revealed a list of candidate genes, whose level of gene expression correlated with the ganetespib susceptibility in the CRC lines (see chapter 6.1), gene hits with a p-value $<0.005$ are shown).

Among these genes with statistically relevant expression difference between ganetespib-resistant and -sensitive cell lines, UGT1A stood out due to its known function in drug metabolizing processes. The three UGT1A probes on the microarray (designated as UGT1A6 and UGT1A8 in the list of gene hits in chapter 6.1) were designed to bind the UGT1A mRNA in the common exons 2-5 and were therefore able to bind all nine isoforms of UGT1A (see chapter 1.6.3 for detailed description of the gene locus).

To assess whether the in vitro mRNA levels of UGT1A of the eleven CRC cell lines reflect the expression distribution suggested by the microarray analysis, mRNA was isolated from the cell lines, reversely transcribed to cDNA and analyzed by quantitative RT-PCR (qPCR). Indeed, the qPCR analysis revealed that the two groups of cell lines can be 
distinguished by their expression levels of UGT1A. The ganetespib-resistant cells exhibit high levels of UGT1A mRNA expression (Figure 3.1 a, red bars). Also, they had high levels of UGT1A protein compared to ganetespib sensitive cell lines, as determined by immunoblotanalysis (Figure $3.1 \mathrm{~b}$ ). This hints at a causal link between the presence of UGT1A and the resistance to ganetespib treatment.

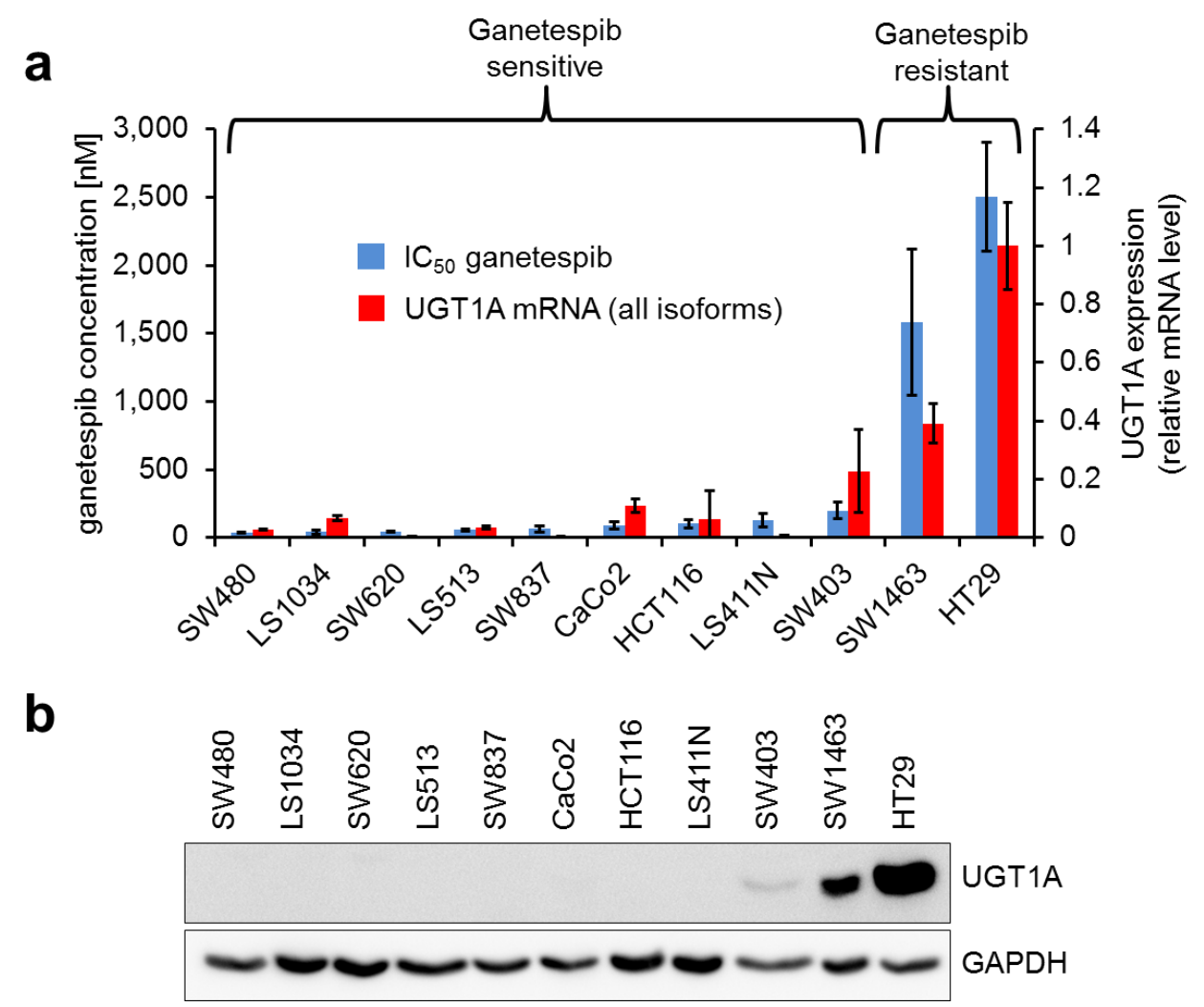

Figure 3.1: Ganetespib resistance correlates with high expression levels of UGT1A in CRC-derived cell lines.

(a) Resistance to ganetespib correlates with high mRNA expression of UGT1A. The growth inhibitory concentration of ganetespib was determined for 11 cell lines derived from CRC (blue columns). Total mRNA was extracted from the eleven CRC cell lines, reversetranscribed, and subjected to qPCR analysis. Relative mRNA levels of all UGT1A isoforms were determined (red columns, Ct values were normalized to values of HPRT1 expression). The error bars represent the standard deviation. Correlation between ganetespib resistance and UGT1A expression levels was highly significant (sample Pearson correlation coefficient $r=0.957$ ). (b) Ganetespib-resistant cell lines SW1463 and HT29 express UGT1A protein at high levels. UGT1A protein levels were determined by immunoblot analysis for the same cell lines as in a. GAPDH detection serves as a loading control. 


\subsection{UGT1A Knockdown Sensitizes Resistant CRC Cell Lines to Ganetespib}

To check whether UGT1A expression contributes to the observed resistance to ganetespib, a siRNA-based knockdown was established in HT29 cells, the cell line with the most profound ganetespib resistance. The siRNA treatment led to a knockdown of the UGT1A mRNA (Figure 3.2 a), which was sufficient to strongly reduce the protein levels for four days (Figure $3.2 \mathrm{~b}$ ).

To determine the effect of UGT1A knockdown on proliferation upon ganetespib treatment, the confluence of the cells after siRNA treatment and subsequent treatment with ganetespib over three days was measured (Figure $3.2 \mathrm{c}$ ). The data show that in cells that were treated with UGT1A siRNA the growth was significantly diminished at ganetespib concentrations as low as $250 \mathrm{nM}$. On the other hand, the growth of the cells treated with scrambled siRNA remained unaffected even at ganetespib concentrations as high as $750 \mathrm{nM}$. These results indicate that the UGT1A knockdown is sensitizing the cells to ganetespib treatment. We further analyzed the effect of UGT1A knockdown on the viability of ganetespib treated HT29 cells using the ATP based CellTiterGlo ${ }^{\circledR}$ Luminescent Cell Viability assay (Figure $3.2 \mathrm{~d}$ ). A difference in the cell viability between cells treated with scrambled siRNA and UGT1A-siRNA was visible at a ganetespib concentration of $250 \mathrm{nM}$.

In case that UGT1A expression affects the overall inhibition of HSP90 by ganetespib, HSP90 clients should degrade much faster in ganetespib-treated, UGT1A-depleted cells. Therefore we detected changes in the levels of the direct HSP90 client AKT and phosphorylated ERK, which can function as a read out for the activity of its HSP90dependent upstream activators RAF and BRAF. The levels were assessed by an immunoblot analysis in the presence of ganetespib (Figure 3.3). Whereas the control knockdown did not exhibit a relevant decrease of the levels of the client proteins even at high concentrations of ganetespib, the cells that were subjected to a UGT1A knockdown prior to the ganetespib treatment, showed a strong reduction in the levels of client protein. Thus, we conclude that the knockdown of UGT1A renders the resistant HT29 cells susceptible to the treatment with ganetespib, which provides the first evidence for the causal link between high UGT1A expression in CRC cells and the ability to withstand high concentrations of ganetespib. 

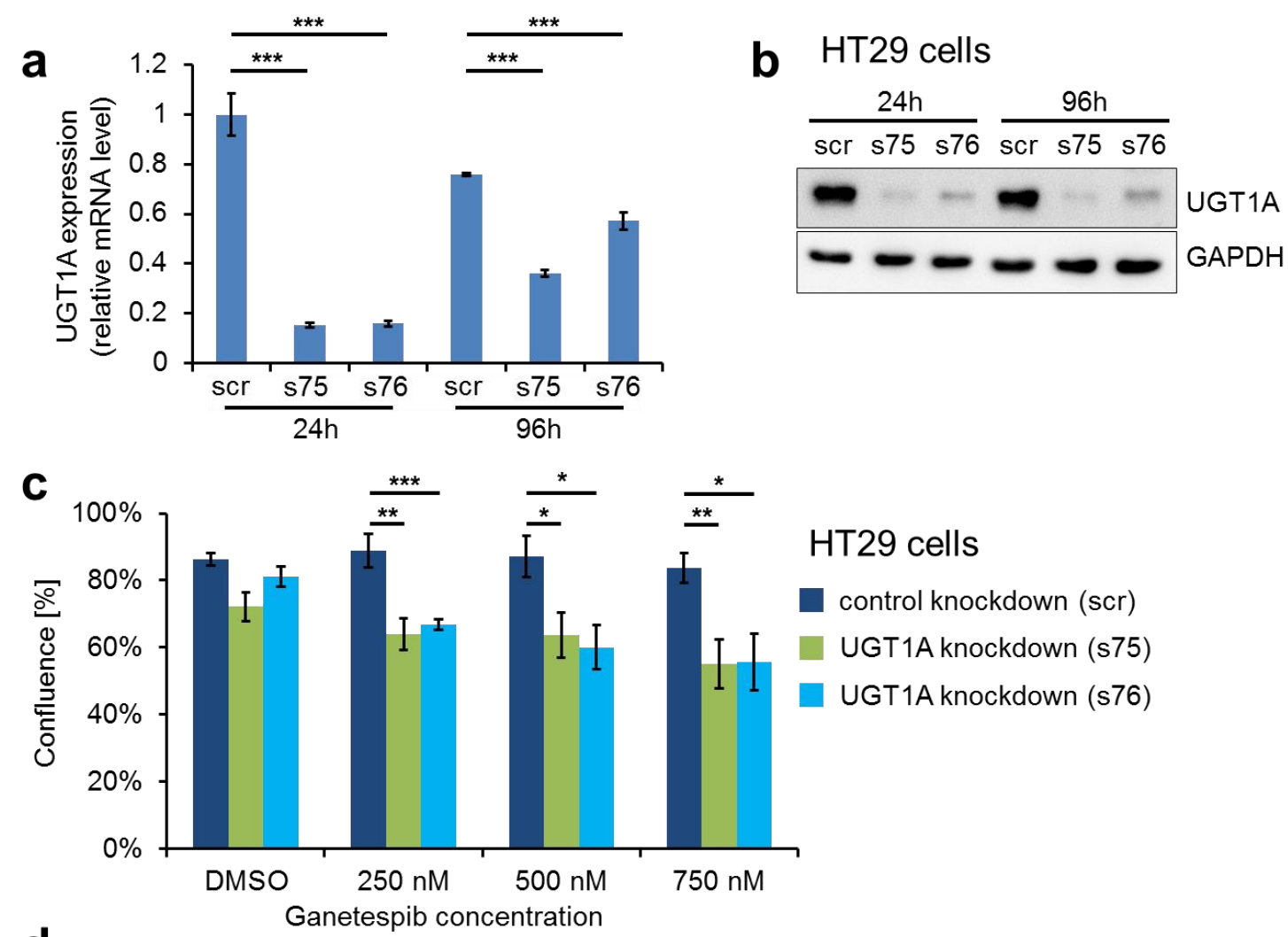

d

HT29 cells

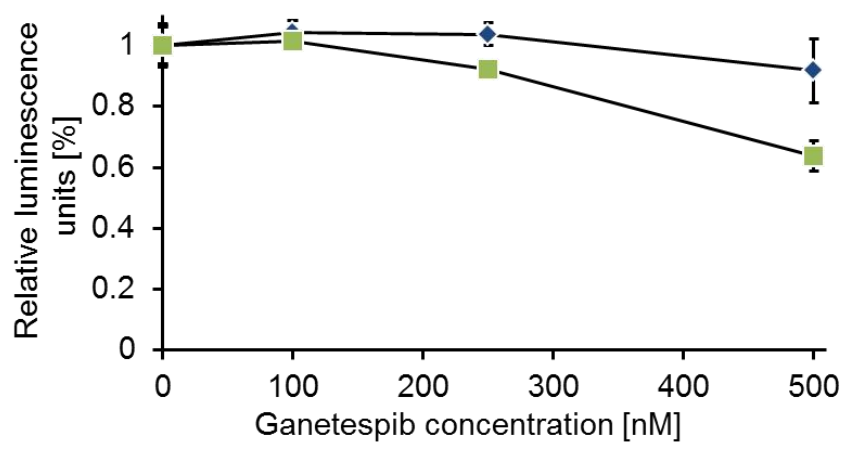

- control knockdown (scr)

UGT1A knockdown (s75)

Figure 3.2: UGT1A knockdown renders HT29 cells more susceptible to ganetespib.

HT29 cells were transfected using Lipofectamine 2000 with two different siRNA oligonucleotides against UGTIA (designated 575 and s76) and a control scrambled siRNA (designated scr). Subsequently UGTIA mRNA and protein levels were determined by qPCR (a, HPRTI expression levels were used for normalization, error bars indicate standard deviation, asterisks show significance by Student's $t$-test; $* * *=p<0.005)$ and immunoblot analysis (b, GAPDH as loading control) at $t=24 \mathrm{~h}$ and $96 \mathrm{~h}$ after start of knockdown. (c) UGT1A knockdown renders HT29 cell less tolerant to ganetespib treatment. $24 \mathrm{~h}$ after siRNA transfection, ganetespib was added to the cells at the indicated concentrations; ganetespib-containing medium was refreshed every $24 \mathrm{~h}$. Cell confluence was determined by quantitative light microscopy $\left(\right.$ Celigo $\left.^{\circledR}\right) 72 \mathrm{~h}$ after first addition of the drug. $*=p<0.05$, $* *=p<0.01$, *** $=p<0.005$ (Student's T-test). (d) Knockdown of UGT1A in HT29 cells decreased cell viability upon ganetespib treatment. Upon treatment as in a, cell viability was determined by assessing the ATP concentration in cell lysates using the CellTiterGlo ${ }^{\circledR}$ Luminescent Cell Viability assay. 


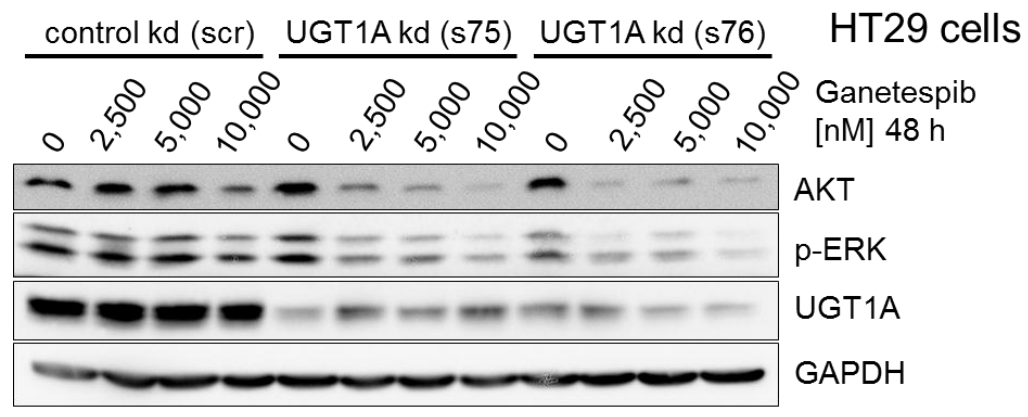

Figure 3.3: UGT1A knockdown in HT29 cells destabilizes HSP90 clients upon ganetespib treatment.

HT29 cells were first transfected with siRNA for $24 \mathrm{~h}$, followed by incubation with different concentrations of ganetespib for $36 \mathrm{~h}$ and immunoblot analysis of HSP9O clients. To avoid inactivation of ganetespib by glucuronidation through residual UGT1A, ganetespibcontaining media were renewed after 3, 6, 9, 12 and $24 \mathrm{~h}$ during the incubation period.

\subsection{Overexpression of UGT1A10 Renders Sensitive Cells Resistant to Ganetespib Treatment}

As UGT1A is expressed in 9 different isoforms, we hypothesized that only a subset of these isoforms might be responsible for the detected ganetespib resistance by glucuronidation. Therefore, we analyzed the mRNA levels of UGT1A gene clusters by selective RT-PCR analysis. The groups of UGT1A isoforms (UGT1A3, -4, -5 and UGT1A7, $-8,-9,-10$, see Figure 3.4 a) are characterized by a high similarity and the gene expression of single isoform cannot be differentially analyzed. 
Therefore we quantified the mRNA levels of the similar isoforms by using primers that recognize all isoforms of one group (for primer sequences see chapter 2.1.7.1, for a detailed description of the gene locus see chapter 1.6.3). This analysis revealed that the cluster composed of isoforms 3,4 and 5 as well as the cluster of isoform 7, 8, 9 and 10 are expressed at particularly high levels in the ganetespib-resistant cell line HT29 (Figure 3.4 b). Consequently, we hypothesized that these clusters are responsible for ganetespib resistance. To test this, isoform 10 was chosen as an example for these clusters and was overexpressed in two ganetespib sensitive cell lines; SW480 and HCT116 (see Figure 3.5 and Figure 3.6).

a
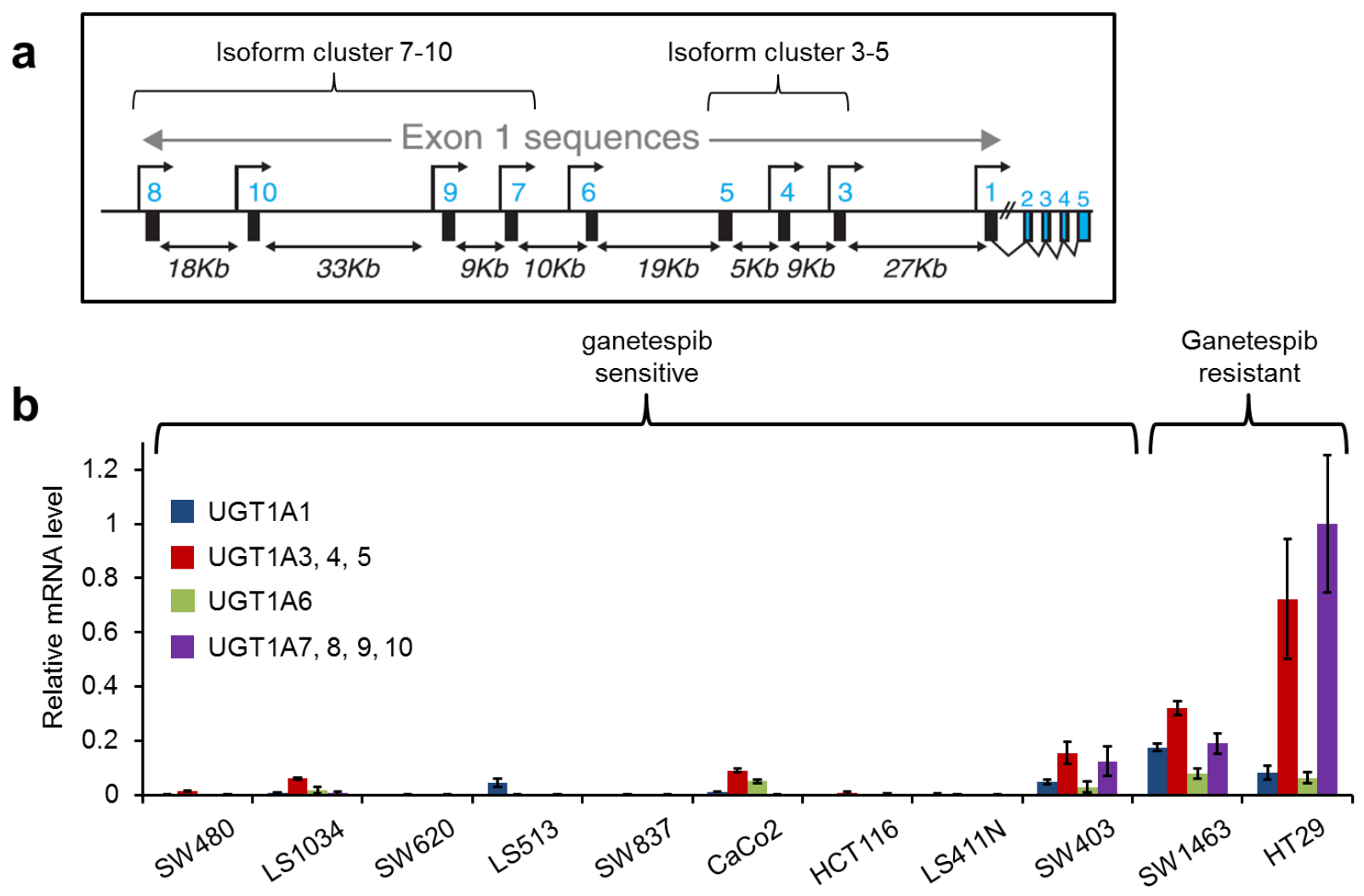

Figure 3.4: Two clusters of UGT1A isoforms are expressed at high levels in ganetespibresistant cell lines.

(a) Structure of the UGT1A gene locus. The two indicated clusters form due to the high similarity of the first exons of the isoforms 3-5 and 7-10 (adapted from ref [80]). (b) Expression of UGT1A isoforms in CRC cell lines. qPCR was performed to determine the different isoforms of UGT1A present in the different cell lines, using primers detecting the isoforms UGT1A1 (blue), UGT1A3-5 (red), UGT1A6 (green) and UGT1A7-10 (purple). The mRNA levels of HPRT1 were used for normalization of the Ct values. The error bars represent the standard deviation of the three biological replicates that were analyzed. 
Monitoring the confluence of the cells after $72 \mathrm{~h}$ of ganetespib treatment, either with a plasmid encoding for UGT1A10 or $\beta$-Galactosidase $(\beta-\mathrm{Gal})$ as an control, revealed a significantly increased tolerance to ganetespib in the presence of UGT1A10 (Figure $3.5 \mathrm{a}$ ). Similar results were obtained analyzing the UGT1A10 and $\beta$-Gal overexpressing cells with the CellTiterGlo ${ }^{\circledR}$ luminescent cell viability assay (Figure $3.5 \mathrm{~b}$ ). The presence of UGT1A10 in the cells increased the tolerance to ganetespib and therefore enhanced the ATP-levels after $48 \mathrm{~h}$ of ganetespib treatment.
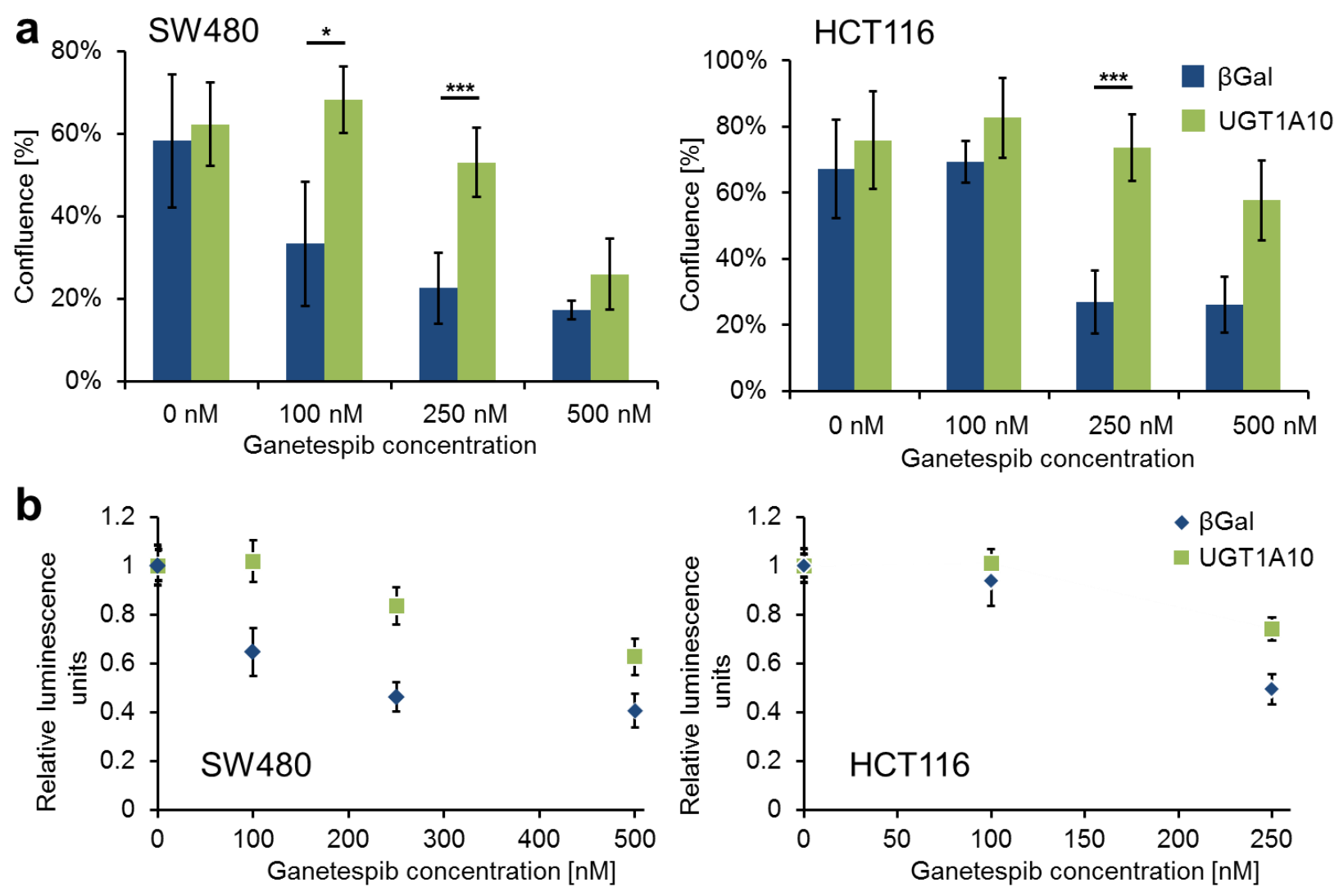

Figure 3.5: Overexpression of UGT1A10 leads to ganetespib-resistance.

(a) UGT1A overexpression renders sensitive cell lines less susceptible to ganetespib treatment. SW480 and HCT116 cells, both sensitive to ganetespib, were transfected using Lipofectamine 2000 to overexpress UGT1A10. Cells were subsequently treated with ganetespib for $72 \mathrm{~h}$. The confluence was determined with the Celigo ${ }^{\circledR}$ Imaging Cell Cytometer. Asterisks show significance by student's t-test $* p<0.05, * * p<0.01$, *** $p<0.005$.

(b) Ganetespib-sensitive cells retain cell viability despite presence of ganetespib when UGT1A10 is overexpressed. The viability of SW480 and HCT116 cells was determined $48 \mathrm{~h}$ after ganetespib treatment using the CellTiterGlo ${ }^{\circledR}$ luminescent cell viability assay as in Figure $3.2 d$. 
UGT1A overexpression and its effect on client protein levels after ganetespib treatment were evaluated by immunoblot analysis (Figure 3.6). Indeed, stabilization of HSP90 client proteins was observed in UGT1A overexpressing cells at ganetespib concentrations usually efficient to inhibit HSP90 chaperoning function. Concluding, overexpression of the isoform UGT1A10 results in a higher ganetespib tolerance of normally ganetespib-sensitive cells.

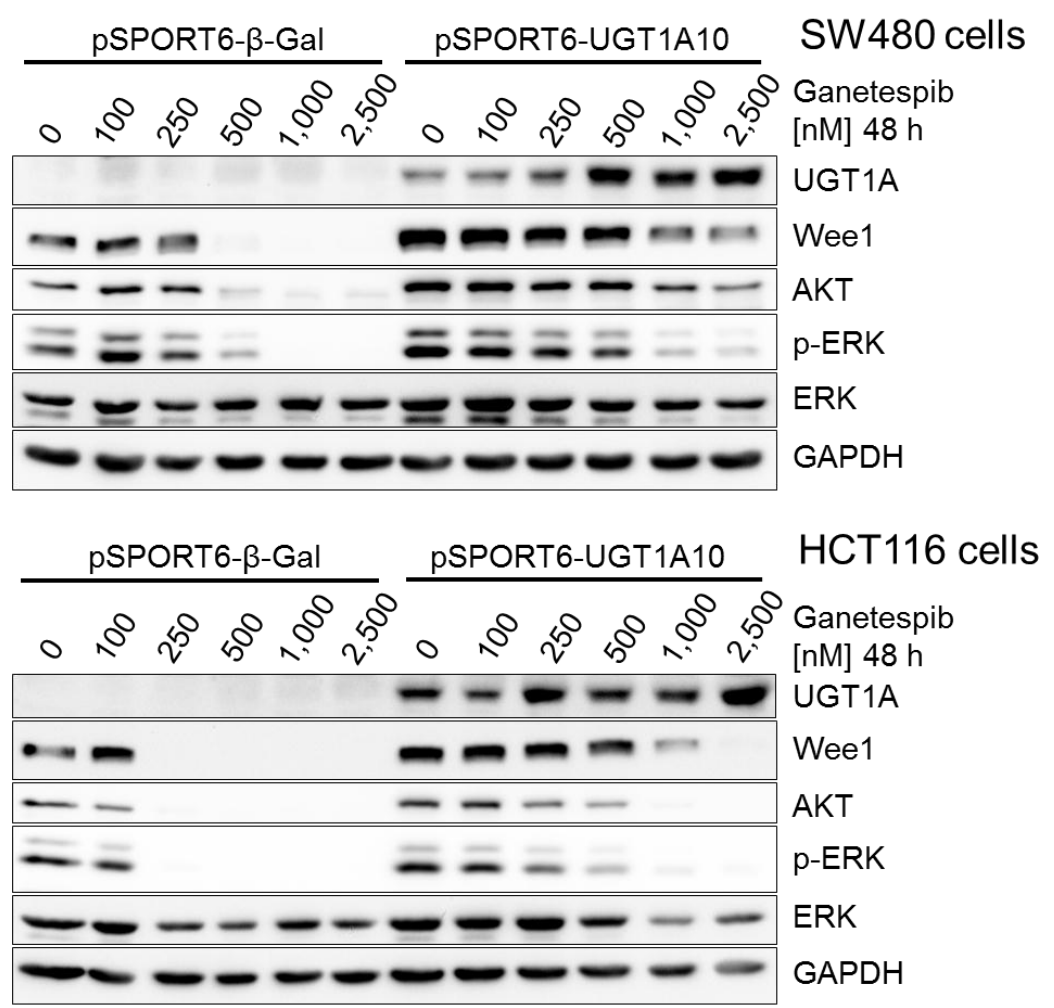

Figure 3.6: HSP90 client proteins are stabilized in ganetespib sensitive cell lines upon UGT1A10 overexpression.

SW480 cells (top) and HCT116 cells (bottom) were transfected with a pCMV-SPORT6 vector encoding for UGT1A10 or $\beta$-Galactosidase ( $\beta$-Gal, control). Subsequently, cells were subjected to the indicated concentration of ganetespib for $48 \mathrm{~h}$ before harvest and preparation of total protein lysates. The HSP90 client proteins Weel and AKT were stained, as well as phosphorylated ERK (p-ERK) and total levels of ERK. GAPDH was stained as a loading control.

\subsection{Verification of Ganetespib Glucuronidation by LC-MS/MS}

The observed ganetespib resistance caused by UGT1A10 suggests that this HSP90 inhibitor is subject to glucuronidation by the transferase. To test whether the conjugation of ganetespib with glucuronic acid does take place in cells resistant to the drug, the corresponding metabolites were detected by LC-MS/MS analysis within the framework of cooperation with Synta Pharmaceuticals ${ }^{\circledR}$. David Proia, Suqin He, and Luisa Shin Ogawa (all 
employees of Synta Pharmaceuticals ${ }^{\circledR}$, Lexington, Kentucky, USA) performed LC-MS/MS analyses on cell lysates and media supernatants from ganetespib-sensitive (SW480, HCT116) and -resistant cells (SW1463, HT29). The levels of unconjugated and glucuronated ganetespib were measured kinetically over $8 \mathrm{~h}$. A fast turnover of ganetespib by glucuronidation was evident by a decrease in ganetespib levels and a rise in ganetespib glucuronides in samples from ganetespib resistant cells, whereas the levels of unconjugated ganetespib were stable in cells sensitive to the drug treatment (Figure 3.7). The kinetics for ganetespib metabolism were slower in SW1463 compared to HT29, with 190 nM and $13 \mathrm{nM}$ ganetespib present respectively after $8 \mathrm{~h}$. This difference in glucuronidation potential reflects the different levels of UGT1A expression in these two lines (Figure 3.1) and the resultant lower ganetespib resistance of SW1463 cells compared to HT29 cells $\left(\mathrm{IC}_{50}\right.$ of 1,582 $\mathrm{nM}$ versus 2,503 $\mathrm{nM}$ respectively).

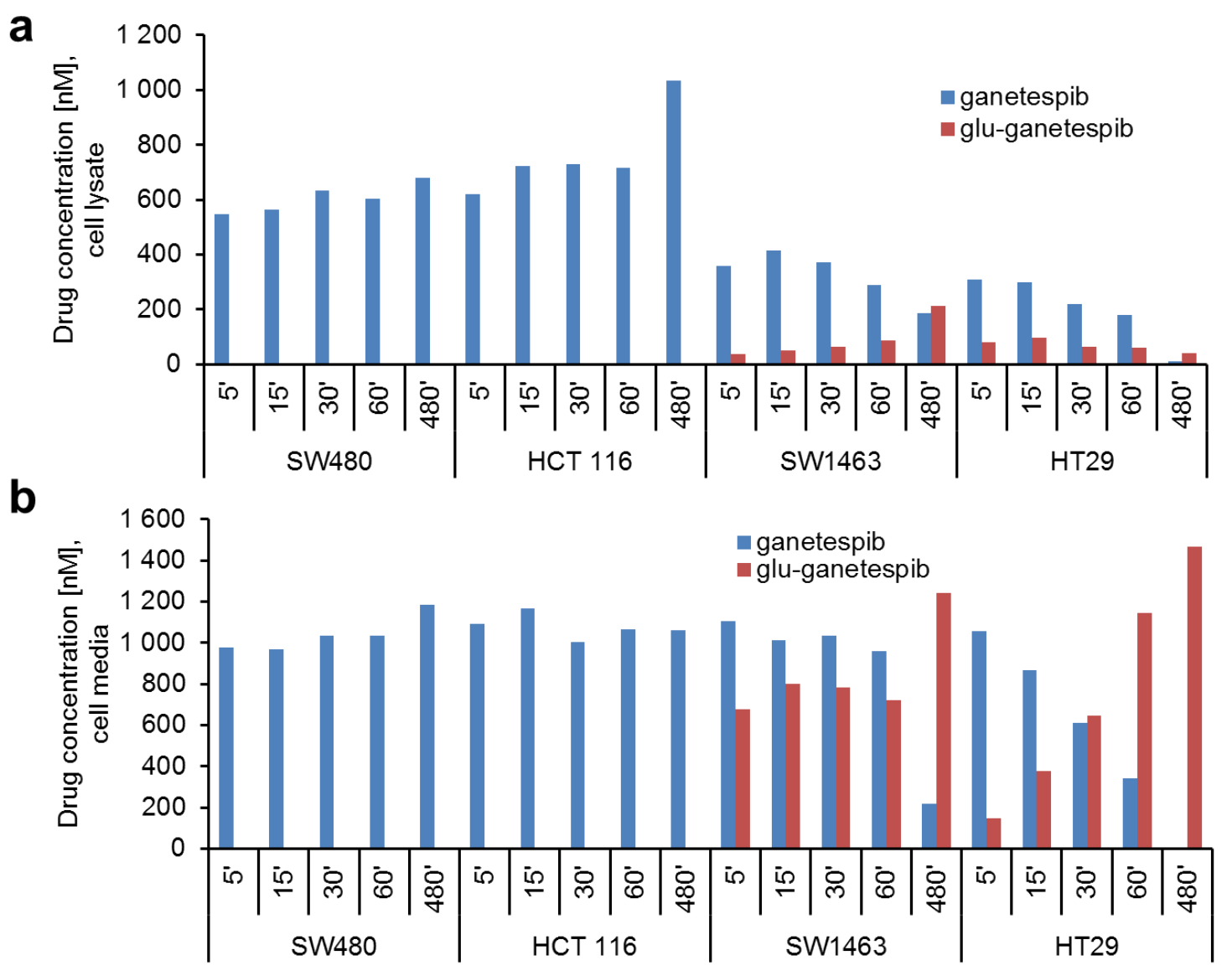

Figure 3.7: Ganetespib is a substrate for UDP-glucuronosyl conjugation by tumor cells. SW480, HCT116, SW1463 and HT29 cells were treated with $1 \mu M$ ganetespib. Cell lysates and culture media were collected at 5, 15, 30, 60 and 480 min. The total concentration of ganetespib and its glucuronidated metabolites in the lysates (a) and the supernatant media (b) were determined by LC-MS/MS (experiments were performed by David Proia, Suqin He, and Luisa Ogawa). 
In addition, a similar bioanalysis was performed on cell lysates and supernatant of HCT116 and HT29 cells treated with AUY922, another resorcinol-based HSP90 inhibitor. An analogous accumulation of AUY922-glucuronide in the supernatant medium of HT29 cells was detected, whereas the HCT116 cells were unable to glucuronidate the drug (Figure 3.8). Due to the lack of the authentic reference material, concentrations of AUY922glucuronide are given as analyte/internal standard peak area ratios.
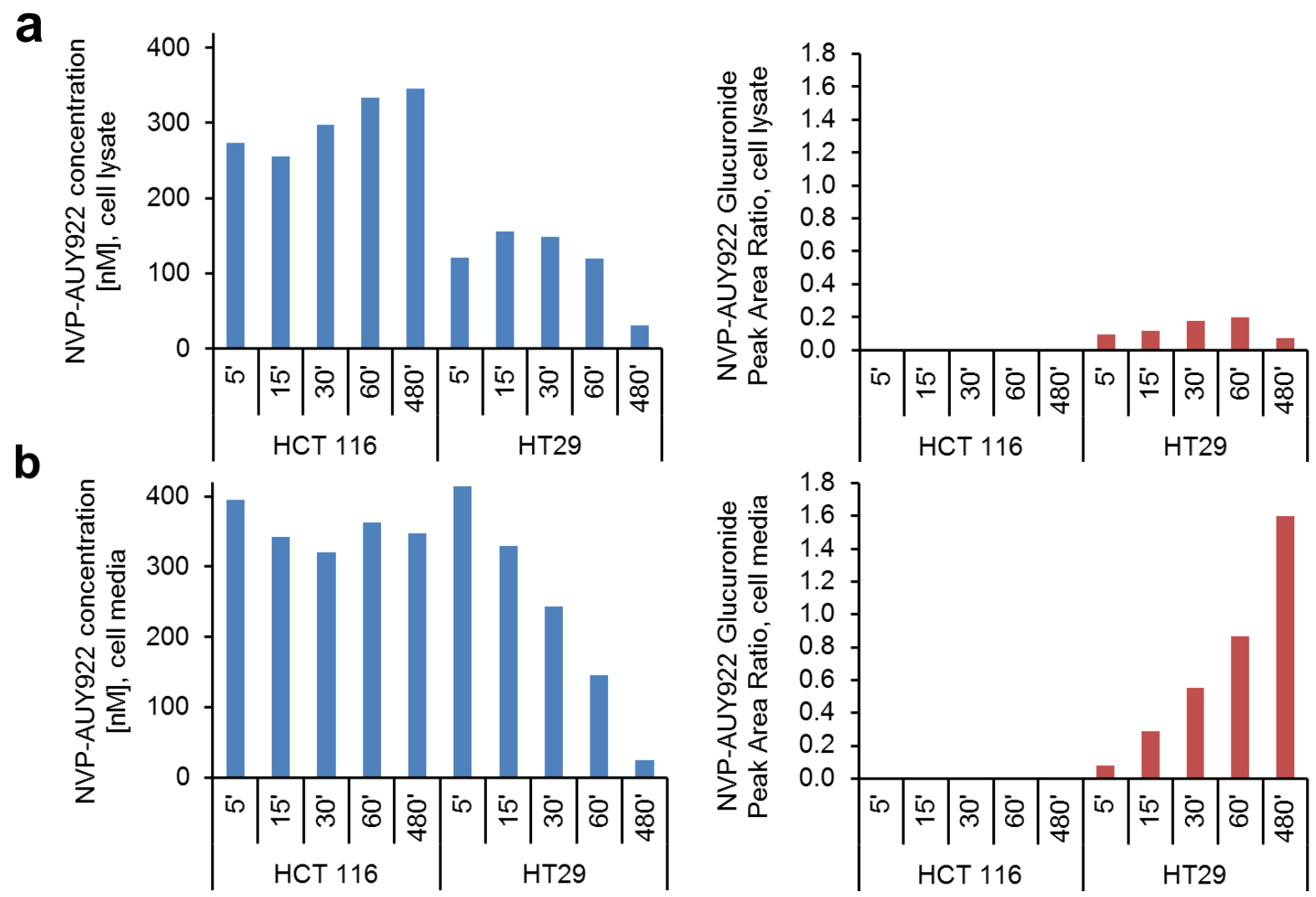

Figure 3.8: Ganetespib is a substrate for UDP-glucuronosyl conjugation by tumor cells. HCT116 and HT29 cells were treated with $1 \mu M$ AUY922. Cell lysates and culture media were collected at 5, 15, 30,60 and $480 \mathrm{~min}$. The total concentration of AUY922 and its glucuronidated metabolites in the lysates (a) and the supernatant media (b) were determined by LC-MS/MS. The levels of glucuronidated AUY922 are given as AUY922 glucuronide peak area ratios (experiments were performed by David Proia, Suqin He, and Luisa Ogawa). 


\subsection{UGT1A Expression Levels do not Correlate to Susceptibility to the First Generation Inhibitor 17-AAG}

To test whether UGT1A expression could also cause resistance to another, structurally unrelated first generation HSP90 inhibitor, the $\mathrm{IC}_{50}$ values for $17-\mathrm{AAG}$ were determined in this panel of eleven CRC cell lines (Figure 3.9). Comparison of the UGT1A expression levels to the 17-AAG $\mathrm{IC}_{50}$ values reveals that the ganetespib-resistant cell lines HT29 and SW1463 are susceptible to 17-AAG treatment and only the ganetespib sensitive cell line $\mathrm{CaCo} 2$ is able to withstand high concentrations of $17-\mathrm{AAG}\left(\mathrm{IC}_{50}>5 \mu \mathrm{M}\right)$. The determined $\mathrm{IC}_{50}$ values for 17-AAG do not correlate with UGT1A expression, indicating that the susceptibility to this HSP90 inhibitor is dependent on different mechanism than UGT1A-catalyzed glucuronidation.

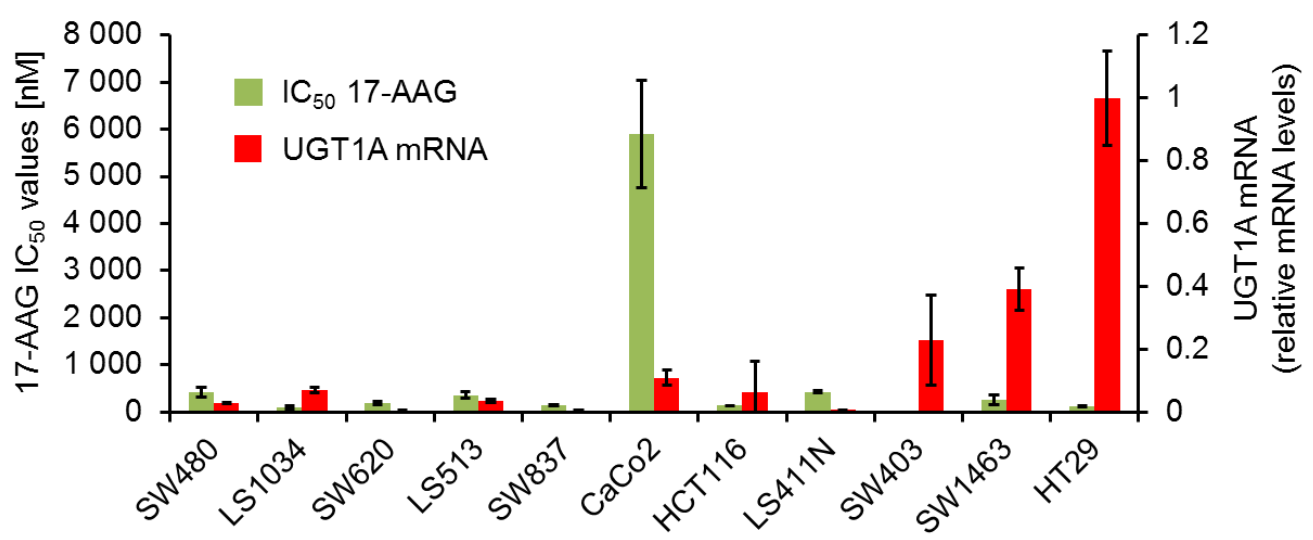

Figure 3.9: 17-AAG resistance does not correlate with UGT1A expression levels.

The same cell lines described in Fig. 1A were assayed for 17-AAG sensitivity (green bars) using the same cell proliferation assay as described in the legend to Fig. $1 A$ and results were compared to UGTIA mRNA levels (red bars) as determined in Fig 1A. The error bars represent the standard deviation from three independent biological replicates.

Furthermore, the protein levels of HSP90 clients from ganetespib sensitive cell lines SW480 and HCT116 and the ganetespib-resistant cell lines SW1463 and HT29 were analyzed after treatment with ganetespib and 17-AAG (Figure 3.10). Ganetespib addition leads to a reduction of the levels of HSP90 clients in ganetespib-sensitive cells, whereas in resistant cells the levels of HSP90 are retained despite the presence of ganetespib. Upon 17-AAG treatment, the levels of client proteins were reduced in HCT116, SW1463 and HT29 cells. In SW480 cells, which display a slightly increased 17-AAG-tolerance, the client protein levels were retained. This result confirms that the two HSP90 inhibitors have different effects on the cell lines, implicating a different response of the CRC cell lines to the drug treatment. 

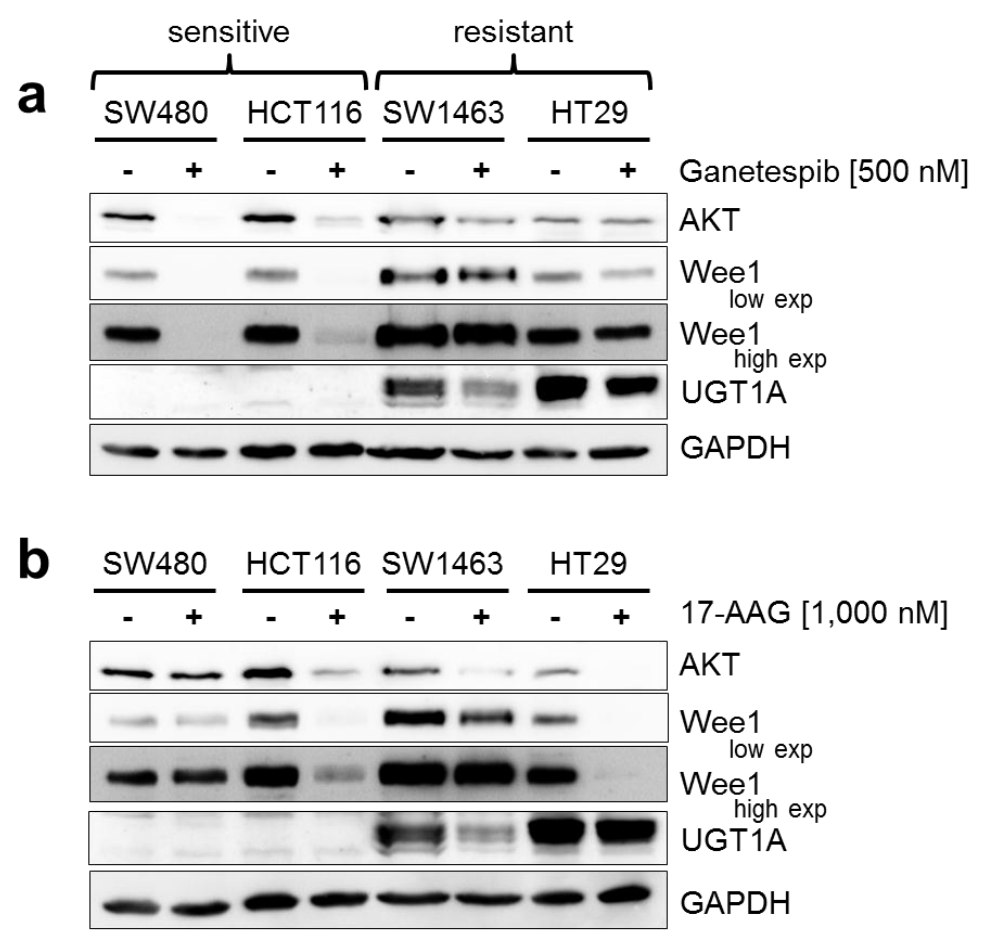

Figure 3.10: Ganetespib and 17-AAG induce different effects on levels of HSP90 clients in CRC cell lines.

Ganetespib-sensitive (SW480, HCT116) and ganetespib-resistant (SW1463, HT29) cells were treated with $500 \mathrm{nM}$ ganetespib (a) and 1,000 nM 17-AAG (b) for $48 \mathrm{~h}$. Subsequently total protein lysates were prepared and an immunoblot analysis of the HSP9O clients AKT and Weel was performed. GAPDH serves as a loading control.

\subsection{Susceptibility of Ganetespib-Resistant and -Sensitive Cell Lines to Second Generation HSP90 Inhibitors}

Next, we addressed the question, whether ganetespib-sensitive and -resistant cells show similar susceptibility to other second generation inhibitors. Therefore, SW480, HCT116, CaCo2, SW1463, and HT29 cells were treated with different concentrations of second generation inhibitors. $\mathrm{IC}_{50}$ values for PU-H71, SNX-2112, AUY922, and ganetespib were assessed based on confluence measurements with the Celigo ${ }^{\circledR}$ system (Figure 3.11). We found that all cell lines are equally susceptible to the treatment with PU-H71, an inhibitor based on a purine scaffold, or SNX-2112, an inhibitor that represents a class of its own. Contrastingly, the ganetespib-resistant cell lines SW1463 and HT29 exhibit increased tolerance to the resorcinolic HSP90 inhibitors AUY922. These data imply that a similar resistance mechanism for AUY922 and ganetespib is present in SW1463 and HT29 cells. 
Taken together our analysis suggests that this mechanism is largely due to UGT1A-mediated glucuronidation of resorcinolic compounds.

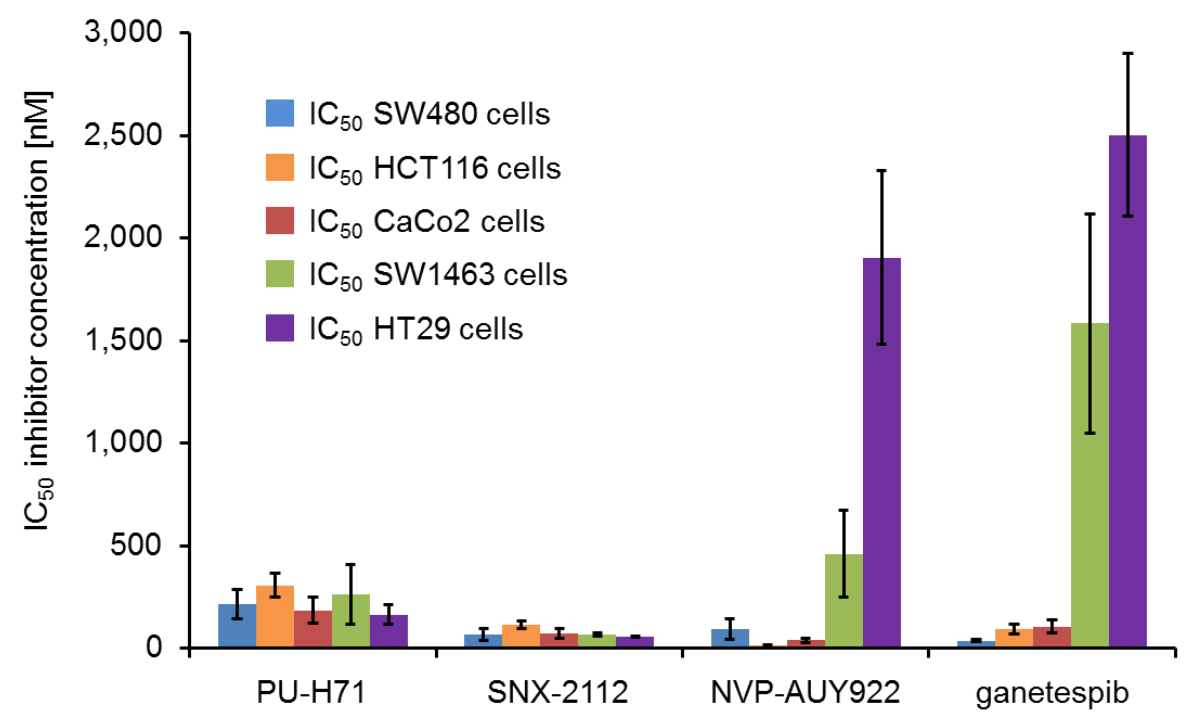

Figure 3.11: Susceptibility of cell lines to different classes of second generation inhibitors. Determination of the $I C_{50}$ values was performed with the Celigo ${ }^{\circledR}$ system as described in chapter 2.2.1.6, for PU-H71, SNX-2112, AUY922 and ganetespib. The error bars represent the standard deviation from three independent replicates. 


\section{Discussion}

\subsection{UGT1A Renders CRC Cells Resistant to Ganetespib}

The second generation HSP90 inhibitor ganetespib is a promising drug for the treatment of several cancer types. ${ }^{[40]}$ However, the susceptibility to this drug varies significantly between cell lines derived from colorectal cancer (CRC) and the aim of this study was to elucidate the determinants that govern the cells response to treatment with this HSP90 inhibitor. We found that ganetespib susceptibility is dependent on the expression of the UDP-glucuronosyl-transferase 1A (UGT1A). This metabolizing enzyme is able to deactivate ganetespib inside the tumor cells by glucuronidation. Therefore, high expression levels of UGT1A renders cells resistant to the treatment with ganetespib (Figure 3.1).

The protecting effect that UGT1A has on CRC cells during ganetespib treatment was observed when screening cell proliferation and HSP90 client protein levels (see chapter 3.1 and 3.2). Our results show that the levels of HSP90 client proteins are no degraded in the presence of UGT1A, despite the treatment with ganetespib. This confirms the direct causal connection of the ganetespib resistance to an abrogation of the HSP90 inhibitory function of the drug. Thus, the resistant cell lines are not better equipped to cope with effects of HSP90 inhibition, but are simply able to deactivate ganetespib in a fast and efficient manner before the drug exerts its inhibitory effect on HSP90. Once the cells are deprived of UGT1A, and therefore of the ability to glucuronate ganetespib, their high tolerance to the drug is lost (Figure 3.2).

In cooperation with Synta Pharmaceuticals ${ }^{\circledR}$, the manufacturer of ganetespib, a bioanalytic study was performed. This analysis confirms the direct glucuronidation of ganetespib by UGT1A via mass-spectrometric detection of the glucuronides in cell lysates and media (Figure 3.7).

The deactivation of the lipophilic xenobiotic ganetespib by UGT1A does not represent a novelty in itself as this process is a known hepatic detoxification system for such compounds and several chemotherapeutics are known substrates of UGT1A (see chapter 4.2). However, our results show that ganetespib is metabolized inside of the cancer cells at a rate that is sufficient to render the cells resistant to the treatment. This is a considerable turnabout for the application of this HSP90 inhibitor for the treatment of cancer. 


\subsection{UGT1A and the Resistance to Other Anti-Cancer Drugs}

Our finding that ganetespib is deactivated by UGT1A in CRC has very important implications for the application of this HSP90 inhibitor in the treatment of cancer. However, UGT1A represents one of the most important drug metabolizing enzymes and has a broad spectrum of substrates. Therefore, its involvement in various resistance mechanisms has already been described. ${ }^{[80]}$

In a previous study, gene expression profiles of xenografts derived from nine different tumor types were correlated with their intrinsic drug resistance to seven different DNAtargeting anticancer drugs. ${ }^{[99]}$ This study identified UGT1A expression as one of 32 genetic markers that influence the susceptibility to anti-cancer drugs in general. Therefore, and based on our own findings, we suggest that a regular screen for UGT1A expression in tumor biopsies prior to chemotherapy will prove helpful for pre-evaluation of chemotherapeutic treatment in general (see also chapter 4.9).

Among the several anti-cancer drugs subject to glucuronidation by UGT1A are the topoisomerase inhibitors irinotecan and etoposide, as well as the hormone receptor binding compounds flutamine and tamoxifen. ${ }^{[100,101]}$

For irinotecan, a standard-of-care drug in second line treatment of advanced CRC, it has been shown that high expression levels of UGT1A can lead to resistance to treatment with this drug. ${ }^{[100]} \mathrm{SN}-38$, the active form of this topoisomerase inhibitor, which is formed by carboxylesterases, is subject to glucuronidation by UGT1A1. ${ }^{[102]}$ Also, the possibility has been proposed that the development of a drug-induced resistance after prolonged treatment of lung cancer cells with irinotecan is due to the upregulation of UGT1A. ${ }^{[103]}$ We suggest that a similar development of resistance might also be observed for ganetespib during treatment of cancers with the drug.

Just as increased UGT1A expression can render CRC cells resistant to irinotecan treatment, conversely the lack of hepatic UGT1A activity can lead to severe irinotecan toxicity in patients with reduced UGT1A activity. For instance, gene polymorphisms in the UGT1A locus which lead to reduced activity of the UGT1A1 isoform expressed in the liver result in a high risk of hematologic toxicity during irinotecan treatment. ${ }^{[104]}$ Therefore, UGT1A1 can be used as a drug related-biomarker for the treatment with irinotecan and the UGT1A locus of patients could be genotyped before treatment. When UGT1A polymorphisms are observed that obstruct the glucuronidation of irinotecan, the drug dose should be reduced. ${ }^{[79,104]}$ Increased toxicity is also possible for ganetespib where the treated 
patients lack hepatic UGT1A activity. Therefore, once the UGT1A isoforms responsible for ganetespib glucuronidation are identified, a similar genotyping step prior to drug administration could be useful for ganetespib treatment to ensure the patient's safety (also see chapter 4.9).

UGT1A does not only have an influence on the metabolism of anti-cancer drugs but it is also responsible for the glucuronidation of carcinogens. ${ }^{[100]}$ Therefore, one has to keep in mind that a loss or impediment of UGT1A activity by mutations or through decreased expression could influence the metabolism of carcinogens as well as chemotherapeutic agents. Following, it will affect the efficacy of both. The overall effect of UGT1A deregulation in cancer might therefore be a complex and multidimensional one. ${ }^{[101]}$ Thus, assumptions based on UGT1A expression levels have to be drawn carefully.

\subsection{Implications for the Different Classes of HSP90 Inhibitors}

As UGT1A is known to be involved in the resistance to many drugs, we hypothesized that it might be involved in the metabolism of other classes of HSP90 inhibitors as well. Therefore, we compared the susceptibility of CRC cell lines to HSP90 inhibitors from other classes. Our results indicate that not all inhibitors exhibit varying susceptibilities in the panel of CRC cell lines.

The high expression of UGT1A in SW1463 and HT29 cells correlates to a tolerance to the HSP90 inhibitors ganetespib and AUY922 (see chapter 3.4 and 3.6). This might be explained by the fact that both drugs contain a resorcinol moiety as a possible glucuronidation site (also see chapter 4.7). For AUY922, the turnover to a glucuronide has already been proposed as the main route of metabolism. ${ }^{[105]}$ Our study proves this directly by detection of the metabolites via mass spectrometry (see chapter 3.4). Meanwhile, increased UGT1A expression does not have any effect on the susceptibility of the CRC cells to HSP90 inhibitors that are not based on resorcinol, i.e. 17-AAG, PU-H71 or SNX-2112 (see Figure 3.9 and Figure 3.11).

The only cell line which exhibits a high tolerance to one of the other drugs is the $\mathrm{CaCo} 2$ cell line, which is able to withstand high concentrations of 17-AAG (see Figure 3.9). The reason for this low susceptibility of $\mathrm{CaCo} 2$ cells to $17-\mathrm{AAG}$ is the lack of NQO1 activity due to a mutation in this gene, which leads to the proteasomal degradation of the protein. As a consequence the pro-drug 17-AAG is not converted to its active form (see chapter $1.5 .5) \cdot{ }^{[106]}$ 
The HSP90 inhibitors PU-H71, which based on a purine scaffold, and SNX-2112, that represents a structural class of inhibitors of its own, are active in all CRC cell lines tested here. Therefore, these two drugs do not appear to be subject to glucuronidation by UGT1A as they do not contain a resorcinol and are not dependent on the activation by NQO1 as they do not contain a quinone moiety.

In conclusion, UGT1A activity determines the resistance of CRC cells to the HSP90 inhibitors that contain a resorcinol, but does not influence the efficacy of inhibitors from other classes.

\subsection{Role of UGT1A Glucuronidation in Other Cancer Types}

Interestingly, very recently a similar resistance to resorcinolic HSP90 inhibitors by UGT1A-catalyzed glucuronidation has been described in bladder cancer cell lines. ${ }^{[107]}$ This study by Acquaviva and coworkers confirms our findings and shows that the concept of resistance to resorcinolic HSP90 inhibitors by glucuronidation can be transferred to other UGT1A expressing cancer types.

The basal UGT1A expression levels in the parental tissue seem to be the determining factor for the capacity of a cancer to exhibit resistance to resorcinolic HSP90 inhibitors. Therefore, our results cannot be transferred to all cancer types. Analysis of the tissue specific mRNA expression levels with the human protein atlas reveals that UGT1A is expressed in liver, kidney, duodenum, urinary bladder, small intestine, esophagus, colon, stomach, and skin (in the order of decreasing amounts of UGT1A mRNA). ${ }^{[108]}$ Epithelial tumors arising from these tissues might exhibit resistance to ganetespib or AUY922 by increased expression of UGT1A. However, some lung and breast cancer cell lines have also been shown to express UGT1A. ${ }^{[103,109]}$

In follow-up experiments to the work presented here, cancer cell lines derived from the tissues mentioned above should be analyzed for their UGT1A expression and tested for their capability to withstand ganetespib or AUY922 treatment. According to the human protein atlas, some cancer cell lines derived from skin $(\mathrm{HaCaT})$ and the urinary bladder (RT-4) express high levels of different UGT1A isoforms. ${ }^{[108]}$ The RT-4 cell line has already been described to show ganetespib resistance. ${ }^{[107]}$ These two, as well as other UGT1A expressing cell lines could be part of further studies to extent our finding to other cancer types. 


\subsection{Other Factors that Might Influence the Efficacy of Glucuronidation by UGT1A}

The list of genes that was retrieved from correlation of microarray data of the CRC cell lines to their ganetespib susceptibility (ganetespib-susceptibility genes) was the initial indication for the linkage of UGT1A to ganetespib resistance. The three different UGT1A probes that were included in the list among the top hits target all UGT1A isoforms (see chapter 6.1). We further investigated UGT1A as it represented the most interesting candidate due to its known function in drug metabolism (chapter 1.6.3). Apart from UGT1A, the list might also contain other candidate genes whose expression levels might correlate with the potential of the cell lines to cope with ganetespib treatment. We did not further investigate any of these other candidate genes.

HSP90 client proteins could play a crucial role in determining the ganetespib susceptibility. For instance, some essential clients might be expressed at lower levels in ganetespib sensitive cells compared to resistant cell lines, and as a consequence treatment with the HSP90 inhibitor would render the sensitive cells completely devoid of these proteins. This could explain the difference in ganetespib susceptibility of the two groups of cell lines. However, none of the known HSP90 clients were found in the list of top hits of the statistical analysis. Also, as described in chapter 4.1 the client protein levels are maintained in resistant cell lines despite HSP90 inhibitor treatment (see Figure 3.6). Therefore, at least in the current study, our results suggest that it is not the degradation of particular client proteins that determines the susceptibility of the cells to ganetespib treatment.

\subsubsection{Transcriptional Regulation}

Like all reactions from the drug metabolism, the glucuronidation of xenobiotics is a process that is accurately regulated in dependence of tissue, environmental influences, and substrate levels. ${ }^{[80]}$ However, the reasons for the constitutively high expression levels of UGT1A in the ganetespib-resistant CRC cell lines remain elusive. Interestingly, the gene list from the microarray correlation contains some transcriptional activators which correlate positively with ganetespib resistance and some transcriptional repressors which correlate negatively with ganetespib resistance. These include the helicase-like transcription factor (HLTF), the transcription elongation factor A protein-like 4 (TCEAL4), hairy and enhancer of split 2 (HES2), and CCR4-NOT transcription complex subunit 2 (CNOT2). It is possible that these transcription factors are responsible for the high differences in UGT1A expression between cell types. Therefore, the UGT1A gene locus could be screened for binding sites of 
these transcriptional regulators and chromatin immunoprecipitation (ChIP) experiments could be performed to investigate their binding to the promoter region of the UGT1A gene locus. If such binding sites are found, the effect of inhibition or depletion of this transcription factor on the mRNA levels of UGT1A could then be investigated.

Apart from these general transcription regulators there are some xenobioticresponsive transcription factors which have been described as regulating the expression of UGT1A isoforms. Among the most important of these receptors are the aryl hydrocarbon receptor $(\mathrm{AhR})$, the constitutive androstane receptor (CAR) and the pregnane $\mathrm{X}$ receptor (PXR). ${ }^{[110]}$ Each receptor responds to different xenobiotic compounds and coordinates the detoxification of many lipophilic xenobiotics by inducing different enzymes from phase I and II of drug metabolism, including varying isoforms of UGT1A. ${ }^{[10,111]}$ They are predominantly found in the liver and the intestine and are also expressed in tumors derived from these tissues. ${ }^{[112]}$ PXR has been described as inducing expression of UGT1A isoforms 1, 9, and 10 and as being involved in drug resistance mechanisms. ${ }^{[112,113]}$ For instance, the upregulation of UGT1A1 by PXR overexpression has been previously shown to render colorectal cancer cells resistant to treatment with irinotecan. ${ }^{[113]}$ Furthermore, a xenobiotic response element and a phenobarbital-responsive element, which can be bound by the AhR and CAR respectively, have been found in the promoter region of UGT1A1. ${ }^{[114,115]}$

None of the xenobiotic-responsive transcription factors were identified in the list of genes potentially relevant for ganetespib-resistance. However, the aryl-hydrocarbon receptor repressor (AHRR) was found among the gene hits (see chapter 6.1) and correlated negatively with ganetespib resistance. Therefore, this repressor element, which is able to suppress the activity of AhR, might be responsible for the low activity of this metabolism-activating factor in ganetespib sensitive cells. ${ }^{[16]}$ A knockdown of this repressor in the sensitive cells could be performed to test this hypothesis.

As the xenobiotic-responsive transcription factors were not included in the list of ganetespib-susceptibility genes, the high constitutive expression levels of UGT1A in SW1463 and HT29 cells seems to be independent of the activation by these transcription factors. However, the microarray data were generated from untreated cells and do not include the effects of drug treatment on the mRNA levels. Therefore, we cannot rule out the induction of UGT1A by xenobiotic-responsive transcription factors after treatment with lipophilic drugs such as ganetespib and they may still play an important role in enhancing ganetespib glucuronidation in resistant CRC cell lines. A vast variety of xenobiotics, i.e. drugs, but also food substances, have been found to bind PXR. ${ }^{[113]}$ The activation of 
xenobiotic-recognizing receptors by co-administered drugs or food substances that would lead to increased UGT1A expression must be taken into account as a possible source of drugdrug interactions, especially as HSP90 inhibitors are intended to be primarily used in combinational treatment. ${ }^{[80]}$

After treating the cells with ganetespib we did not observe higher protein levels of UGT1A (Figure 3.10), hence ganetespib does not seem to influence the levels of UGT1A by binding to receptors that induce its expression. Nevertheless, the cancerous glucuronidation potential might increase after prolonged treatment with one of the resorcinolic HSP90 inhibitors and might lead to drug induced resistance, as has been observed previously with irinotecan. ${ }^{[103]}$

\subsubsection{Factors Regulating the Activity of UGT1A}

Recently it has been found that the sonic hedgehog transcription factor gliomaassociated protein 1 (Gli1) is able to influence the protein stability of UGT1A. The UGT1Amediated Ara-C and ribavirin resistance by glucuronidation of these drugs is dependent on Gli1 activity in cell lines derived from head and neck carcinoma. ${ }^{[117]}$ However, Gli1 has not been found in the list of genes that correlate with ganetespib resistance. Therefore, UGT1A activity in SW1463 and HT29 cells does not seem to be dependent on the stabilizing effect that Gli1 has on UGT1A.

Also, UGT2B7 and UGT1A9 have been shown to interact with other enzymes from the UGT1A family by forming heterodimers, thereby affecting their kinetics. ${ }^{[118,119]}$ UGT2B7 was not listed among the genes that correlate with ganetespib resistance and is therefore probably not influencing the high activity of UGT1A in SW1463 and HT29 cells. The activation of UGT1A enzymes by UGT1A9 might play a role in the ganetespib resistant cells, however the exact levels of individual UGT1A isoforms are not detectable by qPCR analysis (see chapter 4.6).

Listed among the ganetespib-susceptibility genes are several kinases and acyltransferases. Their potential function in stabilizing or regulating the function of UGT1A could be analyzed further to check if they have a significant influence on the glucuronidation of ganetespib. It would be very interesting to study this issue in future experiments as potentially essential UGT1A stabilizing or activating factors could be targeted by inhibitors to compromise the glucuronidation of resorcinolic drugs. 


\subsubsection{Potential Influence of Co-Substrate Supply}

Before UGT1A-catalyzed glucuronidation can occur the co-substrate UDP-glucuronic acid has to be available in amounts sufficient for the conjugation of all xenobiotic molecules. UDP-glucuronic acid is synthesized by the oxidation of UDP-glucose by UDP-glucose 6dehydrogenase (UGDH). ${ }^{[120]}$ As UGDH is not included in the list of statistically relevant hits from the microarray analysis, the glucuronidation step executed by UGT1A seems to be the step determining the success of ganetespib deactivation. Presumably, UGDH, and therefore also the co-substrate UDP-glucuronic acid, are present in sufficient amounts in the resistant cell lines to facilitate the glucuronidation of all ganetespib molecules. Thus, UGDH-catalyzed oxidation of UDP-glucose is not the rate limiting step of the glucuronidation process.

\subsubsection{Potential Influence of Metabolite Transport}

UGT1A is located to the luminal side of the endoplasmic reticulum, and the newly generated glucuronides have to be transported past the membrane enclosing this cellular organelle. There is evidence for an active transport across this membrane for several glucuronides, but the specific transporters have not yet been identified. ${ }^{[121,122,123]}$

The glucuronides that have been transported into the cytoplasm need to be further transported outside of the cell and it has been proposed that glucuronidation has to be accompanied by shuttling via a glucuronide transporter for the manifestation of a de novo resistance. ${ }^{[124]}$ Several transporters from the ATP-binding cassette transporter sub-family C, the multidrug resistance-associated proteins, have been shown to be involved in the excretion of glucuronides from the interior of the cell. ${ }^{[124,125]}$ The xenobiotic glucuronides that are excreted from the cells are then transported further, e.g. in the bile, and finally excreted via urine or feces.

The appearance of one of the multidrug resistance-associated proteins in the list of ganetespib-susceptibility genes would imply that the transport process is highly relevant for the glucuronidation efficacy. However, the list does not include any transmembrane transporters that could facilitate the excretion of glucuronides from the endoplasmic reticulum or the cytoplasm of the cell. Therefore, the resistance-relevant step seems to be the deactivation by UGT1A-catalyzed glucuronidation regardless of the rate or the efficiency of the subsequent transport. 


\subsection{UGT1A Isoforms in Ganetespib Resistance}

Due to the high similarity of the UGT1A genes in the two isozyme clusters (isoforms 3-5 and isoforms 7-10; chapter 1.6.3), it is virtually impossible to design primers that are specific for individual isoforms within each cluster. Therefore, the isoforms were amplified in qPCR using primers targeting the sequences of all isozymes of one cluster (Figure 3.4, see chapter 2.1.7.1 for primer sequences). The cluster of the isoforms 7-10 was highly expressed in the most ganetespib-resistant cell line, HT29. Therefore, the isoform 10 was chosen for overexpression in the ganetespib-sensitive cell lines SW480 and HCT116 in order to establish higher ganetespib tolerance in these cell lines (see Figure 3.5 and Figure 3.6).

Based on the finding that the isoform 10 is able to glucuronate ganetespib and establish tolerance to the drug in CRC cell lines, it would be of interest to check which other isoforms from the clusters 3-5 and 7-10 are also able to metabolize resorcinolic HSP90 inhibitors. These may then be used as biomarkers for ganetespib treatment (see chapter 4.9). The isoforms 7, 8, and 9 are $96-97 \%$ identical to UGT1A10, compared to $75 \%$ for the other five isoforms. Therefore it is likely that isoforms 7, 8 and 9 glucuronidate the same targets as isoform 10 and are also capable of conjugating ganetespib.

UGT1A is very unequally expressed between the CRC cell lines. It is therefore also of interest to find the reasons for this significant difference in expression, as this could give rise to strategies for pretreatment screening of ganetespib susceptibility or for suppressing UGT1A expression to prevent the deactivation of the drug. Continuous activation or overexpression of transcription factors that induce the expression of particular UGT1A isoforms in the ganetespib-resistant CRC cells might be responsible for the observed high levels of the enzyme. Inhibition of these transcription factors could lead to a downregulation of UGT1A expression.

Mutations in the promoter sites of the UGT1A genes could theoretically explain the strikingly low levels of UGT1A expression in the sensitive cell lines, but there is currently no empirical evidence for such a scenario.

Single nucleotide polymorphisms in the common exons 2-5 of the UGT1A gene cluster which encode the active site of the enzyme have previously been shown to influence the glucuronidation capacity of individuals. ${ }^{[126]}$ Mutations in these exons could explain the lack of ganetespib resistance in SW403 cells, which exhibit relatively high UGT1A expression levels, but do not show an increased tolerance to the drug (Figure 3.1). 


\subsection{Strategies to Circumvent Ganetespib Resistance by Glucuronidation}

One strategy to circumvent the deactivation of the resorcinolic HSP90 inhibitors by glucuronidation would be to alter the chemical structure of the drugs to prevent the transfer of the glucuronic acid onto hydrophilic side chains.

Dissection of the chemical structures of the HSP90 inhibitors ganetespib and AUY922 reveals that they share the resorcinol moiety and the adjacent heterocycle (see Figure 4.1). In ganetespib this heterocycle is a triazolone, in AUY922 it is an isoxazole. The resorcinol and the adjacent heterocycle form the core of interaction between the HSP90 inhibitors and the ATP binding pocket of HSP90. ${ }^{[40,105]}$ Our data show that only these two drugs are subject to glucuronidation by UGT1A, in contrast to HSP90 inhibitors from other classes. Thus, it is likely that the glucuronosyl-group gets attached to a site that is only present in these two compounds.
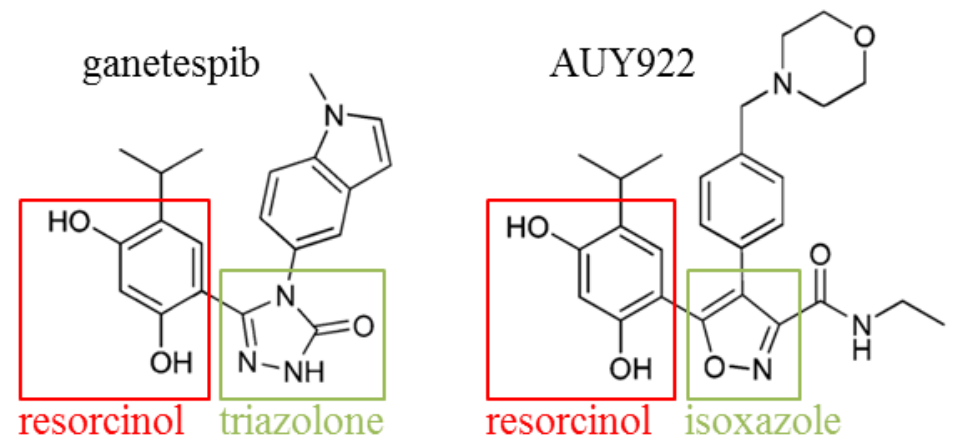

Figure 4.1: Chemical structures of ganetespib and AUY922 with HSP90 interacting sites. Ganetespib, AUY922 with resorcinol (red) and the adjacent heterocycle (green).

Other resorcinol containing compounds have previously been analyzed for their metabolism by glucuronidation. For instance the mycotoxine zearalenone as well as resorcinol itself are subject to glucuronidation at one of the sterically unhindered resorcinolic hydroxyl groups. ${ }^{[127,128]}$ Therefore, it is conceivable that the glucuronate gets attached to the hydroxyl groups of the resorcinol.

A chemical modification of the resorcinol or the adjacent nucleophilic heterocycle might therefore hamper the glucuronidation and prevent the deactivation of the drugs. On the other hand, these moieties constitute the site of drug-target interaction and form hydrogenbonds with the amino acid side chains in the ATP-binding pocket of HSP90. Thus a substitution or modification of these chemical structures would probably compromise the efficacy of the drugs. Therefore, the potential for glucuronidation by UGT1A is an attribute intrinsic to the class of resorcinolic HSP90 inhibitors. 
Another strategy to circumvent the deactivation of the resorcinolic HSP90 inhibitors by glucuronidation would be the inhibition of UGT1A. However, such an approach would only be possible once the responsible UGT1A isoforms are known and isoform-specific inhibitors become available. The inhibition of all isoforms would have deleterious consequences, as for instance the glucuronidation of bilirubin, which is catalyzed by UGT1A1, would also be affected. When bilirubin is not metabolized efficiently, it accumulates in the blood and at high concentrations it passes the blood-brain barrier in to the brain, where it can cause fatal necrosis of neurons. ${ }^{[88]}$ Only the targeted inhibition of particular isoforms which are responsible for glucuronidation of resorcinolic drugs could ensure a safe co-treatment.

Also, once the transcription factors that mediate the upregulation of UGT1A expression in cancer cells are identified, these could also be targeted by inhibitors to prevent the excessive expression of UGT1A and to thereby hamper the glucuronidation.

\subsection{Implications for the Clinical Use of Resorcinolic HSP90 Inhibitors}

The findings described in this work have several very important implications for the clinical application of resorcinolic HSP90 inhibitors.

First of all, it is of pivotal importance to identify the isoforms that are responsible for the glucuronidation of these resorcinolic HSP90 inhibitors (see chapter 4.6). Severe drugdrug interactions may be possible due to the mutual dependence of two drugs on the same UGT1A isoform for glucuronidation. The two compounds would compete for the turnover by UGT1A and could therefore exceed the glucuronidation capacity of the responsible UGT1A isoforms, resulting in drug accumulation. Alternatively, strong adverse effects may be observed when the relevant UGT1A isoforms are inhibited by a co-administered drug. ${ }^{[80]}$ By understanding the exact metabolism of these inhibitors by UGT1A isoforms these drug-drug interactions can be avoided. However, these drug-drug interactions are not very frequent for substrates of phase II reactions of the drug metabolism and the UGT1A enzymes are fairly promiscuous in their substrate specificity. ${ }^{[129]}$ Several UGT1A isoforms might be able to metabolize the components of the drug mixture, which reduces the probability of drug-drug interactions due to enzyme metabolism dependence. ${ }^{[129]}$ Meanwhile, co-administered drugs or food substances could also lead to the increased expression of UGT1A through induction of xenobiotic-recognizing receptors in the liver and intestine as well as in tumors derived from 
these organs (see chapter 4.5.1). The consequence would be reduced activity of the HSP90 inhibitors.

These potential drug-drug interactions have to be considered, especially as the HSP90 inhibitors are presumably mainly used in combinational treatment.

To evaluate the feasibility of ganetespib for clinical applications it is of crucial importance to further elucidate the processes that govern the response to ganetespib treatment in vivo. Therefore, xenograft models and clinical studies are essential.

\subsubsection{Mouse Models for in vivo Studies of Resorcinolic Hsp90 Inhibitors}

To analyze whether the difference in cancer growth can be observed in vivo, resistant and sensitive CRC cells could be used in parallel in a xenograft model under treatment with a resorcinolic HSP90 inhibitor.

In previous xenograft experiments, the ganetespib-sensitive cell line HCT116 was injected in immunodeficient SCID mice to study the effect of ganetespib as a single agent for

cancer treatment. ${ }^{[130]}$ He and coworkers did show that the use of ganetespib alone has only a relatively modest effect on the tumor growth rate (decrease of approx. 50\%) in xenografts. However, treatment of the xenografts with the HSP90 inhibitor increases the chemo- and radio sensitivity of the cancer cells. Therefore, combinational treatment of ganetespib with chemotherapeutics resulted in increased response to conventional chemotherapy. This need for a combinational treatment in xenografts would render the comparison of ganetespib efficacy in the different cancer lines very complicated, as multiple factors would affect the outcome of the applied drug combination.

Moreover, xenograft experiments with ganetespib are further complicated by the fact that ganetespib has to be administered by intravenous injections in mice models, which makes the application in nude mice very finicky, as their tail veins are prone to collapse. ${ }^{[130]}$ The complicated drug application and the fact that direct deduction of differences in ganetespib susceptibility might not be possible when the drug is used in combinational treatment, have to be considered before running xenograft experiments.

Aside from xenograft experiments, a CRC-tumor mouse model could serve as a good substitute for studies in human. As the mouse UGT1A genes are arranged in a similar manner to the human gene locus and are highly conserved between the two species, insights deduced from studies in mouse models can be transferred to humans. ${ }^{[131]}$ For instance, the mouse model system based on AOM/DSS induced colorectal cancer provocation could be used to 
study the response of CRC to resorcinolic HSP90 inhibitor treatment. ${ }^{[132]}$ The developing tumors would be challenged with ganetespib or AUY922 and the growth rates of the individual cancers would be analyzed for a correlation to the in vivo expression levels of UGT1A.

\subsubsection{Clinical Studies}

Of course clinical trials represent the most informative approach for the elucidation of medical benefit. On the other hand, they also carry considerable risk for the participants and their safety has to be ensured. Therefore, thorough preclinical trials should precede the clinical application. For ganetespib and AUY922 these precautions have already been taken and the drugs are currently studied intensively in clinical trials.

The findings presented in this study entail some very important implications for the clinical use of ganetespib. However, a prerequisite for the transfer of the findings to the clinical application is a comparable spectrum of expression levels of UGT1A in primary CRC tumors compared to the CRC cell lines. For the development of a resistance to ganetespib similar to the in vitro resistance observed in CRC cell lines, the primary tumors must express comparable levels of UGT1A.

It has been reported that UGT1A levels are reduced in colon cancer as compared to normal colonic mucosa, albeit not in all cancer samples. ${ }^{[133]}$ On the other hand, it has been previously described that biopsies from CRC patients the expression of UGT1A is often higher than in HT29 cells. ${ }^{[100]}$ In previous studies, microarray hybridization datasets were obtained from 217 colorectal carcinomas. ${ }^{[134,135]}$ When comparing the UGT1A expression levels in the panel of eleven colorectal cancer cell lines with those of primary tumor samples, it becomes apparent that the range of expression of the tumors resembles the range of expression in the CRC cell lines (Figure 4.2). Therefore the resistance to resorcinol-based HSP90 inhibitors in colorectal cancer patients might become a real obstacle for successful treatment.

A clinical trial with resorcinolic HSP90 inhibitors as single agents in CRC patients would have high relevance for the validation of the findings presented in this work. An analysis of the UGT1A expression levels of individual cancer samples could give insight in a potential correlation between UGT1A expression and a response to ganetespib treatment i.e. a change in tumor growth. Also, in long term studies the possibility of drug induced resistance development could be tested. 


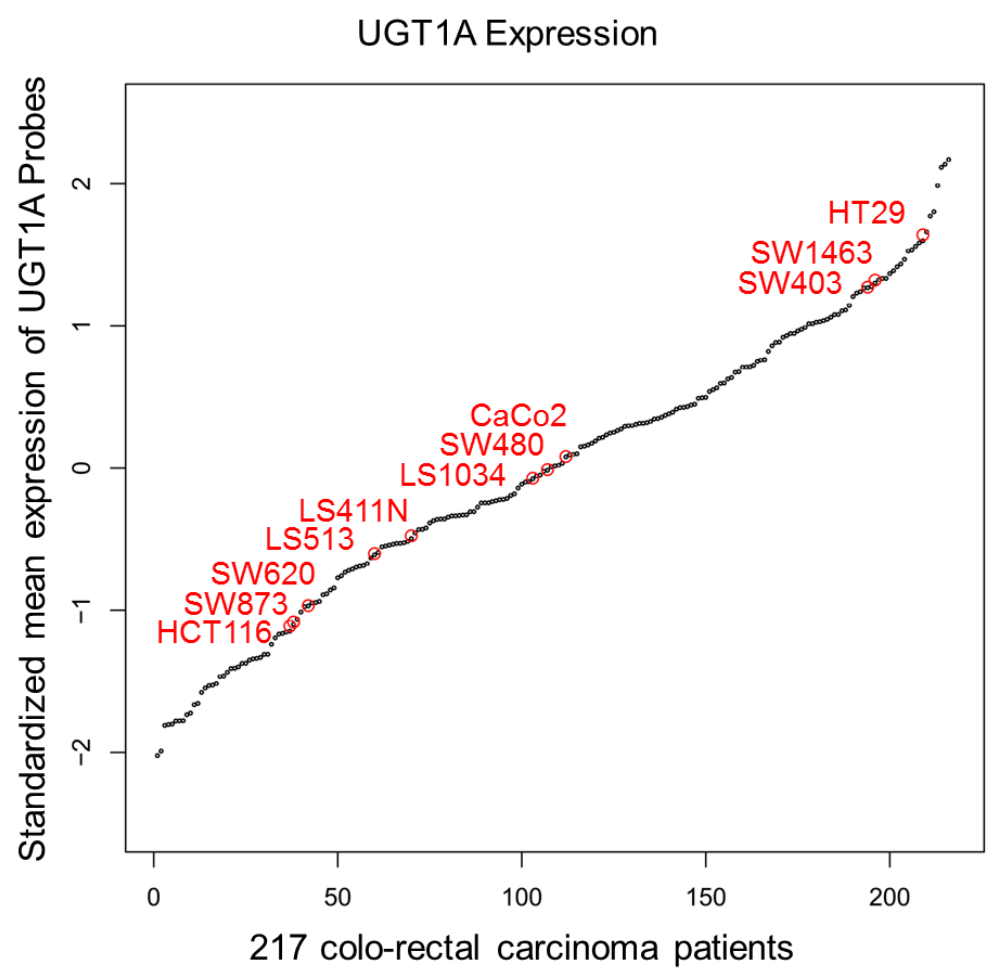

Figure 4.2: Overlay of distributions of UGT1A expression levels in primary tumor samples and in vitro CRC cell lines (graphic kindly provided by Frank Kramer)

The mean hybridization intensities from three UGT1A microarray probes were normalized according to their deviation from the overall mean intensity of all tumors (log2 scale). The UGTIA expression levels of the CRC cell line panel is overlaid on the distribution of the 217 primary tumor samples.

\subsection{UGT1A as a Drug-Related Biomarker for Ganetespib Treatment}

The fact that the resorcinolic HSP90 inhibitors ganetespib and AUY922 are subject to UGT1A-catalyzed glucuronidation is very important for the stratification of treatment in cancer patients. The UGT1A-catalyzed deactivation makes the treatment of cancers from the small intestine and other tissues with high metabolic potential very complicated. Until measures for a reliable screening of UGT1A expression are available, the administration of these drugs should only be considered as a last treatment option when other measures have failed. Until the actual benefit and the possible side-effects can be predicted with reasonable certainty, the application should be limited to specific tumors that were previously shown to be highly susceptible to HSP90 inhibition, like anaplastic lymphoma kinase (ALK)-driven non-small cell lung cancer and Her2-overexpressing breast cancers. ${ }^{[49,50]}$

However, once the screening methods for UGT1A activity in the tumor sites become available, the treatment stratification can be done in a really patient specific way. Only 
tumors with low levels of UGT1A and only patients with sufficient UGT1A activity in the liver should be treated with resorcinolic HSP90 inhibitors to ensure drug efficiency and to prevent toxicity.

There are two general routes to screen for the UGT1A levels in the tumors. Either the protein levels can be detected through antibody-binding or the mRNA levels can be determined by molecular biological methods.

By determining the protein levels through histological methods the tumor levels of UGT1A can be detected in clear distinction from the surrounding tissue. However, it would be virtually impossible to distinguish between the different isoforms of UGT1A, as different, isoform-specific antibodies would have to be used and many tissue sections would have to be stained in parallel. Therefore, it would be preferable to establish a screening for UGT1A mRNA expression levels from primary tumor samples in the clinics, ideally in a highly standardized fashion that guarantees the comparability of expression levels between patients.

\subsubsection{Clinical Assessment of UGT1A mRNA Levels}

Methods for the detection of the whole transcriptome, like microarray analysis or RNA-seq, are very time-consuming and costly and are best suited to identify candidate biomarkers or to elucidate the impact of whole gene set amplification or pathway activation on observed phenotypes. ${ }^{[136,137]}$ For the every-day use in high throughput screenings of the expression of a known single target gene (e.g. UGT1A) the qPCR is the only efficient and economic method. ${ }^{[138]}$ The real-time measurement of the amplification process allows the precise quantification of the amount of starting material, the target mRNA. It is facilitated by real-time quantification of fluorescence, either by using a fluorescent dye that intercalates into the double stranded DNA (see chapter 2.2.2.9), or by TaqMan ${ }^{\circledR}$ probes. TaqMan ${ }^{\circledR}$ probes are fluorescence-labeled DNA fragments that bind specifically to the target sequence and only give a signal when the gene sequence is subject to an amplification reaction with taqpolymerase. ${ }^{[139]}$ The use of TaqMan ${ }^{\circledR}$ probes is costly, but allows the analysis of gene expression in a customizable and standardized fashion that is comparable across samples and laboratories. ${ }^{[140,141]}$ Also, as the TaqMan ${ }^{\circledR}$ probes span a smaller region of DNA compared to primers for standard qPCR, it might be possible to target individual UGT1A isoforms for quantification, something that is not feasible with standard qPCR (see chapter 1.6.3 and 4.6). Depending on the probe design, the $\mathrm{TaqMan}^{\circledR}$ method can also be applied to screen for genetic polymorphisms. ${ }^{[142]}$ Thus, it can not only determine the expression levels of UGT1A 
isoforms, but can also provide information on functional impairment of the isoforms by mutations.

\subsubsection{Standardization of the mRNA Evaluation Process}

The highly standardized evaluation of mRNA expression is essential for the assessment of mRNA levels that are comparable between samples and across laboratories.

Different ways of sample extraction from primary tumor sites might yield samples with different cellular composition and can result in different gene expression profiles. ${ }^{[143]}$ Therefore, standardized obtainment and preservation of mRNA samples from clinical biopsies is the first crucial step in a comparable expression level analysis. The primary tumor samples should be stored in a RNA-preserving reagent or should be frozen immediately at $-80^{\circ} \mathrm{C}$. $^{[144]}$

Absolute gene quantification requires a quantitative calibrator, e.g. a dilution series of the target sequence isolated from a conventional PCR. Reference genes, which are constantly expressed in the analyzed tissue at invariable levels, could be co-amplified to serve as internal standards.

Clinical trials would be necessary to prove the suitability of UGT1A mRNA expression determination as a drug-related biomarker to predict ganetespib response. These trials should be designed such that in the phases I and II, the accuracy, reliability, and reproducibility of the technology can be proven in application to clinical specimen collected in different facilities. The subsequent phase III should evaluate the improvement of clinical outcome under use of the established biomarker in a large number of cases. ${ }^{[145]}$

Additionally to the screening of tumor site expression levels of UGT1A to predict the case specific drug efficacy, the patient's somatic UGT1A genotype should be determined or the systematic activity of the hepatic UGT1A isoforms should be tested, to prevent adverse effects in the patients during treatment with resorcinolic HSP90 inhibitors. When an activityhampering polymorphism or a decreased UGT1A activity is found, the drug dose should be adjusted accordingly. ${ }^{[79]}$ There are many polymorphisms in various metabolic enzymes known to cause severe side effects. However, screening for these mutations is rare and almost exclusively done for patients that exhibit unexplained adverse effects or lack of response. ${ }^{[79]}$ This 'trial-and-error' approach for chemotherapeutic drug dose adjustments is risky and can lead to severe side effects in patients with certain genotypes. ${ }^{[77]}$ 
In the case of the resorcinolic HSP90 inhibitors the clinical application in CRC and other cancers with potential to express UGT1A will have to be preceded by intensive studies on the drug's efficacy and on possible toxicity hazards.

\subsection{Concluding Remarks}

In this study we show that the biological activities of ganetespib and AUY922, two resorcinolic HSP90 inhibitors, are impaired by UGT1A catalyzed glucuronidation in CRC cell lines. The glucuronidation is specific for this class of HSP90 inhibitors and is expected to be more prevalent in cancers derived from tissue with a basal expression of UGT1A.

Some open questions remain to be addressed in the aftermath of this work. For instance the influence of transcription factors, kinases or acyltransferases on the expression and activity of UGT1A could be investigated further. Also, the UGT1A isoforms responsible for the glucuronidation of ganetespib and AUY922 are of major interest for the clinical application of these drugs. The knowledge of the responsible isoforms would enable the screening of hepatic UGT1A activity to prevent increased toxicity during drug treatment.

Most importantly, the establishment of a reliable standardized screening of UGT1A expression in cancer cells is crucial to select patients who could benefit from treatment with these drugs. Thus the absence of UGT1A from tumor cells is expected to predict efficient treatment. 


\section{Literature}

[1] Global Cancer Facts \& Figures 2nd Edition. American Cancer Society, Inc., Atlanta, USA (2011).

[2] Bray, F., Jemal, A., Grey, N., Ferlay, J. \& Forman, D. Global cancer transitions according to the Human Development Index (2008-2030): a population-based study. Lancet Oncol. 13, 790-801 (2012).

[3] Dobbelstein M. \& Moll, U. Targeting tumour-supportive cellular machineries in anticancer drug development. Nat. Rev. Drug Discov. 13, 179-96 (2014).

[4] Bourzac, K. Three known unknowns. Nature 509, S69-S71 (2014).

[5] Krebs in Deutschland Häufigkeiten und Trends, 9. Ausgabe. Robert Koch-Institut, Berlin, Germany (2013).

[6] Continuous Update Project Report. Food, Nutrition, Physical Activity, and the Prevention of Colorectal Cancer. World Cancer Research Fund / American Institute for Cancer Research. Washington DC, USA (2011).

[7] Smith, K.J. et al. The APC gene product in normal and tumor cells. Proc. Natl. Acad. Sci. USA 90, 2846-50 (1993).

[8] Walker, A.S. et al. Future Directions for the Early Detection of Colorectal Cancer Recurrence. J. Cancer 5, 272-280 (2014).

[9] Cunningham, D. et al. Colorectal cancer. Lancet 375, 1030-47 (2010).

[10] Koopmana, M., Venderbosch, S., Nagtegaalb, I.D., van Krieken, J.H. \& Punt C.J. A review on the use of molecular markers of cytotoxic therapy for colorectal cancer, what have we learned? Eur. J. Cancer 45, 1935-49 (2009).

[11] Van Schaeybroeck. S., Allen, W.L., Turkington, R.C. \& Johnston, P.G. Implementing prognostic and predictive biomarkers in CRC clinical trials. Nat. Rev. Clin. Oncol., 8, 222-32 (2011).

[12] Reya, T. \& Clevers, H. Wnt signalling in stem cells and cancer. Nature 434, 843-50 (2005).

[13] Fearon, E.F. \& Vogelstein, B. A Genetic Model for Colorectal Tumorigenesis. Cell 61, 759-67 (1990).

[14] Arends, J.W. Molecular interactions in the Vogelstein model of colorectal carcinoma. J. Pathol. 190, 412-6 (2000).

[15] Petersen, S.H., Harling, H., Kirkeby, L.T., Wille-Jørgensen, P. \& Mocellin, S. Postoperative adjuvant chemotherapy in rectal cancer operated for cure. Cochrane Database Syst Rev. 14, 3:CD004078 (2012). 
[16] Dai, C., Dai, S. \& Cao, J. Proteotoxic stress of cancer: implication of the heat-shock response in oncogenesis J. Cell Physiol. 227, 2982-7 (2012).

[17] Negrini, S., Gorgoulis, V.G. \& Halazonetis, T.D. Genomic instability - an evolving hallmark of cancer. Nature reviews. Mol. Cell Biol. 11, 220-8 (2010).

[18] Whitesell, L. \& Lindquist, S.L. HSP90 and the chaperoning of cancer. Nat. Rev. Cancer 5, 761-72 (2005).

[19] Pratt, W. B. The hsp90-based chaperone system: involvement in signal transduction from a variety of hormone and growth factor receptors. Proc. Soc. Exp. Biol. Med. 217, 420-431 (1998).

[20] Rebbe, N.F., Ware, J., Bertina, R.M., Modrich, P. \& Stafford, D.W. Nucleotide sequence of a cDNA for a member of the human $90-\mathrm{kDa}$ heat-shock protein family. Gene 53, 235-45 (1987).

[21] Taherian, A., Krone, P.H. \& Ovsenek, N. A comparison of Hsp90a and Hsp90b interactions with cochaperones and substrates. Biochem Cell Biol. 45, 37-45 (2008).

[22] Subbarao Sreedhar, A., Kalmár, É., Csermely, P. \& Shen, Y.-F. Hsp90 isoforms: functions, expression and clinical importance. FEBS Letters 562, 11-5 (2004).

[23] Trepel, J., Mollapour, M., Giaccone, G. \& Neckers, L. Targeting the dynamic HSP90 complex in cancer. Nat. Rev.Cancer 10, 537-49 (2010).

[24] Zuehlke, A. \& Johnson, J.L. Hsp90 and co-chaperones twist the functions of diverse client Proteins. Biopolymers 93, 211-7 (2010).

[25] Nemoto, T., Ohara-Nemoto, Y., Ota, M., Takagi, T. \& Yokoyama, K. Mechanism of dimer formation of the 90-kDa heat-shock protein. Eur. J. Biochem / FEBS 233, 1-8 (1995).

[26] Prodromou, C. et al. Identification and structural characterization of the ATP/ADPbinding site in the Hsp90 molecular chaperone. Cell 90, 65-75 (1997).

[27] Hessling, M., Richter, K. \& Buchner, J. Dissection of the ATP-induced conformational cycle of the molecular chaperone Hsp90. Nat. Struct. Mol. Biol. 16, 287-93 (2009).

[28] Ali, M.M.U. et al. Crystal structure of an Hsp90-nucleotide-p23/Sba1 closed chaperone complex. Nature 440, 1013-7 (2006).

[29] Dutta, R. \& Inouye, M. GHKL, an emergent ATPase / kinase superfamily. Trends Biochem. Sci. 25, 24-28 (2000).

[30] Neckers, L. \& Workman, P. Hsp90 molecular chaperone inhibitors: Are we there yet? Clin Cancer Res. 18, 64-76 (2012).

[31] Roe, S.M. et al. Structural basis for inhibition of the Hsp90 molecular chaperone by the antitumor antibiotics radicicol and geldanamycin. J. Med. Chem. 42, 260-6 (1999). 
[32] Shiau, A.K., Harris, S.F., Southworth, D.R. \& Agard, D.A. Structural Analysis of E. coli hsp90 reveals dramatic nucleotide-dependent conformational rearrangements. Cell 127, 329-40 (2006).

[33] Blagosklonny, M.V., Toretsky, J., Bohen, S. \& Neckers, L. Mutant conformation of p53 translated in vitro or in vivo requires functional HSP90. Proc. Natl. Acad. Sci. USA 93, 8379-83 (1996).

[34] Li, D. et al. Functional inactivation of endogenous MDM2 and CHIP by HSP90 causes aberrant stabilization of mutant p53 in human cancer cells. Mol. Cancer Res. 9, 577-88 (2011).

[35] Chiosis G. \& Neckers L. Tumor Selectivity of Hsp90 Inhibitors: The Explanation Remains Elusive. ACS Chem. Biol.1, 279-84 (2006).

[36] Prodromou, C. Strategies for Stalling Malignancy: Targeting Cancers Addiction to Hsp90. Curr. Top. Med. Chem.9, 1352-68 (2009).

[37] Kamal, A. et al. A high-affinity conformation of Hsp90 confers tumour selectivity on Hsp90 inhibitors. Nature 425, 407-10 (2003).

[38] Eiseman, J.L. et al. Pharmacokinetics and pharmacodynamics of 17-demethoxy 17-[[(2-dimethylamino)ethyl]amino]geldanamycin (17DMAG, NSC 707545) in C.B17 SCID mice bearing MDA-MB-231 human breast cancer xenografts. Cancer Chemother Pharmacol. 55, 21-32 (2005).

[39] Vilenchik, M. et al. Targeting Wide-Range Oncogenic Transformation via PU24FCl, a Specific Inhibitor of Tumor Hsp90. Chem. Biol. 11, 787-797 (2004).

[40] Ying, W. et al. Ganetespib, a unique triazolone-containing Hsp90 inhibitor, exhibits potent antitumor activity and a superior safety profile for cancer therapy. Mol. Cancer Ther. 11, 475-84 (2012).

[41] Deboer, C., Meulman, P.A., R.J. Wnuk and \& Peterson, D.H. Geldanamycin, a new antibiotic. J. Antibiot. (Tokio) 442-447 (1970).

[42] Whitesell, L., Shifrin, S.D., Schwab, G \& Neckers, L.M. Benzoquinonoid Ansamycins Possess Selective Tumoricidal Activity Unrelated to src Kinase Inhibition. Cancer Res. 52, 1721-8 (1992).

[43] Whitesell, L., Mimnaugh, E.G., De Costa, B., Myers, C.E. \& Neckers, L.M. Inhibition of heat shock protein HSP90-pp60v-src heteroprotein complex formation by benzoquinone ansamycins: essential role for stress proteins in oncogenic transformation. Proc. Natl. Acad. Sci. USA 91, 8324-8 (1994).

[44] Biamonte, M. et al. Heat shock protein 90: inhibitors in clinical trials. J. Med. Chem. 53, 3-17 (2010).

[45] Powers, M.V. \& Workman, P. Targeting of multiple signalling pathways by heat shock protein 90 molecular chaperone inhibitors. Endocr. Relat. Cancer 13, S125-35 (2006). 
[46] Jhaveri, K., Taldone, T., Modi, S. \& Chiosis, G. Advances in the clinical development of heat shock protein 90 (Hsp90) inhibitors in cancers. Biochim Biophys Acta. 1823, 742-55 (2012).

[47] Hanson, B.E. \& Vesole, D.H. Retaspimycin hydrochloride (IPI-504): a novel heat shock protein inhibitor as an anticancer agent. Expert. Opin. Investig. Drugs. 18, 1375-83 (2009).

[48] http://clinicaltrials.gov/ct2/results?term=ganetespib\&Search=Search, Verified August, 2014

[49] Socinski, M.A. et al. A multicenter phase II study of ganetespib monotherapy in patients with genotypically defined advanced non-small cell lung cancer. Clin. Cancer Res. 19, 3068-77 (2013).

[50] Friedland, J.C. et al. Targeted inhibition of Hsp90 by ganetespib is effective across a broad spectrum of breast cancer subtypes. Invest. New Drugs 32, 14-24 (2014).

[51] Cheung, K.-M.J. et al. The identification, synthesis, protein crystal structure and in vitro biochemical evaluation of a new 3,4-diarylpyrazole class of Hsp90 inhibitors. Bioorg. Med. Chem. Lett. 15, 3338-43 (2005).

[52] Brough, P. et al. 4,5-diarylisoxazole Hsp90 chaperone inhibitors: potential therapeutic agents for the treatment of cancer. J. Med. Chem. 51, 196-218 (2008).

[53] Patel, H.J., Modi, S., Chiosis, G. \& Taldone, T. Advances in the discovery and development of heat-shock protein 90 inhibitors for cancer treatment. Expert. Opin. Drug. Discov. 6, 559-87 (2011).

[54] Caldas-Lopes, E. et al. Hsp90 inhibitor PU-H71, a multimodal inhibitor of malignancy, induces complete responses in triple-negative breast cancer models, Proc. Natl. Acad. Sci. USA 106, 8368-73 (2009).

[55] Fadden, P. et al. Application of chemoproteomics to drug discovery: Identification of a clinical candidate targeting Hsp90. Chem. Biol. 17, 686-94 (2010).

[56] Okawa, Y., et al. SNX-2112, a selective Hsp90 inhibitor, potently inhibits tumor cell growth, angiogenesis, and osteoclastogenesis in multiple myeloma and other hematologic tumors by abrogating signaling via Akt and ERK. Blood 113, 846-55 (2009).

[57] Rajan, A. et al. A Phase I Study of PF-04929113 (SNX-5422), an Orally Bioavailable Heat Shock Protein 90 Inhibitor, in Patients with Refractory Solid Tumor Malignancies and Lymphomas. Clin Cancer Res. 17, 6831-9 (2011).

[58] Fasulo, B. et al. Chk1 and Wee1 kinases coordinate DNA replication, chromosome condensation, and anaphase entry. Mol. Biol. Cell 23, 1047-57 (2012).

[59] Aligue, R., Akhavan-Niak, H. \& Russell, P. A role for Hsp90 in cell cycle control: Weel tyrosine kinase activity requires interaction with Hsp90. EMBO J. 13, 6099-106 (1994). 
[60] Sugimoto, K. et al. Hsp90-inhibitor geldanamycin abrogates G2 arrest in p53negative leukemia cell lines through the depletion of Chk1. Oncogene 27, 3091-101 (2008).

[61] Sato, S., Fujita, N. \& Tsuruo, T. Modulation of Akt kinase activity by binding to Hsp90. Proc. Natl Acad. Sci. USA 97, 10832-7 (2000).

[62] Solit, D.B., Basso, A.D., Olshen, A.B., Scher, H.I. \& Rosen, N. Inhibition of heat shock protein 90 function down-regulates Akt kinase and sensitizes tumors to Taxol. Cancer Res.; 63, 2139-44 (2003).

[63] Tanno, S. et al. Serine/Threonine Kinase AKT Is Frequently Activated in Human Bile Duct Cancer and Is Associated with Increased Radioresistance. Cancer Res. 64, 3486-90 (2004).

[64] Guo, G. et al. Expression of ErbB2 enhances radiation-induced NF-kappaB activation. Oncogene. 23, 535-45 (2004).

[65] Pirollo, K.F., Hao, Z., Rait, A., Ho, C.W. \& Chang, E.H. Evidence supporting a signal transduction pathway leading to the radiation-resistant phenotype in human tumor cells. Biochem. Biophys. Res. Commun. 230, 196-201 (1997).

[66] Yin, X. et al. BIIB021, a novel Hsp90 inhibitor, sensitizes head and neck squamous cell carcinoma to radiotherapy. Int. J. Cancer 126, 1216-25 (2010).

[67] Koga, F. et al. Hsp90 inhibition transiently activates Src kinase and promotes Srcdependent Akt and Erk activation. Proc. Natl. Acad. Sci. USA. 103, 11318-22 (2006).

[68] Donzé, O., Abbas-Terki, T. \& Picard, D. The Hsp90 chaperone complex is both a facilitator and a repressor of the dsRNA-dependent kinase PKR. EMBO J. 20, 3771-80 (2001).

[69] McCollum A.K. et al. P-Glycoprotein-Mediated Resistance to Hsp90-Directed Therapy Is Eclipsed by the Heat Shock Response. Cancer Res. 68, 7419-27 (2008).

[70] Dai, C., Whitesell, L., Rogers, A. B. \& Lindquist, S. Heat shock factor 1 is a powerful multifaceted modifier of carcinogenesis. Cell 130, 1005-1018 (2007).

[71] McCollum A.K. et al. Cisplatin abrogates the geldanamycin-induced heat shock response. Mol. Cancer Ther. 7, 3256-64. (2008).

[72] Taldone, T. et al. Experimental and Structural Testing Module to Analyze ParalogueSpecificity and Affinity in the Hsp90 Inhibitors Series. J. Med. Chem. 56, 6803-18 (2013).

[73] Zhou, D., et al. A rat retinal damage model predicts for potential clinical visual111^1 disturbances induced by Hsp90 inhibitors. Toxicol. Appl. Pharmacol. 273, 401-9 (2013).

[74] Dunphy, M. PET Imaging of Cancer Patients Using 124I-PUH71: A Pilot Study. available from: http://clinicaltrials.gov/ct2/show/NCT01269593?term=PET+imaging+ of+cancer+patients\&rank=1, Verified August, 2014 
[75] Guo,W. et al. Formation of 17-allylamino-demethoxygeldanamycin (17-AAG) hydroquinonebyNAD(P)H:quinoneoxidoreductase 1: role of 17-AAG hydroquinone in heat shock protein 90 inhibition. Cancer Res. 65, 10006-15 (2005).

[76] Kelland, L.R., Sharp, S.Y., Rogers, P.M. \& Myers, T.G. DT-Diaphorase Expression and Tumor Cell Sensitivity to 17-Allylamino,17-demethoxygeldanamycin, an Inhibitor of Heat Shock Protein 90. J. Natl. Cancer Inst. 91, 1940-9 (1999).

[77] Relling, M.V. \& Dervieux, T. Pharmacogenetics and cancer therapy. Nat. Rev. Cancer 1, 99-108 (2001).

[78] Sahasranaman, S., Howard, D. \& Roy, S. Clinical pharmacology and pharmacogenetics of thiopurines. Eur. J. Clin. Pharmacol. 64, 753-67 (2008).

[79] Swen, J.J. et al. Pharmacogenetics: From Bench to Byte-An Update of Guidelines. Clin. Pharmacol Therap. 89, 662-73 (2011).

[80] Brunton, L.L., Chabner, B.A. \& Knollmann, B.C. Goodman \& Gilman's The Pharmacological Basis of Therapeutics, 12 $2^{\text {th }}$ edition, New York, USA 2011

[81] Ritter, J.K. Roles of glucuronidation and UDP-glucuronosyltransferases in xenobiotic bioactivation reactions. Chem. Biol. Interact. 129, 171-93 (2000).

[82] Rooseboom, M. Enzyme-Catalyzed Activation of Anticancer Prodrugs. Pharmacol. Rev. 56, 53-102 (2004).

[83] Hayes, J.D., Flanagan, J.U. \& Jowsey, I.R. Glutathion transferases. Annu. Rev. Pharmacol. Toxicol. 45, 51-88 (2005).

[84] Dutton, G.J. \& Storey, I.D.E. The isolation of a compound of uridine diphosphate and glucuronic acid from liver. Proc. Biochem. Soc. 53, 279-288 (1953).

[85] Mackenzie P.I. et al. The UDP glycosyltransferase gene superfamily: Recommended nomenclature update based on evolutionary divergence. Pharmacogenet. 7, 255-69. (1997).

[86] Liston, H.L., Markowitz, J.S. \& Devane, L. Drug Glucuronidation in Clinical Psychopharmacology J. Clin. Psychopharmacol. 21, 500-15 (2001).

[87] Tukey, R.H. \& Strassburg, C.P. Genetic Multiplicity of the Human UDPGlucuronosyltransferases and Regulation in the Gastrointestinal Tract. Mol. Pharmacol. 59, 405-14, (2001).

[88] Tukey, R.H. \& Strassburg, C.P. Human UDP-Glucuronosyltransferases: Metabolism, Expression, and Disease. Annu. Rev. Pharmacol. Toxicol. 40, 581-616 (2000).

[89] Gonga, Q.H. et al. Thirteen UDPglucuronosyltransferase genes are encoded at the human UGT1 gene complex locus. Pharmacogenetics 11, 357-68 (2001).

[90] Paul, D., Standifer, K.M., Inturrisi, C.E. \& Pasternak, G.W., Pharmacological characterization of morphine-6-beta-glucuronide, a very potent morphine metabolite. J. Pharmacol. Exp. Ther. 251, 477-83 (1989). 
[91] Barretina, J. et al. The Cancer Cell Line Encyclopedia enables predictive modelling of anticancer drug sensitivity. Nature 483, 603-7 (2012).

[92] Spitzner, M. et al. A gene expression signature for chemoradiosensitivity of colorectal cancer cells. Int. J Radiation Oncol. Biol. Phys. 78, 1184-92 (2010).

[93] Wettenhall, J.M. \& Smyth, G.K. limmaGUI: a graphical user interface for linear modeling of microarray data. Bioinformatics 20, 3705-6 (2004).

[94] Shapiro, A.L., Vinuela, E. \& Maizel, J.V. Molecular weight estimation of polypeptide chains by electrophoresis in SDS-polyacrylamide gels. Biochem. Biophys. Res.

Commun. 28, 815-20 (1967).

[95] Laemmli, U.K. Cleavage of structural proteins during the assembly of the head of bacteriophage T4. Nature 227, 680-85 (1970).

[96] Bolstad, B.M., Irizarry, R.A., Astrand, M. \& Speed, T.P. A comparison of normalization methods for high density oligonucleotide array data based on variance and bias. Bioinformatics, 19, 185-93 (2003).

[97] Smyth, G.K. Linear models and empirical bayes methods for assessing differential expression in microarray experiments. Stat. Appl. Genet mol. Biol. 3, Article3 (2004).

[98] Hochberg, Y.\& Benjamini, Y. More powerful procedures for multiple significance testing. Stat. Med. 9, 811-8 (1990).

[99] Zembutsu, H. et al. Genome-wide cDNA Microarray Screening to Correlate Gene Expression Profiles with Sensitivity of 85 Human Cancer Xenografts to Anticancer Drugs. Cancer Res. 62, 518-27 (2002).

[100] Cummings, J. et al. Glucuronidation as a Mechanism of Intrinsic Drug Resistance in Human Colon Cancer: Reversal of Resistance by Food Additives. Cancer Res. 63, 8443-50 (2003).

[101] Nagar, S. \& Remmel, R.P. Uridine diphosphoglucuronosyltransferase pharmacogenetics and cancer. Oncogene 25, 1659-72 (2006).

[102] Innocenti, F. et al. Genetic Variants in the UDP-glucuronosyltransferase 1A1 Gene Predict the Risk of Severe Neutropenia of Irinotecan. J. Clin. Oncol. 22, 1382-8 (2004).

[103] Takahashi, T. et al. The role of glucuronidation in 7-ethyl-10-hydroxycamptothecin resistance in vitro. Jpn. J. Cancer Res. 88, 1211-7 (1997).

[104] Hoskins, JM. \& McLeod, H.L. UGT1A and Irinotecan Toxicity: Keeping It in the Family. J. Clinc. Oncol. 27, 2129-21 (2009).

[105] Eccles, S.E. et al. NVP-AUY922: A Novel Heat Shock Protein 90 Inhibitor Active against Xenograft Tumor Growth, Angiogenesis, and Metastasis. Cancer Res. 68, 2850-60 (2008). 
[106] Siegel, D., Anwar, A., Winski, S.L., Kepa, J.K., Zolman, K.L. \& Ross, D. Rapid polyubiquitination and proteasomal degradation of a mutant form of NAD(P)H:quinone oxidoreductase 1. Mol. Pharmacol. 59, 263-268 (2001).

[107] Acquaviva, J. et al. FGFR3 Translocations in Bladder Cancer: Differential Sensitivity to HSP90 Inhibition Based on Drug Metabolism. Mol. Cancer Res. 12, 1042-54 (2014).

[108] Uhlen, M., et al. Towards a knowledge-based Human Protein Atlas. Nat. Biotechnol. 28, 1248-50 (2010).

[109] Guillemette, C., Millikan, R.C., Newman, B. \& Housman, D.E. Genetic Polymorphisms in Uridine Diphospho-Glucuronosyltransferase 1A1 and Association with Breast Cancer among African Americans. Cancer Res. 60, 950-6 (2000).

[110] Buckley, D.B. \&Klaassen C.D. Induction of Mouse UDP-Glucuronosyltransferase mRNA Expression in Liver and Intestine by Activators of Aryl- Hydrocarbon Receptor, Constitutive Androstane Receptor, Pregnane X Receptor, Peroxisome Proliferator-Activated Receptor, and Nuclear Factor Erythroid 2-Related Factor 2. Drug Metabol. Dispos. 37, 847-56, (2009).

[111] Willson, T.M. \& Kliewer, S.A. PXR, CAR and drug metabolism. Nat. Rev. Drug. Discov. 1, 259-66 (2002).

[112] Chen, Y. \& Nie, D. Pregnane X receptor and its potential role in drug resistance in cancer treatment. Recent. Pat. Anticancer Drug Discov. 4, 19-27 (2009).

[113] Raynal, C. et al. Pregnane X Receptor (PXR) expression in colorectal cancer cells restricts irinotecan chemosensitivity through enhanced SN-38 glucuronidation. Mol. Cancer 9, 46 (2010).

[114] Yueh, M.F. et al. Involvement of the Xenobiotic Response Element (XRE) in Ah Receptor-mediated Induction of Human UDP-glucuronosyltransferase 1A1. J. Biol. Chem. 278, 15001-6 (2003).

[115] Sugatani, J. et al. The phenobarbital response enhancer module in the human bilirubin UDP-glucuronosyltransferase UGT1A1 gene and regulation by the nuclear receptor CAR. Hepatology 33, 1232-8 (2001).

[116] Hahn, M.E., Allan, L.A. \& Sherrb, D.H. Regulation of Constitutive and Inducible AHR Signaling: Complex Interactions Involving the AHR Repressor. Biochem Pharmacol. 77, 485-97 (2009).

[117] Zahreddine, H.A. et al. The sonic hedgehog factor GLI1 imparts drug resistance through inducible glucuronidation. Nature 51, 90-3 (2014).

[118] Fujiwara, R. et al. Interactions between human UDP-glucuronosyltransferase (UGT) 2B7 and UGT1A enzymes. J. Pharm. Sci. 99, 442-54 (2010).

[119] Fujiwara, R. et al. Effects of coexpression of UGT1A9 on enzymatic activities of human UGT1A isoforms. Drug Metab. Dispos. 35, 747-57 (2007). 
[120] Axelrod, J., Kalckar, H.M., Maxwell, E.S. \& Strominger, J.L. Enzymatic formation of uridine diphosphoglucuronic acid. J. Biol. Chem. 224, 79-90 (1957).

[121] Banhegy, G. et al. Evidence for an UDP-glucuronic acid/phenol glucuronide antiport in rat liver microsomal vesicles. Biochem. J. 315, 171-6 (1996).

[122] Csala, M. et al. Evidence for multiple glucuronide transporters in rat liver microsomes. Biochem Pharmacol. 68, 1353-62 (2004).

[123] Wlcek, K., Hofstetter, L. \& Stieger, B. Transport of estradiol-17ß-glucuronide, estrone-3-sulfate and taurocholate across the endoplasmic reticulum membrane: evidence for different transport systems. Biochem. Pharmacol. 88, 106-18 (2014).

[124] Cummings, J. et al. Glucuronidation as a mechanism of intrinsic drug resistance in colon cancer cells: contribution of drug transport proteins. Biochem. Pharmacol. 67, 31-9 (2004).

[125] Borst, P., de Wolf, C. \& van de Wetering, K. Multidrug resistance-associated proteins 3, 4, and 5. Eur. J. Physio. 453, 661-73 (2007).

[126] Court, M.H. et al. The UDP-Glucuronosyltransferase (UGT) 1A Polymorphism c. 2042C > G (rs8330) Is Associated with Increased Human Liver Acetaminophen Glucuronidation, Increased UGT1A Exon 5a/5b Splice Variant mRNA Ratio, and Decreased Risk of Unintentional Acetaminophen-Induced Acute Liver Failures. J. Pharmacol. Exp. Ther. 345, 297-307 (2013).

[127] Pfeiffer, E., Hildebrand, A., Mikula, H., \& Metzler, M. Glucuronidation of zearalenone, zeranol and four metabolites in vitro: formation of glucuronides by various microsomes and human UDP-glucuronosyltransferase isoforms. Mol. Nutr. Food Res. 54, 1468-76 (2010).

[128] Merker, P.C., Yeung, D., Doughty, D. \& Nacht, S. Pharmacokinetics of resorcinol in the rat. Res. Commun. Chem. Pathol. Pharmacol. 38, 367-88. (1982).

[129] Williams, J. A. et al. Drug-drug interactions for UDP-glucronosyltransferase substrates: a pharmacokinetic explanation for typically observed low exposure (AUCi/AUC) ratios. Drug Metabol. Dispos. 32, 1201-8 (2004).

[130] He, S. et al. The HSP90 inhibitor ganetespib has chemosensitizer and radiosensitizer activity in colorectal cancer. Invest. New Drugs 32, 577-86 (2014).

[131] Zhang, T., Haws, P. \& Wu, Q. Multiple variable first exons: a mechanism for celland tissue-specific gene regulation. Genome Res.14, 79-89 (2004).

[132] Robertis, M.D. et al. The AOM/DSS murine model for the study of colon carcinogenesis: From pathways to diagnosis and therapy studies. J Carcinog 10:9 (2011).

[133] Giuliani, L. et al. UDP-glucuronosyltransferases 1A expression in human urinary bladder and colon cancer by immunohistochemistry. Oncol Rep., 13, 185-91 (2005). 
[134] Grade, M. et al. Gene expression profiling reveals a massive, aneuploidy-dependent transcriptional deregulation and distinct differences between lymph node-negative and lymph node-positive colon carcinomas. Cancer Res. 67, 41-56 (2007).

[135] Ghadimi, B.M. et al. Effectiveness of gene expression profiling for response prediction of rectal adenocarcinomas to preoperative chemoradiotherapy. J. Clin. Oncol. 23, 1826-38 (2005).

[136] Schena, M., Shalon, D., Davis, R.W. \& Brown P.O. Quantitative monitoring of gene expression patterns with a complementary DNA microarray. Science 270, 467-70 (1995).

[137] Wang, Z., Gerstein, M. \& Snyder M. RNA-Seq: a revolutionary tool for transcriptomics. Nat. Rev. Genet. 10, 57-63 (2009).

[138] Arya, M. et al. Basic principles of real-time quantitative PCR. Expert. Rev. Mol. Diagn. 5, 209-19 (2005).

[139] Holland, P.M., Abramson, R.D., Watson, R. \& Gelfand, D.H. Detection of specific polymerase chain reaction product by utilizing the $5^{\prime} \rightarrow 3^{\prime}$ exonuclease activity of Thermus aquaticus DNA polymerase. Proc. Natl.Acad.Sci.USA 88, 7276-80 (1991).

[140] Applied Biosystems. User Bulletin Applied Biosystems TaqMan ${ }^{\circledR}$ Low Density Array. September 5, 2010 (retrieved from http://www3.appliedbiosystems.com/cms/groups/ mcb_support/documents/generaldocuments/cms_042326.pdf, $11^{\text {th }}$ July 2014)

[141] Bauer, J.W., Bilgic, H. \& Baechler, E.C.gene-expression profiling in rheumatic disease: tools and therapeutic potential. Nat. Rev. Rheumatol. 5, 257-65 (2009).

[142] Li, B., Kadura, I., Fu, D.J. \& Watson, D.E. Genotyping with TaqMAMA. Genomics 83, 311-20. (2004).

[143] Symmans, W.F. et al. Total RNA Yield and Microarray Gene Expression Profiles from Fine-Needle Aspiration Biopsy and Core-Needle Biopsy Samples of Breast Carcinoma. Cancer 97, 2960-71 (2003).

[144] Cui, G. et al. Improvement of real-time polymerase chain reaction for quantifying TNF-a mRNA expression in inflamed colorectal mucosa: An approach to optimize procedures for clinical use. Scand. J. Clin. Lab. Invest. 66, 249-60 (2006).

[145] Pusztai, L. \& Hess, K.R. Clinical trial design for microarray predictive marker discovery and assessment. Ann. Oncol. 15, 1731-7 (2004). 


\section{Appendix}

\subsection{Gene List from the Statistical Analysis}

(Gene list is showing all genes of statistical relevance with a p-value of $<0.005$ and additional hits relevant for this work, the UGT1A hits are shown in bold and underlined, other hits mentioned in the discussion are shown as underlined italics)

\begin{tabular}{|c|c|c|c|c|c|}
\hline rank & gene name & rank & gene name & rank & gene name \\
\hline 1 & ENST00000299350 & 38 & RAB9P1 & 75 & DPY19L4 \\
\hline 2 & FAM24B & 39 & BU618765 & 76 & PLS3 \\
\hline 3 & AADAT & 40 & LYRM4 & 77 & AV714556 \\
\hline 4 & C6orf32 & 41 & NIBP & 78 & PTK2 \\
\hline 5 & CUZD1 & 42 & LOC286144 & 79 & IMPAD1 \\
\hline 6 & THC2664263 & 43 & CHRAC1 & 80 & TMEM17 \\
\hline 7 & BAMBI & 44 & ACOT9 & 81 & TATDN1 \\
\hline 8 & SORBS3 & 45 & MSX2P1 & 82 & A_32_P55438 \\
\hline 9 & ONECUT2 & 46 & SLC45A4 & 83 & PHF20L1 \\
\hline 10 & ONECUT2 & 47 & VDAC3 & 84 & LUZP1 \\
\hline 11 & ARHGAP4 & 48 & UBE4B & 85 & TSNARE1 \\
\hline 12 & C6orf32 & 49 & WIPI1 & 86 & THC2666580 \\
\hline 13 & AW444553 & 50 & THC2692456 & 87 & XIST \\
\hline 14 & АK075052 & 51 & K03200 & 88 & MTBP \\
\hline 15 & C9orf58 & 52 & DRAM & 89 & THC2560073 \\
\hline 16 & ENST00000325458 & 53 & RAB9A & 90 & BHLHB3 \\
\hline 17 & ATF7IP2 & 54 & LOC728537 & 91 & FBXO32 \\
\hline 18 & C9orf58 & 55 & TACC1 & 92 & $\underline{H L T F}$ \\
\hline 19 & KIAA0265 & 56 & RAB3IP & 93 & AK123083 \\
\hline 20 & PLEKHF1 & 57 & AK025613 & 94 & UTRN \\
\hline 21 & ZFAT & 58 & ENST00000330140 & 95 & C8orf5 \\
\hline 22 & SIDT1 & 59 & MICB & 96 & SAMD12 \\
\hline 23 & SH3YL1 & 60 & AK056119 & 97 & AK027383 \\
\hline 24 & ONECUT2 & 61 & ZNF702 & 98 & PHF20L1 \\
\hline 25 & $\underline{\text { UGT1A8 }}$ & 62 & TOM1L2 & 99 & CB529149 \\
\hline 26 & A_24_P839075 & 63 & LOC340888 & 100 & DERL1 \\
\hline 27 & IQCE & 64 & KIAA0196 & 101 & $\underline{T C E A L 4}$ \\
\hline 28 & TM4SF4 & 65 & DRAM & 102 & АСОТ9 \\
\hline 29 & GOLGA7 & 66 & CCNL2 & 103 & ENST00000340536 \\
\hline 30 & CR603982 & 67 & HSPA2 & 104 & TACC1 \\
\hline 31 & ST6GAL1 & 68 & ENST00000377548 & 105 & NLRP3 \\
\hline 32 & LYRM4 & 69 & IMPACT & 106 & RNF14 \\
\hline 33 & FAM84B & 70 & C17orf92 & 107 & LRRC8B \\
\hline 34 & MGC4172 & 71 & CX165016 & 108 & AK095225 \\
\hline 35 & PSTPIP2 & 72 & CYB5B & 109 & VDAC3 \\
\hline 36 & PHF20L1 & 73 & TACC1 & 110 & FGF18 \\
\hline 37 & RAB3IP & 74 & CD93 & 111 & ZNF572 \\
\hline
\end{tabular}

\begin{tabular}{ll} 
rank & gene name \\
\hline 112 & THC2538841 \\
113 & ENST00000355436 \\
114 & A_24_P212355 \\
115 & BE614051 \\
116 & DA292134 \\
117 & THC2657931 \\
118 & BC053363 \\
119 & MSX2 \\
120 & C21orf135 \\
121 & ENOSF1 \\
122 & XR_015431 \\
123 & RNF14 \\
124 & C21orf113 \\
125 & RNF146 \\
126 & BFSP1 \\
127 & RPL7 \\
128 & C9orf105 \\
129 & TMEM192 \\
130 & AF277188 \\
131 & ENST00000377837 \\
132 & COMMD1 \\
133 & BCLAF1 \\
134 & JRK \\
135 & A_24_P915894 \\
136 & KIAA0888 \\
137 & PSTPIP2 \\
138 & ENST00000353323 \\
139 & AKR1B10 \\
140 & LRRC8B \\
141 & IL6R \\
142 & RAB3IP \\
143 & A_24_P666795 \\
144 & FAM84B \\
145 & LOC285141 \\
146 & DERL1 \\
147 & AKR1B10 \\
148 & SOCS2 \\
&
\end{tabular}




\begin{tabular}{|c|c|c|c|}
\hline rank & gene name & rank & gene name \\
\hline 149 & C1orf93 & 191 & THC2678006 \\
\hline 150 & CHCHD5 & 192 & GDPD5 \\
\hline 151 & THC2672675 & 193 & THC2632411 \\
\hline 152 & CCDC52 & 194 & SLC9A6 \\
\hline 153 & NSMCE2 & 195 & CCDC52 \\
\hline 154 & SAMD12 & 196 & A_24_P641406 \\
\hline 155 & GOLGA7 & 197 & CNOT2 \\
\hline 156 & MC1R & 198 & A_24_P624792 \\
\hline 157 & PTP4A2 & 199 & $\mathrm{RGS12}$ \\
\hline 158 & SDC3 & 200 & A_32_P233769 \\
\hline 159 & THC2628387 & 201 & $\mathrm{ZADH} 1$ \\
\hline 160 & ADRA2C & 202 & SS18L1 \\
\hline 161 & SRP19 & 203 & SNX9 \\
\hline 162 & HLTF & 204 & BX337332 \\
\hline 163 & HSPA12A & 205 & PTK2 \\
\hline 164 & TCFL5 & 206 & C11orf45 \\
\hline 165 & LOC401357 & 207 & PHF20L1 \\
\hline 166 & TATDN1 & 208 & NUFIP1 \\
\hline 167 & VCL & 209 & SLCO1B1 \\
\hline 168 & COMMD1 & 210 & CYB5R2 \\
\hline 169 & Al369133 & 211 & TMEM192 \\
\hline 170 & SNTG1 & 212 & AK023391 \\
\hline 171 & HS2ST1 & 213 & HOXA9 \\
\hline 172 & MTHFSD & 214 & SNX9 \\
\hline 173 & FBXO31 & 215 & FER1L4 \\
\hline 174 & THC2615760 & 216 & ADAMTS13 \\
\hline 175 & PTK2 & 217 & WNT3 \\
\hline 176 & PTK2 & 218 & BF513730 \\
\hline 177 & RAD21 & 219 & PTK2 \\
\hline 178 & Al559980 & 220 & THC2680492 \\
\hline 179 & MRPL13 & 221 & PTK2 \\
\hline 180 & PDLIM2 & 222 & GDPD5 \\
\hline 181 & ZNF702 & 223 & PCBP4 \\
\hline 182 & BIK & 224 & C3orf38 \\
\hline 183 & THC2651534 & 225 & LOC399744 \\
\hline 184 & LYRM4 & 226 & FN3KRP \\
\hline 185 & THC2755690 & 227 & Al885390 \\
\hline 186 & CNOT2 & 228 & DLG3 \\
\hline 187 & $\overline{C 2 C D 2}$ & 229 & FGF18 \\
\hline 188 & DERL1 & 230 & THC2570492 \\
\hline 189 & $\mathrm{CHCHD} 5$ & 231 & HTT \\
\hline 190 & HS2ST1 & 232 & PTK2 \\
\hline
\end{tabular}

\begin{tabular}{ll} 
rank & gene name \\
\hline 233 & PTDSS1 \\
234 & ZADH1 \\
235 & BLVRA \\
236 & BC008476 \\
237 & TCP11L2 \\
238 & EEF1D \\
239 & BX089701 \\
240 & A_23_P119152 \\
241 & SPTLC2 \\
242 & CFH \\
243 & CADPS2 \\
244 & C9orf3 \\
245 & CCL25 \\
246 & A_24_P452326 \\
247 & GJB6 \\
248 & THEG \\
249 & KIAA2018 \\
250 & LYPD6 \\
251 & PKN2 \\
252 & MAN1A1 \\
253 & CALCA \\
254 & DAPP1 \\
255 & ZNF75A \\
256 & AKAP7 \\
257 & DOM3Z \\
258 & BC007917 \\
259 & PTK2 \\
260 & PTK2 \\
261 & ATP11C \\
262 & AK025797 \\
263 & LRRC51 \\
264 & SLC45A3 \\
265 & C8orf53 \\
266 & ATP11C \\
267 & CFHR3 \\
268 & MRPL41 \\
269 & CAPN13 \\
270 & MNT \\
& PTK2 \\
272072817 \\
273 \\
2730
\end{tabular}

\begin{tabular}{|c|c|}
\hline 275 & THC2538610 \\
\hline 276 & A_24_P110201 \\
\hline 277 & PTK2 \\
\hline 278 & KIAA1305 \\
\hline 279 & GATC \\
\hline 280 & THC2652817 \\
\hline 281 & MAN1A1 \\
\hline 282 & PTK2 \\
\hline 283 & FLJ39582 \\
\hline 284 & ALPK3 \\
\hline 285 & BMP7 \\
\hline 286 & RNF20 \\
\hline 287 & C9orf125 \\
\hline 288 & PLEKHF1 \\
\hline 289 & MAGED2 \\
\hline 290 & S1PR2 \\
\hline 291 & $\underline{H E S 2}$ \\
\hline 292 & AK023526 \\
\hline 293 & NDUFA8 \\
\hline 294 & PTP4A2 \\
\hline 295 & KIAA0888 \\
\hline 296 & MTFR1 \\
\hline 297 & KIAA1704 \\
\hline 298 & PSEN2 \\
\hline 299 & ENST00000292543 \\
\hline 300 & A_32_P85880 \\
\hline 301 & CA4 \\
\hline 302 & C17orf92 \\
\hline 303 & ENAH \\
\hline 304 & GIT2 \\
\hline 305 & EXT1 \\
\hline 306 & $\underline{\text { UGT1A6 }}$ \\
\hline 307 & THC2586764 \\
\hline 308 & Al090167 \\
\hline 309 & SPRED2 \\
\hline 310 & BBS10 \\
\hline 311 & C11orf47 \\
\hline 312 & THC2548807 \\
\hline 313 & THC2638025 \\
\hline 314 & TUBB6 \\
\hline 315 & GABRP \\
\hline 316 & ARSG \\
\hline
\end{tabular}




\begin{tabular}{|c|c|c|c|c|c|c|c|}
\hline rank & gene name & rank & gene name & rank & gene name & rank & gene name \\
\hline 317 & LRRC51 & 359 & SLC4A11 & 401 & UBE2K & 443 & DDX51 \\
\hline 318 & C8orf32 & 360 & CNOT2 & 402 & SSPN & 444 & $\mathrm{CDC} 23$ \\
\hline 319 & VRK3 & 361 & FLJ11151 & 403 & THC2689164 & 1042 & $\underline{A H R R}$ \\
\hline 320 & KIAA1688 & 362 & PTPRU & 404 & THC2646867 & & \\
\hline 321 & THC2611791 & 363 & WIPF2 & 405 & BC023274 & & \\
\hline 322 & THC2564393 & 364 & BC051879 & 406 & ZNF664 & & \\
\hline 323 & ENOSF1 & 365 & SDF2L1 & 407 & АК000925 & & \\
\hline 324 & Al367654 & 366 & A_24_P289854 & 408 & USP24 & & \\
\hline 325 & DNAJC21 & 367 & CCDC88C & 409 & A_32_P135489 & & \\
\hline 326 & ACP6 & 368 & TMEM65 & 410 & AK023737 & & \\
\hline 327 & BF939434 & 369 & NFE2 & 411 & DEGS1 & & \\
\hline 328 & CA337741 & 370 & ARFGEF1 & 412 & AF090903 & & \\
\hline 329 & KIAA1211 & 371 & IMPACT & 413 & PML & & \\
\hline 330 & RAI16 & 372 & AF086288 & 414 & SCYL2 & & \\
\hline 331 & TFCP2L1 & 373 & NDUFB9 & 415 & RAB3IL1 & & \\
\hline 332 & PARP6 & 374 & SLC11A1 & 416 & CISD3 & & \\
\hline 333 & EIF2S2 & 375 & LOC100132053 & 417 & АК021693 & & \\
\hline 334 & ZHX1 & 376 & CHD7 & 418 & RTN3 & & \\
\hline 335 & KLHL3 & 377 & A_32_P31021 & 419 & EIF2AK4 & & \\
\hline 336 & NEBL & 378 & LOC441016 & 420 & SUZ12 & & \\
\hline 337 & $\mathrm{CFH}$ & 379 & AW858928 & 421 & C19orf55 & & \\
\hline 338 & ZNF334 & 380 & REEP5 & 422 & TUBB3 & & \\
\hline 339 & NLE1 & 381 & ZSWIM6 & 423 & ZNF331 & & \\
\hline 340 & AF116708 & 382 & THC2701686 & 424 & MAPK1 & & \\
\hline 341 & C3orf38 & 383 & ITGA2 & 425 & ZSCAN18 & & \\
\hline 342 & $\mathrm{CFH}$ & 384 & TMEM101 & 426 & LOC654350 & & \\
\hline 343 & THC2694422 & 385 & DSCR4 & 427 & KIAA1211 & & \\
\hline 344 & MED30 & 386 & FKSG43 & 428 & BC047952 & & \\
\hline 345 & GGNBP2 & 387 & MMP11 & 429 & TRPA1 & & \\
\hline 346 & HGSNAT & 388 & ENST00000400700 & 430 & ACYP2 & & \\
\hline 347 & AK124137 & 389 & THC2688497 & 431 & MAGI3 & & \\
\hline 348 & A_23_P158699 & 390 & AVPI1 & 432 & NLRP6 & & \\
\hline 349 & $\underline{\text { UGT1A6 }}$ & 391 & CA9 & 433 & RAB8B & & \\
\hline 350 & $\mathrm{PHYH}$ & 392 & BBS10 & 434 & CRIPAK & & \\
\hline 351 & ARHGEF4 & 393 & ENST00000397057 & 435 & IL17RD & & \\
\hline 352 & FAM120C & 394 & PSEN2 & 436 & THC2764893 & & \\
\hline 353 & EEF1D & 395 & THC2648967 & 437 & FOXO4 & & \\
\hline 354 & C1QTNF2 & 396 & ANXA10 & 438 & THC2523793 & & \\
\hline 355 & IFT122 & 397 & TTC22 & 439 & RAB2A & & \\
\hline 356 & A_24_P230009 & 398 & RNF41 & 440 & SEMA3E & & \\
\hline 357 & AKR7A3 & 399 & $\mathrm{CSH} 1$ & 441 & EEF1D & & \\
\hline 358 & $\mathrm{CSH} 2$ & 400 & CR603951 & 442 & LOC730286 & & \\
\hline
\end{tabular}




\section{Acknowledgement}

First of all I want to thank Prof. Matthias Dobbelstein for his support and guidance during my time in the lab. He always encouraged my own ideas and was extremely helpful with his broad knowledge and inspiring creativity. I am very grateful for his appreciation of my work and the patience he had with a chemist starting in his biology lab. I learned a lot about biological research and about science in general during my time in the Dobbelstein lab.

I also want to thank Prof. Ute Moll for giving me the opportunity to do my $\mathrm{PhD}$ in her group in Göttingen. The discussions with Prof. Moll were always very helpful due to her critical and goal-oriented view of things. Her opinion was always highly appreciated. I also would thank her for reading the paper-manuscript and providing helpful advice on possible amendments.

Further, I would like to thank Prof. Heidi Hahn and Prof. Dieter Kube for being in my thesis committee and that they were on hand with help and advice during the progress of this work, but also for their genuine interest in my project. I also would like to thank my extended committee members Dr. Halyna Shcherbata, Prof. Ralph Kehlenbach, and Dr. Wilfried Kramer for taking their time to discuss my project with me during the defense.

I would like to thank those who contributed to this project:

I want to thank Frank Kramer, who did a terrific job in analyzing the statistical relevance of the genes correlating with ganetespib susceptibility in CRC. Without his great performance I would not have been able to even start this project.

I want to say thank you to David Proia, Suqin He, and Luisa Ogawa who performed the LC-MS/MS study of the glucuronidation metabolites on CRC cell lines. They provided us with the data necessary for the direct prove of glucuronidation. Thank you for the very fruitful cooperation.

Also, I want to thank Marian Grade, Jochen Gaedcke, and Michael Ghadimi who provided the cell lines, and the microarray data of CRC cell lines and of the primary tumor samples. I also would thank Marian Grade for reading the paper-manuscript and providing helpful advice on possible amendments.

I greatly appreciate the support of the Göttingen Graduate School for Neurosciences, Biophysics and Molecular Biosciences (GGNB) in providing me with many helpful courses and their friendly helpfulness.

I would not have been able to accomplish my thesis without my great lab members of the Department of Molecular Oncology, always enabling me to practice science in an enjoyable, friendly and helpful atmosphere. I thank you all very much indeed for your scientific support, great discussions, good ideas and many cheerful moments during the last years.

I would like to thank Daniela Kramer, as she was extremely helpful in my time in the lab and she was always there to join me in troubleshooting during the course of my experiments.

I would like to thank Daniela Kramer, Shelley Edmunds, Frederick Küpper, Sonja Krönung and Ulrike Keitel for proofreading my thesis.

I want to thank my mom for her support through the years of my studies, and for the trust she had in me. I owe you everything! 
Last but not least I want to thank my girlfriend Anna for her constant support throughout the tough times during my PhD. I love you and I am the happiest man alive, thanks to you! 